Review

\title{
Proteasome Biology: Chemistry and Bioengineering Insights
}

\author{
Lucia Račková * and Erika Csekes \\ Centre of Experimental Medicine, Institute of Experimental Pharmacology and Toxicology, \\ Slovak Academy of Sciences, Dúbravská cesta 9, 84104 Bratislava, Slovakia; erika.csekes@savba.sk \\ * Correspondence: lucia.rackova@savba.sk or rackova.luci@gmail.com
}

Received: 28 September 2020; Accepted: 23 November 2020; Published: 4 December 2020

\begin{abstract}
Proteasomal degradation provides the crucial machinery for maintaining cellular proteostasis. The biological origins of modulation or impairment of the function of proteasomal complexes may include changes in gene expression of their subunits, ubiquitin mutation, or indirect mechanisms arising from the overall impairment of proteostasis. However, changes in the physico-chemical characteristics of the cellular environment might also meaningfully contribute to altered performance. This review summarizes the effects of physicochemical factors in the cell, such as $\mathrm{pH}$, temperature fluctuations, and reactions with the products of oxidative metabolism, on the function of the proteasome. Furthermore, evidence of the direct interaction of proteasomal complexes with protein aggregates is compared against the knowledge obtained from immobilization biotechnologies. In this regard, factors such as the structures of the natural polymeric scaffolds in the cells, their content of reactive groups or the sequestration of metal ions, and processes at the interface, are discussed here with regard to their influences on proteasomal function.
\end{abstract}

Keywords: proteasome; posttranslational modifications; protein aggregates; immobilization

\section{Introduction}

Proteasomes are unique multisubunit proteolytic complexes that play a critical role in the mechanisms aimed at the maintenance of proteostasis, a critical homeostatic process regulating the mass and localization of proteins [1-4]. This pathway not only acts as a non-lysosomal garbage disposal mechanism for damaged, redundant, and misfolded proteins but also regulates the levels of many short-lived regulatory proteins related to cellular metabolism and gene expression. Moreover, it also plays essential roles in immune functions.

One of the proteasome assemblies abundant in cells is represented by a cylinder-shaped multimeric complex with a sedimentation coefficient of 20S. The eukaryotic $20 \mathrm{~S}$ proteasome (core particle, CP) is a tightly packed hollow cylindrical structure, consisting of four stacked heptameric rings [5]. The two outer rings are composed of seven different $\alpha$ subunits, while the two inner rings consist of seven diverse $\beta$ subunits. The four rings form a hollow interior with three large chambers (the catalytic chamber, formed by the two $\beta$ rings, and two antechambers, formed by one $\alpha$ and one $\beta$ subunit ring) interconnected by a narrow channel with restricted orifices. Three of the $\beta$ subunits harbor active sites that face the inner cavity of the cylinder, whereas the $\alpha$-rings control substrate access to the inner catalytic chamber via a dynamic gating process. The subunits $\beta 1, \beta 2$, and $\beta 5$ provide three hydrolytic activities—caspase-like (or peptidyl-glutamyl peptide-hydrolyzing-like), the trypsin-like, and the chymotrypsin-like activities-for the cleavage of acidic, basic, and hydrophobic amino acids, respectively, which together ensure the complete degradation of the substrates. All three proteolytic activities rely on the nucleophilic attack of the $\gamma$-hydroxyl group of an $\mathrm{N}$-terminal threonine residue of each catalytic site on the carbonyl group of the peptide bond within the targeted protein [6]. 
Structural analysis of the unassembled 20S proteasome indicates that the gate formed by the $\alpha$ subunits is almost closed, thus preventing penetration of the substrates into the interior of the $\beta$-ring [7]. Assembling of the $20 \mathrm{~S}$ proteasome with regulatory particles not only increases its enzyme activity but also directs its substrate specificity. Thus, the $20 \mathrm{~S}$ protease can associate with a 'cap' of one or two 19S (PA700) regulatory units forming the 26S proteasome (asymmetric or symmetric, respectively), which can degrade proteins in a ubiquitin-dependent or independent fashion [8]. Ubiquitin-dependent $26 \mathrm{~S}$ proteasomal degradation represents the primary degradation pathway of the cell and comprises a multistep route by which proteins are tagged for degradation by the covalent linking of a chain of ubiquitin ( $\mathrm{Ub}$, a highly conserved 76 amino acid polypeptide) molecules, which targets ubiquitinated proteins for hydrolysis by the $26 \mathrm{~S}$ proteasome. This is performed through the concerted action of enzymes of the ubiquitin thioester cascade-namely, the E1-activating enzyme, E2-conjugating enzyme, and E3 ubiquitin ligase. Additionally, an E4 enzyme may also be required for efficient poly-ubiquitin chain assembly. The $20 \mathrm{~S}$ gate opening, substrate unfolding, and entry of the protein substrate into the catalytic chamber is assisted by the $19 \mathrm{~S}$ regulatory cap. This process requires both ATP and $\mathrm{Mg}^{2+}$. The 195 complex comprises 6 ATPase (in Saccharomyces cerevisiae named Rpt1-Rpt6) and 13 non-ATPase subunits (Rpn1-3, Rpn5-13, and Rpn15) [9]. Three non-ATPase subunits, Rpn1, Rpn2, and Rpn13, with Rpn1 and Rpn2 comprising large alpha solenoids that offer multiple binding sites for ubiquitin and ubiquitin-like proteins (on Rpn1) and a binding site for the ubiquitin receptor Rpn13, form a part of regulatory particle known as the 'base' [2,10-12]. At the center of the base there are six distinct ATPase subunits (Rpt1-Rpt6 in yeast) creating the ring-shaped heterohexamer of the AAA+ (ATPase associated with various cellular activities) ATPases that engross and unfold substrate polypeptides to allow for their translocation into the proteolytic pore of the 20S CP [2,5]. The 'lid' of regulatory particle contains six PCI (proteasome-CSN-initiation factor 3) domain-containing subunits (Rpn3, Rpn5, Rpn6, Rpn7, Rpn9, and Rpn12), as well as two subunits (Rpn8 and Rpn11) with an MPN (Mpr1-Pad1 N-terminal) domain [2]. An additional Ub-receptor subunit, Rpn10, bridges the 'lid' and 'base' in the gathered regulatory particle [13]. Cryo-electron microscopy studies discovered that the yeast proteasome implements the main conformational states referred to as $\mathrm{s} 1$, $\mathrm{s} 2, \mathrm{~s} 3$, and $\mathrm{s} 4[14,15]$, while the related conformations of the human proteasome are termed $\mathrm{S}_{\mathrm{A}}, \mathrm{S}_{\mathrm{B}}$, $\mathrm{S}_{\mathrm{C}}$, and $\mathrm{S}_{\mathrm{D}}(1,2,3)[16,17]$. Most abundant conformations of the $26 \mathrm{~S}$ proteasome are in the closed-gate state, except for s4 [15] and SD [17], in the open conformation, and s2 and s3, in the partly open conformation [15]. Proteolysis starts with initial recognition of the polyubiquitinated substrate by high affinity ubiquitin receptor sites (19S subunits Rpn10 and Rpn13), followed by its tight binding and deubiquitination via deubiquitinating enzymes (DUBs) (ubiquitin carboxyl-terminal hydrolase 6 (Ubp6/Usp14 in mammals), ubiquitin carboxyl-terminal hydrolase 37 (UCH37, also termed UCHL5), and Rpn11). Finally, the protein is unfolded and translocated through the $\alpha$-gate to the $20 \mathrm{SCP}$ for degradation.

The inducible form of the $20 \mathrm{~S}$ proteasome is termed 'immunoproteasome' (i20S). It comprises the three constitutive catalytic subunits $\beta 1, \beta 2$, and $\beta 5$, substituted by their inducible counterparts $\beta 1 \mathrm{i}$ (low-molecular-weight protein (LMP2)), $\beta 2 \mathrm{i}$ (multicatalytic endopeptidase complex subunit 1 , (MECL-1)), and $\beta 5 \mathrm{i}$ (LMP7), respectively. The inducible subunits are upregulated during the immune response as a result of tumor necrosis factor- $\alpha$ (TNF- $\alpha$ ) and interferon- $\gamma$ (IFN- $\gamma$ ) stimulation [18]. Nevertheless, other molecules can stimulate the production of immune subunits, such as LPS [19], type I interferons [20], nitric oxide [21], and glycoxidized proteins [22]. The i20S associates preferably with the regulatory particle 11S, also known as PA28, composed of two homologous subunits, namely PA28 $\alpha$ (REG $\alpha$ or PSME1) and PA28 $\beta$ (REG $\beta$ or PSME2). The immunoproteasome produces short oligopeptides with hydrophobic amino acids in the C-terminal position utilized for antigen presentation on major histocompatibility complex (MHC) class I molecules. In addition, immunoproteasome participates in multiple cellular processes, including the control of T lymphocyte expansion [23], visual function [24], and the production of cytokines $[25,26]$. Unlike cytoplasmic PA28 $\alpha \beta$, the regulator PA28 $\gamma$ is found in the nucleus and has been shown to be involved in regulating the turnover of the p53 tumor suppressor [27]. 
Taking into account the mixed content of both inducible and constitutive subunits, which has been confirmed in the core particles [28], 36 diverse theoretical subtypes of the 20S proteasomes in total, differing in their specificity and proteolytic capacity, were proposed. This number increases further when considering the fact that the $20 \mathrm{~S}$ can associate with either 19S or 11S, or their combinations, forming a 'mixed' type or 'hybrid' proteasome, resulting in a variety of patterns in the proteasomal peptide products. Alternatively, only one regulator can bind to 20S, leaving the other end unbound. It is known that from one-third to one-half of the proteasomes in the liver, colon, small intestine, and kidney encompass both constitutive and immune subunits in-between constitutive and inducible proteasomes [1]. There are two dominant types of intermediate $20 \mathrm{~S}$ proteasomes, namely, Type I ( $\beta 5 i)$ and Type II ( $\beta 1 \mathrm{i}$ and $\beta 5 \mathrm{i})$, with $\beta 1 / \beta 2 / \beta 5 \mathrm{i}[29]$ and $\beta 1 \mathrm{i} / \beta 2 / \beta 5 \mathrm{i}$ architectures [30], respectively. Both types display increased chymotrypsin-like activity and trypsin-like activity compared to the constitutive proteasome; however, Type II shows lower caspase-like activity [31].

The exclusive form of $20 \mathrm{~S}$ proteasomes known as thymoproteasome resides in the cortical thymic epithelial cells containing $\beta 1 \mathrm{i}$ and $\beta 2 \mathrm{i}$ subunits, as well as the distinctive catalytic subunit $\beta 5 \mathrm{t}$ (PSMB11). This form produces unique peptides with optimal affinity for $\mathrm{T}$ cell receptors to successfully promote the positive selection of CD8+ lymphocytes [32].

Finally, the assembly of the 20S particle with PA200 plays an essential role in male fertility and DNA repair [33]. In addition, PA200 (termed Blm10 in yeast) also forms hybrid proteasomes with the 19S regulator and $20 \mathrm{~S}$ core proteasome accumulating on chromatin in response to ionizing-radiation-induced DNA damage, leading to an increase in proteolytic activity [34].

The $26 \mathrm{~S}$ proteasome is the only form that can degrade folded and fully functional proteins. For comparison, the $20 \mathrm{~S}$ proteasome is only able to recognize and degrade the proteins that are already unfolded [35-37]. The exposed hydrophobic patches in the oxidatively damaged protein serve as recognition signals for proteolytic degradation. In this regard, both the immunoproteasome and the $20 S$ proteasome, bound or unbound to PA28 regulators, also have the capability to degrade oxidatively damaged proteins [38]. Moreover, regulators were shown to generally enhance the $20 \mathrm{~S}$ proteasome and immunoproteasome capacity of this specific degradation. The regulators $11 S$ and PA200 do not recognize ubiquitinated proteins and stimulate $20 \mathrm{~S}$ proteolytic activity without requiring ATP. The mixed types can degrade proteins both ATP-dependently and independently [35,36].

\section{Kinetics of Proteasomal Degradation}

Proteasomal degradation generally has a complex kinetic mechanism involving such events as unfolding of the protein, substrate translocation through the $\alpha$-rings, the protein's subsequent movement through the interior chamber, or the eventual partial re-folding of the substrate inside the internal cavities of the proteasome. Earlier studies suggested that the in vitro degradation rate of substrates obeys Michaelis-Menten (MM) kinetics [39]. However, the initial and steady-state velocities of the chymotrypsin substrate cleavage by the 20S proteasome at a substrate concentration greater than about $40 \mu \mathrm{M}$ were shown to be smaller than predicted via simple MM kinetics [40]. This study indicated that the $20 \mathrm{~S}$ proteasome is a hysteretic enzyme and is subject to substrate inhibition. Furthermore, $20 S$ was suggested to be a conformationally flexible protein that can adjust to the binding of ligands and regulatory complexes and has multiple and cooperative active sites. The "bite-chew" model proposed by Kisselev et al. [41] considered all three active sites in the $20 \mathrm{~S}$ and $26 \mathrm{~S}$ proteasomes interacting with each other through allosteric regulation.

Mathematical modelling is a well-established approach to explain the kinetics of complex enzymes. Several models for the kinetics of proteasome degradation have been described for short peptides and long substrates considering the preferential cleavage site [42-44]. A mathematical model suggested that the substrate residence time inside the proteolytic chamber (governed by the gate size of the axial channel) significantly affects the produced fragment length distribution and the proteasome kinetics [39]. This model exhibited MM kinetics with a three-peak length distribution of products that correlated with experimental observations [45]. The first peak corresponds to 2-3 amino acid (AA) 
residues, the second corresponds to 8-10 AA residues, and the third one corresponds to a wide peak at 20-30 AA residues [45]. Vmax was proposed to be either efflux-limited or cleavage-limited. The model predicted that the enhanced efficiency of the $26 \mathrm{~S}$ complex in the cleavage activity limits the capacity of long fragments to run off the proteolytic chamber. This increases the frequency of shorter products with respect to those produced by less active 20S.

A limited core proteasome volume was used to determine that, for long substrates kinetic constants, Vmax and $\mathrm{Km}$ decrease with the length of the substrate. In contrast, a minimal substrate length was also required to efficiently cleave the sequence. For short peptides $(<10 \mathrm{AA})$, the degradation rate increased with an increase in substrate length. However, a different mathematical model, ProteaMAlg, predicted that not only the substrate length but also the AA composition of the substrate has an effect on the overall degradation rate [46].

Ubiquitination and deubiquitination can also affect substrate degradation causing a time delay in the MM kinetics of the 26S proteasome [47]. The conjugation of a chain of at least four lysine 48-linked ubiquitins to a substrate protein is generally required to ensure protein's tight interaction with the $26 \mathrm{~S}$ proteasome for degradation. However, the ultimate rate of degradation seems to actually be determined by more factors. Specifically, the level of ubiquitin on a substrate drives proteasome-substrate interactions, and the chain configuration of ubiquitin affects substrate translocation into the axial channel of the proteasome [48]. Furthermore, cryo-EM studies revealed that tetraUb-induced conformational changes in the proteasome can initiate substrate degradation-namely, conformation with stabilized ubiquitin receptors and a previously unreported orientation of the lid, assigned as a Ub-accepted state $\mathrm{C} 1-\mathrm{b}$, and another structure C3-b with localized Lys48 (K48)-Ub4 to the toroid region of Rpn1, assigned as a substrate-processing state [49]. Moreover, the polyubiquitin chains can also dramatically affect the unfolding of a protein, even after their removal from the substrate at an early stage of degradation [50]. Consequently, the polyubiquitin substrate can induce an alteration of the proteasome into an activated state persisting throughout the degradation process. Recently, by employing fluorescence resonance energy transfer (FRET) and anisotropy-based analysis, a complete kinetic picture of $26 \mathrm{~S}$ proteasomal degradation was determined, suggesting that the engagement steps prior to substrate commitment are rapid compared to the subsequent deubiquitination, translocation, and unfolding [51]. This unfolding was proposed to be a rate-limiting step of protein degradation by the proteasome and substrate's contact with the AAA+ motor and was suggested to be the trigger for a conformational switch of the proteasome. Substrates with poor initiation regions are quickly rejected; however, excessive ubiquitin chains promote the degradation of otherwise poor substrates.

Substrate length also influences the kinetics of substrate degradation via immunoproteasomes equipped with PA28 $\alpha \beta$. In addition, the PA28 $\alpha \beta$ regulator increased Vmax and reduced $\mathrm{Km}$ for the hydrolysis of fluorogenic peptide substrates [52]. The ProteaMAlg model showed that the PA28 subunit increases the gate opening of the proteasome $\mathrm{CP}$ and possibly changes the transport mechanism of long fragments within the proteasome chamber [46]. However, PA28 $\alpha \beta-20 S$ immunocomplexes were shown to hydrolyze longer substrates, including proteins, at the same rates as 20S immunoproteasomes but much less efficiently than $26 \mathrm{~S}$ immunoproteasomes. The sterical constraint created by the regulator situated at the proteasomal outer $\alpha$ ring was suggested to obstruct the free diffusion of large polypeptide chains into the internal proteasomal lumen. The PA28 $\alpha \beta$ may also produce a selective efflux of the produced peptides favoring the exit of hydrophilic peptides longer than 6-7 AA, while retaining others whose cleavage is proceeded prior to their exit from the proteasome.

The kinetics of proteasomal degradation in vivo can be significantly influenced by various pathological states, such as neurodegenerative disorders, cataracts, and muscle atrophy. $\mathrm{K} m$ was shown to increase with age in rat liver and lens tissue, indicating a loss of the proteasome's affinity for its substrates. These changes, accompanying maturation and ageing, are likely caused by structural changes of the proteasome or decreased content of its regulatory components [53]. In this regard, the disease-state-related changes in proteasomal activity and structure can be compensated by the de novo synthesis of ubiquitin-proteasome system (UPS) components regulated by stress-related 
transcription factors, including the Kelch-like ECH-associated protein (Keap-1)/nuclear factor erythroid 2-related factor (Nrf2)/electrophile response elements (EpRE) pathway [54]. Multiple subunits were shown to be upregulated in mice liver and fibroblasts in response to electrophile treatment $[55,56]$. Remarkably, UPS plays a prominent role in the regulation of Nrf2 through its ubiquitination via the Keap1-Cullin-3 (Cul3)-RING-box protein (Rbx)-complex and degradation by the 26S proteasome. The transcription factor Nrf1 has been reported to be a vital regulator of proteasome gene expression in response to proteasome inhibition in mammalian cells [57]. Moreover, although Nrf2 recognizes the same consensus sequence as Nrf1, proteasome genes appear to be predominantly regulated by Nrf1 and not Nrf2 [58,59]. On the other hand, the expression of immunoproteasome subunits and PA28 $\alpha \beta$ seems to be controlled by the Janus kinase 2 (Jak2)/signal transducer and activator of transcription 1 (STAT1) pathway induced by interferon- $\gamma$ or advanced glycation end-products $[22,60,61]$ and can also be upregulated via the NF-KB pathway induced by oxidative stress or Toll-like receptor activation $[61,62]$.

Physicochemical parameters such as temperature and $\mathrm{pH}$ in the intracellular environment (Table $1 \mathrm{a}-\mathrm{c}$ ) are also crucial determinants of enzyme activity but have attracted less attention, especially as suspected disease mechanisms [63]. The enzymatic activity of proteasomal complexes in vivo may be additionally modulated by posttranslational modifications, such as the glycosylation, ubiquitination, phosphorylation/dephosphorylation, oxidation, or nitration of amino acid residues (Tables 2a-e and 3a,b, Figure 1).

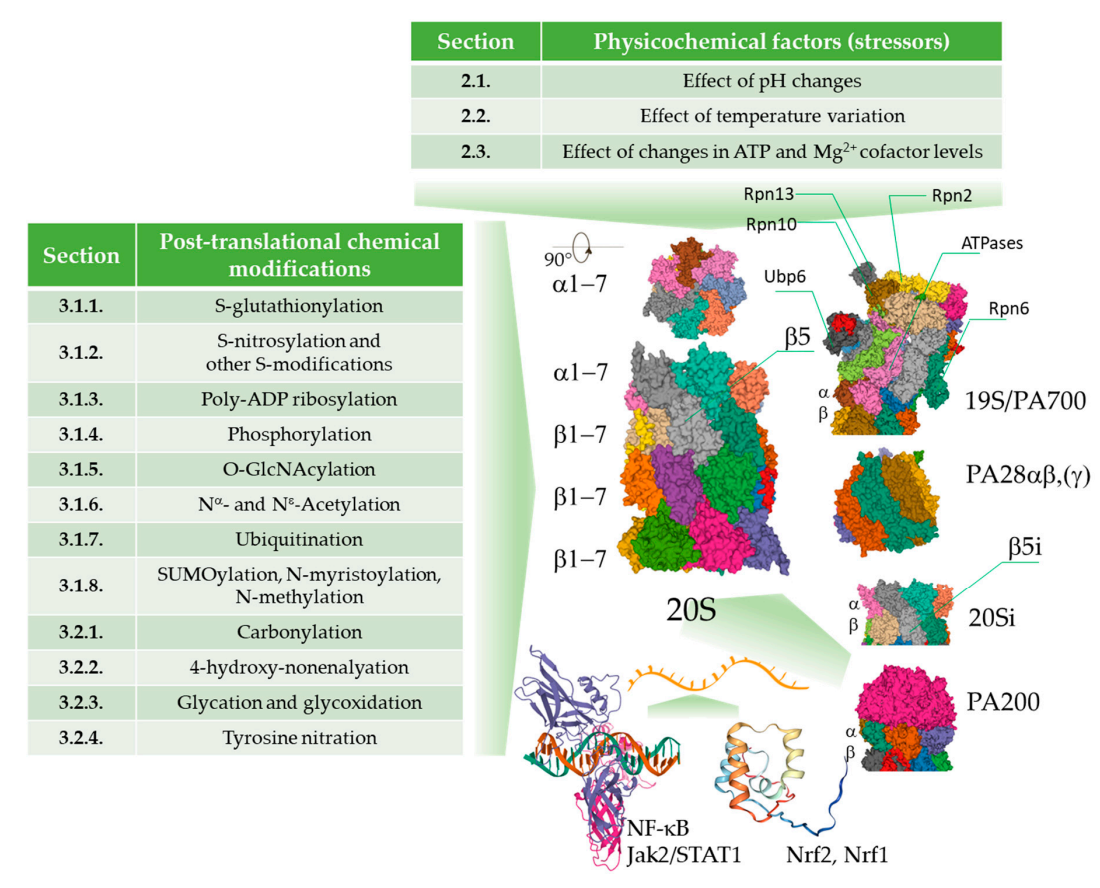

Figure 1. An overview of the physico-chemical effects of the cellular environment on the function of the proteasome. The activity of the proteasome can be modulated by pathological and physiological $\mathrm{pH}$ and temperature fluctuations, changes in the levels of cofactors, reversible and irreversible covalent modifications leading to modulation of performance of the proteasomal complexes, or irreversible damage of those complexes. The changes promoted by the physico-chemical stressors can be compensated by de novo synthesis of the proteasome subunits. Images are from the RCSB PDB (rcsb.org) of PDB ID: 6RGQ [64,65], 5A5B [65,66], 5MX5 [65,67], 6E5B [65,68], 6KWY [65,69], 2RAM [65,70], 2LZ1 [65,71].

\section{Physico-Chemical Parameters of the Cellular Environment}

\subsection{Effect of $p H$ Changes}

Changes in intracellular $\mathrm{pH}(\mathrm{pHi})$ were confirmed to provoke changes in the proteasomal system as a part of both pathological and physiological mechanisms (Table 1a-c). Chronic renal failure-associated 
acidosis was shown to augment the transcription of genes encoding ubiquitin and proteasome subunits in the muscle [72]. Cytosolic $\mathrm{pH}$ can act as a specific cellular signal upon glucose depletion for the accumulation of the proteasomes in so-termed proteasome storage granules (PSG), which protect proteasomes from autophagic degradation $[73,74]$. Furthermore, it was suggested that acidic pHi can enhance whole-cell protein ubiquitination in cancer cells upon entry to quiescence as a chemo-resistance mechanism in response to Paclitaxel treatment [75].

Changes in intracellular $\mathrm{pH}$ were hypothesized to also cause chemical alterations of the proteasomal system $[63,76]$. The relevant mechanisms can include changes in the ionization state of amino acid residues, followed by the induction of conformational changes in the protein structure, and ultimately subunit displacement. A pH change can also promote oxidant processes (through facilitating iron delocalization and the induction of Fenton-type reactions), resulting in oxidative damage of the enzyme. In addition, changes in intracellular $\mathrm{pH}$ may alter charges in the substrate such that the substrate can neither bind to the active site nor undergo catalysis. Furthermore, an interesting study on quiescent yeast also showed that acidic $\mathrm{pHi}$ induces extensive macromolecular protein assembly and leads to a solid-like cytoplasm with reduced mobility and increased mechanical stability [77].

Earlier studies on $20 \mathrm{~S}$ and $26 \mathrm{~S}$ proteasomes purified from rat liver [78] showed that all the peptide degrading activities are maximal at a neutral to weakly alkaline $\mathrm{pH}$, with the maximum chymotrypsin-like activity of both forms at $\mathrm{pH} \sim 8$. However, unlike with the $20 \mathrm{~S}$ proteasome, all three hydrolytic activities of the $26 \mathrm{~S}$ proteasome noticeably declined with a $\mathrm{pH}$ decrease from 7.5 to 7.0. Analogously, the $\mathrm{pH}$ optima for the three peptidase activities in the neutral or slightly alkaline region were confirmed for purified ostrich liver proteasome (with chymotryptic-like and caspase-like activities exhibiting maxima at $\mathrm{pH} 7.0$ and tryptic-like activity a maximum at $\mathrm{pH}$ 8.0) [79]. Accordingly, the human platelet $20 \mathrm{~S}$ proteasome was also shown to exert chymotryptic-like activity under a broad $\mathrm{pH}$ range, with an optimum $\mathrm{pH}$ between 7.5-8.0 and 5.0-5.5 [80]. However, the $\mathrm{pH}$ effect on the proteasome was shown to be influenced by the substrate and assay buffer composition [79].

Intracellular acidosis in the $\mathrm{pH}$ range of 6.5-7.0 was described during such conditions as cardiac and cerebral ischemia [81]. Moreover, the oxidative insult in cellular models was also shown to be accompanied by a drop in intracellular $\mathrm{pH}$. For instance, in glioma $\mathrm{C} 6$ cells and astrocytes, treatment with $\mathrm{H}_{2} \mathrm{O}_{2}$ resulted in intracellular acidification (a decrease by $0.33 \pm 0.07$ and $0.37 \pm 0.04 \mathrm{pH}$ units, respectively), explained as a consequence of the inhibition of glycolysis and oxidative phosphorylation followed by ATP hydrolysis [82]. This seems to correlate with the established role of the ATP-independent $20 \mathrm{~S}$ proteasome as an antioxidant defense system less vulnerable to oxidative damage, which may be also less sensitive to oxidative-stress-induced $\mathrm{pH}$ fluctuations compared to the $26 \mathrm{~S}$ form [83].

The formation of stable complexes between the 20 S proteasome and chaperones was also described, suggesting a dynamic link and control between degradation and refolding phenomena. Nevertheless, this interaction may be influenced by $\mathrm{pH}$ changes. The proteasome and the heat shock proteins (HSPs, HSP90, and HSP70) have been found to be segregated in the centrosome of HeLa and HEK293 cells [84]. The $\mathrm{pH}$ was also shown to affect the kinetic properties of the HSP90-20S proteasome recognition process. The maximum bell-shaped $\mathrm{pH}$ dependency of kinetic association constants was found around $\mathrm{pH}$ 7.5. On the other hand, the two proteins were not favorably associated at a $\mathrm{pH}$ below 6.5 or a $\mathrm{pH}$ above 7.5. However, at a physiological $\mathrm{pH}$, the binding was characterized by a high affinity (the association constant was $10^{7} \mathrm{M}^{-1} \cdot \mathrm{s}^{-1}$ ).

In addition, in vitro observations suggested that $\mathrm{pH}$ changes may also affect the E1-E2-E3 ubiquitin cascade. The anaphase-promoting complex (APC), a multisubunit E3 ubiquitin ligase targeting specific cell cycle-related proteins for degradation, was shown to be highly sensitive to a $\mathrm{pH}$ lower than 7.5, and low $\mathrm{pH}$ caused its precipitation or dissociation [85].

Although the importance of intracellular $\mathrm{pH}$ as a cellular signal has been highlighted [73-76], the physiological meaning of proteasome regulation by $\mathrm{pH}$ change still needs to be fully clarified. In this regard, the real mechanistic impact of $\mathrm{pH}$ on the proteasome in vivo can be determined by other specific factors and effectors (including ATP levels or posttranslational modifications; see Sections 2.3 and 4), 
yielding enzyme behavior that is different from the in vitro observations. This is supported by the studies where, in contrast to the in vitro data, hypoxia-evoked decreases in both extracellular and intracellular $\mathrm{pH}$ correlated to an increase in proteasomal activity [86].

\subsection{Effect of Temperature Variation}

The evidence that proteasome inhibition leads to the induction of the same set of heat shock genes as those induced by heat exposure points to the vulnerability of the proteasomal system to damage from high temperature [87]. However, the effect of elevated temperature on the proteasomal functions observed in diverse models of hyperthermia treatment are varied. In cultured myotubes, heating paradoxically increased degradation of short- and long-lived proteins through ATP-dependent proteolysis with the maximum effect at $41^{\circ} \mathrm{C}$ [88]. Serially passaged human skin fibroblasts exposed to repeated mild heat shock at $41^{\circ} \mathrm{C}$ for $60 \mathrm{~min}$ twice a week increased three proteasomal activities by $40 \%$ to $95 \%$ in early- and mid-passage cultures [89]. The heat-shock-stressed cells also contained a 2 -fold higher amount of the proteasome activator 11S, and the extent of the bound activator was doubled in early- and mid-passage cells only. Recent studies showed that C. elegans exhibits tissue-specific responses of the ubiquitin-proteasome system (UPS) as an organismal strategy to cope with a rise in ambient temperature [90]. An ambient temperature shift from 20 to $25^{\circ} \mathrm{C}$ increased UPS activity in the intestine but not in the body wall muscle tissue, where a concomitant accumulation of polyubiquitinated proteins occurred. However, these changes in the UPS activity and levels of polyubiquitinated proteins were not detectable in whole animal lysates. However, mild heat stress did not upregulate the content of the 195 proteasome regulator. In the HT22 hippocampal tumor cell line, heat stress induced an increase in HSP70 and proteasome levels, as well as proteasome activity in the nucleus [91]. This defense mechanism was shown to be Nrf2-pathway-dependent, suggesting that Nrf2 targeting can be a useful approach to overcome thermotolerance in cancer thermotherapy.

By contrast, Pajonk et al. [92] reported that $26 \mathrm{~S}$ proteasome activity was inhibited by exposure to $44{ }^{\circ} \mathrm{C}$ for $1 \mathrm{~h}$ in different human prostate cancer cell lines to about $40 \%$ of untreated control cells. However, hyperthermia did not affect $20 \mathrm{~S}$ activity, suggesting that thermosensitive proteasome units are located in the 195 caps. Accordingly, the maximum of all three peptidase activities of the purified $20 \mathrm{~S}$ proteasome was determined at about $40^{\circ} \mathrm{C}$, whereas chymotrypsin-like activity of the $26 \mathrm{~S}$ complex was unstable above $\sim 35^{\circ} \mathrm{C}$. The temperature effects on the caspase-like and trypsin-like activities of both forms were similar [78]. Interestingly, unlike the chymotrypsin-like activity of the $20 \mathrm{~S}$ proteasome, heat impairment of Suc-LLVY-AMC degradation via the $26 \mathrm{~S}$ complex was not irreversible, since the addition of SDS significantly restored its full activity, even at $50^{\circ} \mathrm{C}$. The conformational changes causing the impaired $26 \mathrm{~S}$ proteasome assembly were suggested as a cause of its heat-induced inactivation in cancer cells [93]. This study also indicated locking of the 20S proteasomes in a latent inactive state, further impairing activation of the $26 \mathrm{~S}$ proteasome via ATP. In addition, proteasomal inactivation can also be associated with decreased proteasome mRNA levels and rapid cellular redistribution of the proteasome following heat exposure. The temperature-dependence of proteasome activity was also observed by Geng et al. [94]. These studies showed that the low-level-ATP activating effect in ischemic heart extracts was 4-5-fold higher when enzyme assays were performed at $4{ }^{\circ} \mathrm{C}$ (conditions during cold ischemia) compared to $37^{\circ} \mathrm{C}$. However, the absolute chymotrypsin-like activity in non-ischemic heart extracts was 8 -fold lower at $4{ }^{\circ} \mathrm{C}$ compared the measurements at $37^{\circ} \mathrm{C}$.

Overall, elevated temperature can mostly lead to the upregulation of the proteasomal system in vivo, likely due to the activation of stress-response signaling pathways. However, heat-induced conformational changes may explain the decrease in proteasomal function observed in cellular models.

\subsection{Effect of Changes in ATP and $\mathrm{Mg}^{2+}$ Cofactor Levels}

The $26 \mathrm{~S}$ proteasome is an $\mathrm{Mg}^{2+}$ - and ATP-dependent enzyme, and $\mathrm{Mg}^{2+} / \mathrm{ATP}$ is known to regulate its activity, assembly, and stability [94]. Substrate unfolding is the only step among the five essential actions mediated by the ATPases in the 19S subunit that actually requires ATP hydrolysis [95]. 
Consequently, the rates of clearance of ubiquitinated proteins were shown to be directly proportional to the rates of ATP hydrolysis. However, the polypeptide structure was found to determine the overall ATP consumed and the time required for its degradation. Consequently, tighter folding of the substrate decreased the rate of degradation and increased ATP consumption [96]. However, although the other steps (association of the ATPases with the 20S particle, their selective substrate binding, induction of the $20 S$ gate-opening, and facilitation of the translocation of the unfolded substrate through the ATPase ring) do not require ATP hydrolysis, they can be supported by ATP binding alone. In addition, the attachment of ubiquitin to the $\varepsilon$-amine of lysine residues of the target proteins requires a series of enzymatic steps by E1, E2, and E3 enzymes, which are also ATP-dependent. Thus, it can be predicted that changes in the levels of ATP accompanying pathological conditions could affect the $26 \mathrm{~S}$ proteasomal function, as well as the overall ubiquitin-proteasome pathway. Accordingly, Höglinger et al. [97] showed that the inhibitors of mitochondrial complex I, rotenone, and 1-methyl-4-phenylpyridinium suppressed proteasomal activity in a cellular model of Parkinson disease via ATP depletion. Furthermore, a link between a decline in maintenance of the $26 \mathrm{~S}$ proteasome assembly and decreased ATP levels resulting from impaired mitochondrial function was also suggested in aged flies [98]. By contrast, the impaired activity of respiratory complex I and subsequent reprogramming of the Krebs cycle with a shortage of aspartate and electron acceptors resulted in reduced $26 \mathrm{~S}$ proteasome activity despite maintenance of ATP production via enhanced glycolysis [99]. These results point to a novel mechanism of how mitochondrial metabolism adaptively regulates protein degradation through the proteasome.

Table 1. (a) Effects of physico-chemical factors (stressors) on functionality of proteasome: Effect of $\mathrm{pH}$.

(b) Effects of physico-chemical factors (stressors) on functionality of proteasome: Effect of temperature.

(c) Effects of physico-chemical factors (stressors) on functionality of proteasome: Effect of changes in co-factors.

(a)

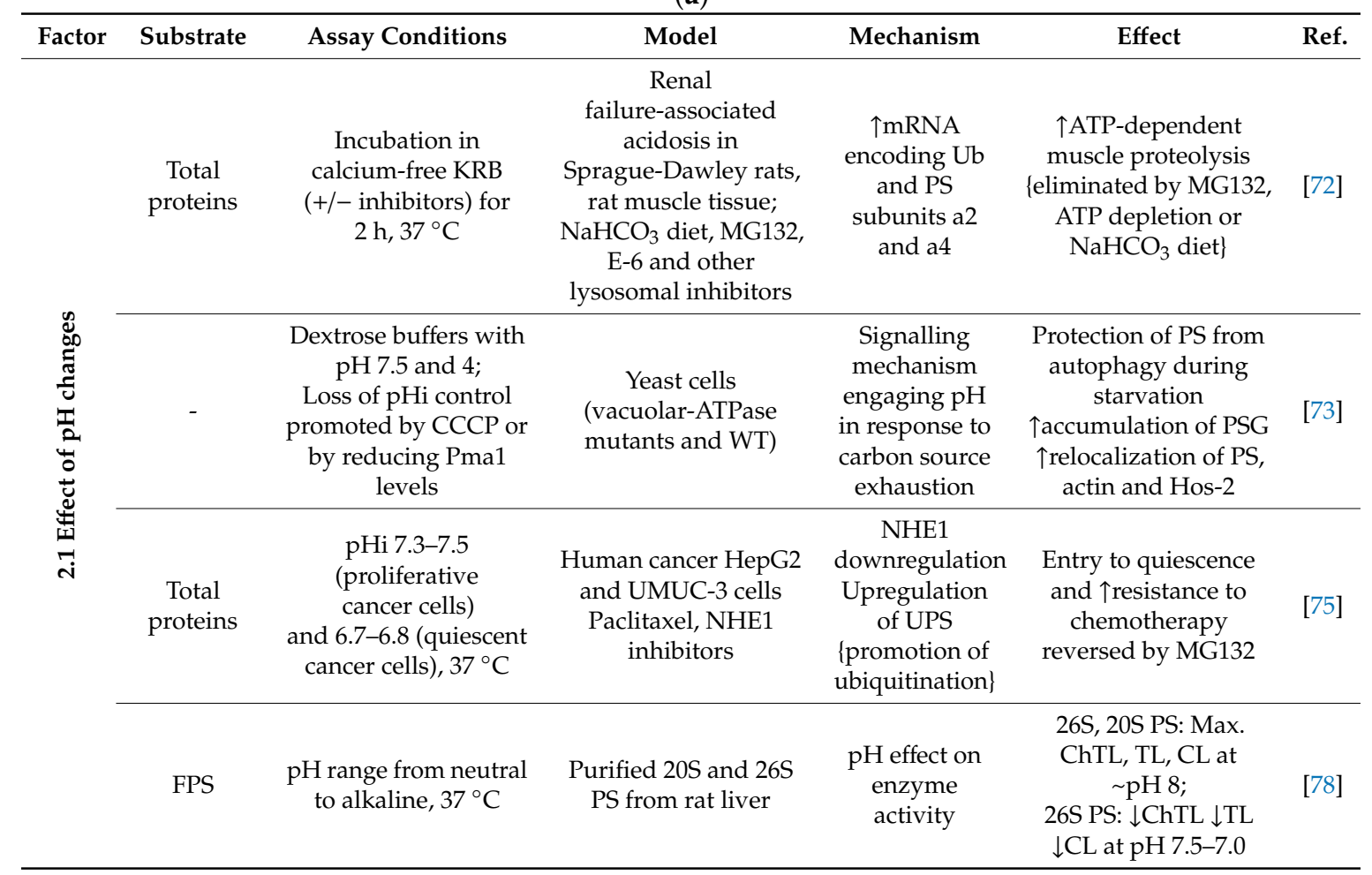




\begin{tabular}{|c|c|c|c|c|c|c|}
\hline Factor & Substrate & Assay Conditions & Model & Mechanism & Effect & Ref. \\
\hline & FPS & $\begin{array}{c}\mathrm{pH} \text { range from } 3.5 \\
\text { to } 10.5 \\
\{50 \mathrm{mM} \text { Na citrate }(\mathrm{pH} \\
3.5-6.0), 50 \mathrm{mM} \\
\text { TrisHCl }(\mathrm{pH} 7.0-8.0) \\
\text { and } 50 \mathrm{mM} \\
\text { glycine- } \mathrm{NaOH}(\mathrm{pH} \\
8.5-10.5)\}, 37^{\circ} \mathrm{C}\end{array}$ & $\begin{array}{l}\text { Purified PS from } \\
\text { ostrich liver }\end{array}$ & $\begin{array}{l}\mathrm{pH} \text { effect on } \\
\text { enzyme } \\
\text { activity }\end{array}$ & $\begin{array}{c}\text { pH optima for ChTL, } \\
\text { TL, CL: neutral or } \\
\text { slightly alkaline } \\
\text { Max. ChTL, CL at } \\
\text { pH 7.0 } \\
\text { Max. TL at pH } 8.0\end{array}$ & [79] \\
\hline & FPS & $\begin{array}{c}\text { pH 3.5-6.0 }(25 \mathrm{mmol} / \mathrm{l} \\
\text { Hepes-acetic } \\
\text { acid/acetate buffer }) \\
\text { pH } 6.5-9.0(25 \mathrm{mmol} / 1 \\
\text { Hepes-NaOH buffer }) \\
30 \text { or } 60 \mathrm{~min}, 37^{\circ} \mathrm{C}\end{array}$ & $\begin{array}{l}\text { Purified 20S PS from } \\
\text { human platelets }\end{array}$ & $\begin{array}{l}\mathrm{pH} \text { effect on } \\
\text { enzyme } \\
\text { activity }\end{array}$ & $\begin{array}{c}\text { pH optimum for } \\
\text { ChTL: } \mathrm{pH} 7.5-8.0 \text { and } \\
5.0-5.5\end{array}$ & [80] \\
\hline & FPS & $\begin{array}{c}\mathrm{pH} 8,30 \mathrm{~min}, 37^{\circ} \mathrm{C} \\
\text { \{peptidase activity\} } \\
\text { Kinetic } \\
\text { association/dissociation } \\
\text { of Hsp90-20S } \\
\text { proteasome complex } \\
\text { measured in pH range } \\
6.0-8.0\end{array}$ & $\begin{array}{l}\text { 20S PS and HSP90 } \\
\text { purified from bovine } \\
\text { thymus }\end{array}$ & $\begin{array}{l}\text { Kinetic } \\
\text { properties of } \\
\text { the HSP90-20S } \\
\text { proteasome } \\
\text { complex } \\
\text { controlled by } \\
\text { protons }\end{array}$ & $\begin{array}{c}\uparrow \mathrm{TL} \\
\text { HSP90 and } 20 \mathrm{~S} \text { do not } \\
\text { associate at } \mathrm{pH}<6.5 \\
\text { and at } \mathrm{pH}>7.5 \text {, high } \\
\text { affinity binding at } \\
\text { physiological } \mathrm{pH}\left(\mathrm{k}_{a s}\right. \\
\left.10^{7} \mathrm{M}^{-1} . \mathrm{s}^{-1}\right) .\end{array}$ & [84] \\
\hline & - & $\begin{array}{c}\text { Lysates } \\
+/- \text { PS inhibitors } \\
\text { ALLN, ALLM \{in } \\
\text { medium }\}\end{array}$ & $\begin{array}{l}\text { Human endothelial } \\
\text { cells (HUVECs and } \\
\text { HPMVECs); } \\
\text { hypoxia }\end{array}$ & - & $\begin{array}{c}\uparrow P S \text { activity promoted } \\
\text { by } \downarrow \text { extracellular } \mathrm{pH} \\
\text { and } \mathrm{pHi} \\
\uparrow \mathrm{LPS} \text {-stimulated } \\
\text { expression of ICAM-1 } \\
\text { and lymphocyte } \\
\text { adhesion } \\
\downarrow \text { cytoplasmic IKB }\end{array}$ & [86] \\
\hline
\end{tabular}

ChTL, chymotrypsin-like activity; TL, trypsin-like activity; CL, caspase-like activity; FPS, fluorogenic peptide substrate; PS, proteasome; MG132, PS inhibitor; E-64, inhibitor of the calpains; ubiquitin, Ub; pHi, intracellular pH; CCCP, carbonyl cyanide m-chlorophenyl hydrazone; Pma1, plasma membrane ATPase 1; PSG, PS storage granules; Hos-2, histone deacetylase; NHE-1, Na+/H+ exchanger 1; HSP, heat shock protein; ALLN, calpain inhibitor I; ALLM, N-acetyl-Leu-Leu-methioninal, calpain inhibitor II; HUVECs, human umbilical vein endothelial cells; HPMVECs, Human pulmonary microvascular endothelial cells; ICAM-1, intercellular adhesion molecule-1; IKB, inhibitor of nuclear factor $\mathrm{kB}$.

(b)

\begin{tabular}{|c|c|c|c|c|c|c|}
\hline Factor & Substrate & Assay Conditions & Model & Mechanism & Effect & $\overline{\text { Ref. }}$ \\
\hline \multirow{3}{*}{ 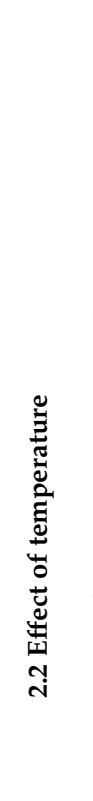 } & FPS & $\begin{array}{c}20 \mathrm{~S} \text { and } 26 \mathrm{~S} \text { PS } \\
\text { incubated with FPS at } \\
20-75^{\circ} \mathrm{C}\end{array}$ & $\begin{array}{l}\text { Purified } 20 S \text { and } 26 S \\
\text { PS from rat liver }\end{array}$ & $\begin{array}{c}\text { High } \\
\text { temperature } \\
\text { effect on enzyme } \\
\text { activity }\end{array}$ & $\begin{array}{l}\text { 20S PS: Max. ChTL, } \\
\text { TL, CL at } \sim 40^{\circ} \mathrm{C} \text {; } \\
\text { 26S PS: ChTL unstable } \\
\text { at T }>\sim 35^{\circ} \mathrm{C} \text {, } \\
\text { Comparable effect of } \\
\text { T on TL and CL of 20S } \\
\text { and 26S; impairment } \\
\text { of ChTL of 26S PS } \\
\text { reversed by SDS }\end{array}$ & [78] \\
\hline & $\begin{array}{l}\text { [3,5- } \\
\left.{ }^{3} \mathrm{H}\right] \mathrm{Tyr}- \\
\text { labelled } \\
\text { long-lived } \\
\text { and } \\
\text { short-lived } \\
\text { proteins }\end{array}$ & $\begin{array}{l}\text { Protein degradation } \\
\text { measured at } 37 \text { and } \\
41^{\circ} \mathrm{C} \\
\text { (+/- energy-depleting } \\
\text { medium, E64, Ca-free } \\
\text { medium, lysosomal } \\
\text { and PS inhibitors) }\end{array}$ & $\begin{array}{l}\text { L6 rat skeletal muscle } \\
\text { (myotubes) }\end{array}$ & $\begin{array}{l}\text { Not dependent } \\
\text { on changes in } \\
\text { mRNA levels for } \\
\text { Ub and } \\
\text { subunit } \beta 2\end{array}$ & $\begin{array}{l}\uparrow \text { degradation of short- } \\
\text { and long-lived } \\
\text { proteins (max. effect } \\
\text { at } 41^{\circ} \mathrm{C} \text {, with greater } \\
\text { effect in long-lived } \\
\text { proteins) suppressed } \\
\text { by PS inhibitors or } \\
\text { ATP depletion }\end{array}$ & [88] \\
\hline & FPS & Cell lysates, $37^{\circ} \mathrm{C}$ & $\begin{array}{c}\text { Human skin fibroblast } \\
\text { undergoing ageing } \\
\text { in vitro } \\
\text { exposed to RMHS at } \\
41^{\circ} \mathrm{C} \text { for } 60 \text { min twice } \\
\text { a week }\end{array}$ & $\begin{array}{l}\uparrow \text { levels of } 11 S \\
\text { and } 11 S \text { bound } \\
\text { to } 20 \mathrm{~S} \text { PS in } \\
\text { early- and } \\
\text { mid-passage } \\
\text { cells only }\end{array}$ & $\begin{array}{c}\uparrow C h T L \uparrow T L \uparrow C L \text { in } \\
\text { early- and } \\
\text { mid-passage cultures; } \\
\text { loss of upregulation in } \\
\text { late passage }\end{array}$ & [89] \\
\hline
\end{tabular}




\begin{tabular}{|c|c|c|c|c|c|c|}
\hline Factor & Substrate & Assay Conditions & Model & Mechanism & Effect & Ref. \\
\hline & - & $\begin{array}{l}\text { Shift from } 20 \text { to } 25^{\circ} \mathrm{C} \\
\text { for } 1 \text { day (in vivo) }\end{array}$ & $\begin{array}{c}\text { C. elegans (whole } \\
\text { animal lysates and in } \\
\text { tissue-specific } \\
\text { transgenic reporter } \\
\text { strains) } \\
\text { hsp-4p and } \\
\text { hsp-16.2p::GFP } \\
\text { reporters; } \\
\text { UbG76V - Dendra2; } \\
\text { UIM2::GFP::MODC }\end{array}$ & $\begin{array}{l}\text { PS subunit } \\
\text { translation or } \\
\text { posttranscriptional } \\
\text { regulation, } \\
\text { regulatory } \\
\text { interactors, } \\
\text { substrate } \\
\text { ubiquitination, } \\
\text { or protein } \\
\text { folding }\end{array}$ & $\begin{array}{l}\text { } U P S \text { activity in the } \\
\text { intestine, but not in } \\
\text { the body wall } \\
\text { muscle tissue; } \\
\text { } \text { polyUb proteins in } \\
\text { body wall } \\
\text { muscle tissue }\end{array}$ & [90] \\
\hline & FPS & Cell lysates, $37^{\circ} \mathrm{C}$ & $\begin{array}{l}\text { HT22 cells (whole and } \\
\text { nuclear lysates); } \\
\text { Nrf2-siRNA } \\
\text { transfected cells; } \\
\text { hyperthermia at } 42^{\circ} \mathrm{C} \\
\text { for } 1 \mathrm{~h} \text { with or } \\
\text { without recovery }\end{array}$ & $\begin{array}{c}\uparrow N r f 2 \\
\text { expression }\end{array}$ & $\begin{array}{c}\uparrow \text { nuclear ChTL and } \\
\uparrow \beta 5 \text { subunit and } \\
\uparrow H S P 70 \text { expression, } \\
\uparrow H O-1 \text { and GST } \alpha \\
\text { expression }\end{array}$ & [91] \\
\hline & FPS & $\begin{array}{l}\text { Cell lysates, } 37^{\circ} \mathrm{C} \\
(+/- \text { ATP or SDS) }\end{array}$ & $\begin{array}{l}\text { PC-3, LnCaP, DU-145 } \\
\text { human prostate } \\
\text { cancer cells; } \\
\text { hyperthermia at } 44{ }^{\circ} \mathrm{C} \\
\text { for } 1 \mathrm{~h}\end{array}$ & $\begin{array}{c}\text { Thermosensitivity } \\
\text { of } 19 \mathrm{~S}\end{array}$ & $\begin{array}{c}\downarrow \text { ChTL of } 26 S, \text { no } \\
\text { effect on } 20 S ; \\
\uparrow \text { apoptosis and } \\
\text { radiosensitization; } \\
\uparrow \text { stabilization IkB } \\
\downarrow \text { androgen receptor }\end{array}$ & [92] \\
\hline & FPS & $\begin{array}{c}\text { 20S and 26S PS } \\
\text { fractions from density } \\
\text { gradient or purified } \\
\text { proteins } \\
\text { (+/- ATP or SDS })\end{array}$ & $\begin{array}{c}\text { Murine RMA cells, } \\
\text { 3T3 and B8 fibroblasts } \\
\text { Heat shock for } 25 \text { min } \\
\text { at } 42{ }^{\circ} \mathrm{C} \text { with or } \\
\text { without recovery }\end{array}$ & $\begin{array}{c}\text { Tlocked inactive } \\
\text { latent } \\
\text { conformation of } \\
\text { 20S PS; } \downarrow \text { mRNA } \\
\text { PS levels and de } \\
\text { novo PS } \\
\text { maturation }\end{array}$ & $\begin{array}{c}\downarrow C h T L \text { activity of } 26 S \\
\text { and } 20 S \text { PS; } \uparrow \text { cellular } \\
\text { redistribution } \\
\text { \{nucleus and } \\
\text { membrane\}; positive } \\
\text { effects during heat } \\
\text { shock response }\end{array}$ & [93] \\
\hline & FPS & $\begin{array}{c}\text { Rat heart extracts, } 4 \\
{ }^{\circ} \mathrm{C} \text { or } 37^{\circ} \mathrm{C}, \\
\text { physiological or } \\
\text { actual ATP }\end{array}$ & $\begin{array}{l}\text { Cold myocardial } \\
\text { ischemia, } 4{ }^{\circ} \mathrm{C} \\
\text { purified } 20 \mathrm{~S} / 26 \mathrm{~S} \mathrm{PS} \\
\text { preparations from } \\
\text { human erythrocytes }\end{array}$ & $\begin{array}{c}\text { Hypothermia } \\
\text { effect on enzyme } \\
\text { activity; reduced } \\
\text { competing effect } \\
\text { of natural } \\
\text { protein } \\
\text { substrates } \\
\text { \{activation effect }\end{array}$ & $\begin{array}{l}\text { 4-5-fold } \uparrow \text { activation } \\
\text { ChTL at } 4{ }^{\circ} \mathrm{C} \\
\text { ChTL \{non-ischemic } \\
\text { hearts\} } 8 \text {-fold } \downarrow \text { at } 4^{\circ} \mathrm{C} \\
\text { vs. } 37^{\circ} \mathrm{C}\end{array}$ & [94] \\
\hline
\end{tabular}

ChTL, chymotrypsin-like activity; TL, trypsin-like activity; CL, caspase-like activity; FPS, fluorogenic peptide substrate; PS, proteasome; Ub, ubiquitin; RMHS, repeated mild heat shock; HSP, heat shock protein; MODC, mouse ornithine decarboxylase; UIM, ubiquitin-interacting motif; GFP, green fluorescence protein; Nrf2, nuclear factor erythroid 2-related factor 2; HO-1, heme oxygenase; GST $\alpha$, glutathione S-transferase $\alpha$; IkB, inhibitor of nuclear factor kB; SDS, sodium dodecyl sulfate; RMA cells, murine T cell lymphoma cell line; UPS, ubiquitin-proteasome system; $\mathrm{Ub}^{\mathrm{G} 76 \mathrm{~V}}$ - Dendra2, Dendra2 fluorescent protein linked to a non-cleavable $\mathrm{Ub}$ moiety $\left(\mathrm{Ub}^{\mathrm{G} 76 \mathrm{~V}}\right)$.

(c)

\begin{tabular}{|c|c|c|c|c|c|c|}
\hline Factor & Substrate & Assay Conditions & Model & Mechanism & Effect & Ref. \\
\hline \multirow{2}{*}{ 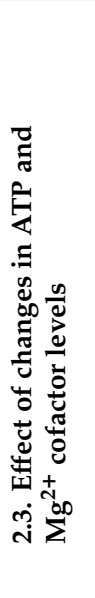 } & $\begin{array}{c}\text { FPS, } \\
{ }^{32}{\mathrm{P}-U b_{5}}^{-} \\
\text {DHFR } \\
\text { Ub } b_{n-S i c 1} \\
\text { Poly-Ub- } \\
\text { proteins }\end{array}$ & $\begin{array}{c}\text { Purified PS } \\
\text { (+/- ATP or ATP } \gamma S) \\
\text { 32 } \mathrm{P}-\mathrm{Ub}_{5} \text {-DHFR } \\
\text { (+folate })\end{array}$ & $\begin{array}{l}\text { Purified 26S PS } \\
\text { yeast-WT and } \\
\text { mutants preventing } \\
\text { ATP binding to Rpt3, } \\
\text { Rpt5, or Rpt6; } \\
\text { Purified 26S PS from } \\
\text { mouse fibroblasts }\end{array}$ & $\begin{array}{l}\text { Polypeptide } \\
\text { structure } \\
\text { determines } \\
\text { energy } \\
\text { expenditure; } \\
\text { cooperative } \\
\text { function of } \\
\text { ATPase } \\
\text { subunits }\end{array}$ & $\begin{array}{c}\downarrow \text { similar basal and } \\
\text { stimulated ATP } \\
\text { hydrolysis and } \\
\downarrow \text { degradation of } \\
\text { Ub-substrates } \\
\text { in mutants } \\
\uparrow \text { time of degradation } \\
\text { and ATP expenditure } \\
\text { in tightly folded } \\
\text { substrates by WT PS }\end{array}$ & [96] \\
\hline & FPS & $\begin{array}{c}\text { Cell lysates } \\
\text { (endogenous ATP) }\end{array}$ & $\begin{array}{c}\text { Primary } \\
\text { mesencephalic rat cell } \\
\text { cultures } \\
\text { Rotenone, MPP } \\
\text { epoxomicin, MG132, } \\
\text { Gluc, NAC }\end{array}$ & $\begin{array}{l}\text { ATP depletion } \\
\text { and highly } \\
\text { energy- } \\
\text { dependent PS }\end{array}$ & $\begin{array}{c}\downarrow C h T L \downarrow T L \downarrow C L \\
\uparrow R O S \text { production } \\
\uparrow \text { complex } \\
\text { I-inhibition-induced } \\
\text { neurotoxicity } \\
\text { enhanced by } \\
\text { PS inhibition }\end{array}$ & [97] \\
\hline
\end{tabular}




\begin{tabular}{|c|c|c|c|c|c|c|}
\hline Factor & Substrate & Assay Conditions & Model & Mechanism & Effect & Ref. \\
\hline & FPS & $\begin{array}{c}\text { Whole fly extracts } \\
\text { (endogenous ATP) } \\
\text { Colorimetric and in } \\
\text { gel assay }\end{array}$ & $\begin{array}{c}\text { Drosophila } \\
\text { melanogaster } \\
\text { flies 1-2 days of age } \\
\text { (young) } \\
\text { flies 43-47 days of age } \\
\text { (old) }\end{array}$ & $\begin{array}{l}\text { Ageing-promoted } \\
\text { decline }(\sim 50 \%) \\
\text { in ATP affecting } \\
\text { assembly and } \\
\text { activity of } 26 S \\
\text { PS }\end{array}$ & $\begin{array}{c}\downarrow \text { ChTL } \downarrow \text { TL } \downarrow \text { CL of } \\
26 S \text { PS in old flies; } \\
\downarrow \text { assembly of } 26 S \\
\downarrow \text { ATP level } \\
\uparrow U b \text {-proteins } \\
\downarrow \text { locomotor function }\end{array}$ & [98] \\
\hline & FPS & $\begin{array}{c}\text { Cell lysates } \\
\text { (endogenous ATP) } \\
\text { Luminometric and in } \\
\text { gel assay }\end{array}$ & $\begin{array}{l}\text { Mouse embryonic } \\
\text { fibroblasts from } \\
\text { mtDNA mutator mice }\end{array}$ & $\begin{array}{c}\text { Impaired } \\
\text { activity of } \\
\text { respiratory } \\
\text { complex I; TCA } \\
\text { reprogramming } \\
\text { with shortage of } \\
\text { aspartate and } \mathrm{e}^{-} \\
\text {acceptors }\end{array}$ & $\begin{array}{c}\downarrow \text { ChTL and assembly } \\
\text { of 26S PS in mutator } \\
\text { cells despite of stable } \\
\text { ATP production via } \\
\text { glycolysis }\end{array}$ & [99] \\
\hline & $\begin{array}{l}\text { FPS } \\
\text { GFP-CL1 } \\
\text { GFP-dgn/RFP }\end{array}$ & $\begin{array}{c}\text { Cell lysates } \\
\text { (endogenous ATP) } \\
\text { Purified PS } \\
(0-4 \text { mM ATP }) \\
\text { Fluorometric assay } \\
\{\text { WB for degrons }\end{array}$ & $\begin{array}{c}\text { Purified 26S PS; } \\
\text { K562, P388, } \\
\text { NCI-H460, and } \\
\text { SH-SY5Y cells; } \\
\text { Oligomycin, 2DG }\end{array}$ & $\begin{array}{c}\text { Negative } \\
\text { regulatory effect } \\
\text { of basal level of } \\
\text { ATP on PS } \\
\text { serving likely as } \\
\text { a layer of } \\
\text { safeguard for } \\
\text { the PS reserve }\end{array}$ & $\begin{array}{c}<50 \mu \mathrm{M} \text { ATP } \uparrow \mathrm{ChTL} \\
>100 \mu \mathrm{M} \text { ATP } \downarrow \text { ChTL } \\
\uparrow \text { substrates } \\
\text { degradation at low } \\
\text { ATP; } \uparrow \text { resistance of } \\
\text { leukemic cells to PS } \\
\text { inhibition at low } \\
\text { ATP levels }\end{array}$ & [100] \\
\hline & FPS & $\begin{array}{c}\text { Tissue cytosolic } \\
\text { extracts } \\
(0-2 \text { mmol/L ATP }) \\
\text { Optimized assay } \\
\text { conditions }\end{array}$ & $\begin{array}{l}\text { Sprague Dawley rats; } \\
\text { cardiac cytosolic } \\
\text { tissue isolates }\end{array}$ & - & $\begin{array}{c}6 \mu \mathrm{mol} / \mathrm{L} \text { ATP } / 10 \mu \mathrm{g} \\
\text { protein max } \uparrow C h T L ; \\
2 \mathrm{mmol} / \mathrm{L} \text { ATP } / 30-90 \\
\mu \mathrm{g} \text { protein } \downarrow C h T L ; \\
\text { Optimal c(ATP) }= \\
6-100 \mu \mathrm{mol} / \mathrm{L} \text { for } \\
\text { ChTL, TL }\end{array}$ & [101] \\
\hline & FPS & $\begin{array}{c}\text { Purified PS } \\
\text { (endogenous ATP) }\end{array}$ & $\begin{array}{l}\text { Isolated } 20 S \text { PS from } \\
\text { diaphragm biopsies } \\
\text { from patients with } \\
\text { and without COPD }\end{array}$ & - & $\begin{array}{c}\uparrow C h T L \text { and } \uparrow C L \text { 20S } \\
\text { PS } \\
\uparrow M A F b x \text { mRNA } \\
\downarrow \text { myosin levels }\end{array}$ & [102] \\
\hline & FPS & $\begin{array}{c}\text { Rat heart extracts, } \\
\text { Purified PS, } 4^{\circ} \mathrm{C} \text { or } 37 \\
{ }^{\circ} \mathrm{C} \text {, physiological or } \\
\text { actual ATP }\end{array}$ & $\begin{array}{l}\text { Cold myocardial } \\
\text { ischemia, } 4{ }^{\circ} \mathrm{C} ; \\
\text { Purified } 20 \mathrm{~S} / 26 \mathrm{~S} \text { PS } \\
\text { preparations from } \\
\text { human erythrocytes }\end{array}$ & $\begin{array}{l}\sim 30 \% \text { subset of } \\
26 S \text { PS are stable } \\
\text { and activated at } \\
\text { very low levels } \\
\text { of ATP; ATP } \\
\text { hydrolysis is } \\
\text { required for } 26 S \\
\text { activation }\end{array}$ & $\begin{array}{c}\uparrow C h T L \uparrow T L \uparrow C L \text { at } \\
\text { low } \mu \mathrm{mol} / \mathrm{L} \\
\text { range ATP } \\
\downarrow C h T L \downarrow T L \downarrow C L \text { at } \\
\text { ATP physiol. range; } \\
\text { activating effect of } \\
\text { low ATP on } 26 S \text { PS } \\
\text { activity suppressed by } \\
\mathrm{Mg}^{2+} \text { chelation }\end{array}$ & {$[94]$} \\
\hline
\end{tabular}

ChTL, chymotrypsin-like activity; TL, trypsin-like activity; $\mathrm{CL}$, caspase-like activity; FPS, fluorogenic peptide substrate; PS, proteasome; ATP $\gamma \mathrm{S}$; nonhydrolyzable ATP analogue; $\mathrm{Ub}$, ubiquitin; $\mathrm{Ub}_{5}-\mathrm{DHFR}$, pentaUb-dihydro-folate reductase conjugate; $\mathrm{Ub}_{n}$-Sic1, polyUb-conjugated substrate and inhibitor of the cyclin-dependent protein kinase CDC28 (Sic1); MPP+, 1-methyl-4-phenylpyridinium; 2-DG, 2-deoxyglucose; COPD, chronic obstructive pulmonary disease; TCA, tricarboxylic acid cycle; WB, western blot; WT, wild type; MG132, PS inhibitor; NAC, N-acetyl-L-cysteine; Gluc, glucose; mtDNA, mitochondrial DNA; GFP-dgn, green fluorescence protein-degron conjugate; RFP, red fluorescence protein; WB, western blotting; K562 and P388, leukemic cells; NCI-H460, human non-small cell lung cancer cell line; SH-SY5Y, neuroblastoma cell line; MAFbx, muscle-specific E3-ligase.

In addition, several studies suggested that the 26S proteasome is a cell-destructive protease that is paradoxically activated as the ATP levels decline and that a sufficient energy supply prevents the tissue from autodestructing [100]. Low ATP levels linked to hypoxia in cancer tissue can also explain the upregulated proteasome activities in cancer cells. Consistent with that assumption, the physiological levels of ATP (generally in the low millimolar range) were shown to inhibit proteasome peptidase activities in vitro [101], whereas activities in the energy-deprived tissues under stress conditions tended to increase [102]. Both with a purified proteasome and in a cellular model, the manipulation of ATP levels was shown to regulate chymotrypsin-like activity in two opposing directions, depending on the levels, showing an optimal stimulatory concentration at 50-100 $\mu \mathrm{M}$ [100]. Geng et al. [94] suggested 
that during ischemic myocardial injury, a condition when ATP concentrations decrease to critically low levels, a discrete portion of the $26 \mathrm{~S}$ proteasome complexes remains stable, thereby accounting for an increase of cardiac proteasome peptidase activity by $225 \%$. When $\mathrm{Mg}^{2+}$ was chelated with EDTA, the overactivating effect of low ATP levels on $26 \mathrm{~S}$ activity disappeared, highlighting the necessity of ATP hydrolysis for maximum action. However, variations in $\mathrm{Mg}^{2+}$ levels did not influence the $26 \mathrm{~S}$ complex stability of the preserved portion of the $26 \mathrm{~S}$ proteasomes. A link between the stoichiometry of ATP binding and 26S activity was also elucidated by Smith et al. [95]. Using an archaeal proteasome-activating nucleotidase (PAN)-20S complex and eukaryotic $26 \mathrm{~S}$ proteasome, these studies suggested that ATP binds in pairs to the ATPase subunits, which exhibit three conformational states with high, low, or no affinity for ATP. This model suggested that the binding of two ATP molecules (or two ATP and two ADP molecules) yields maximum upregulation of the protein substrate binding, association with the core particle, and $20 \mathrm{~S}$ gate-opening. However, binding of the four ATP molecules reduces these functions. Furthermore, this model considered a cooperative and coordinated cyclic ATP binding and hydrolysis. Altogether, high ATP levels can be linked to a 4-bound state of 19S ATPase preventing conformational changes favoring substrate binding, $\alpha$-gate opening, and assembly of the $26 \mathrm{~S}$ proteasome, thus explaining the observed inhibitory effects of high concentrations of ATP.

\section{Intracellular Chemical Modifications of the Proteasome}

\subsection{Regulatory Covalent Modifications}

Proteasomal subunits undergo multiple posttranslational modifications (PTMs), such as S-glutathionylation, phosphorylation, ubiquitination, and O-linked glycosylation or acetylation, which may represent distinct essential regulatory mechanisms of proteasomal activity in response to changes in environmental conditions, such as stresses, immunological challenges, or nutrients [103] (Table 2a-e). Many PTM sites of the proteasome (including 417 phosphorylation and over 500 ubiquitination sites), which may be involved in the dynamic regulation of proteasomal functions, have been identified by mass spectrometry in cardiac proteasomes [104]. More than 345 modification sites substituted with 11 types of modifying structures were discovered via comprehensive proteomic analysis in the yeast $26 \mathrm{~S}$ proteasome [105]. Recent evidence also strongly suggests that extensive complex interplay exists among particular PTMs of the proteasome, which tunes its activity based on diverse environmental stimuli. In addition, modifications of the proteasome may also occur in concert with the PTMs of substrate proteins, thus directing the specificity of their degradation and stability and contributing to the complexity of regulatory mechanisms based on the 'chemistry' of a cell.

Recent advances in mass spectrometric (MS) technologies allow for sensitive, site-specific, and simultaneous mapping of multiple PTMs in a protein. The low abundance of modified proteins and the lability of PTMs represent common challenges in MS analysis. The enrichment methods for PTM peptides based on PTM-targeted affinity chromatography, ultraperformance liquid chromatography, and alternative techniques of peptide fragmentation (such as electron transfer dissociation) preserving labile PTM moieties are the usual approaches to resolve these issues.

\subsubsection{S-Glutathionylation}

S-glutathionylation, a formation of mixed disulfides between protein cysteine residues and glutathione (GSH), belongs to the major redox regulatory mechanisms that 'translate' the chemical features of reactive oxygen and nitrogen species into diverse cell transduction signals. Generally, only a discrete subset of exposed solvents or free cysteine residues on the surfaces of proteins are prone to a range of reversible redox-sensitive modifications. Since cysteine oxidation reactions are bimolecular nucleophilic substitution (SN2) reactions, susceptibility to such a modification is largely influenced by the steric accessibility of a protein thiol $(\mathrm{pSH})$ group and its low $\mathrm{pKa}$ value, ensuring its dissociation and the prevalence of a more reactive thiolate form $\left(\mathrm{pS}^{-}\right)$at a physiological $\mathrm{pH}$ [106]. Besides reactions facilitated basically through the action of glutathione-S-transferase P (GSTP or 
GSTP $\pi$ ), S-glutathionylation was proposed to also occur non-enzymatically via a thiol-disulfide exchange reaction of protein thiolate $\left(\mathrm{pS}^{-}\right)$with the oxidized form of glutathione (GSSG) or via the reaction of GSH with the partially oxidized reactive protein thiol (thiyl radical (pS·), S-nitrosylated (pS-NO), or S-sulfenylated (pS-OH) intermediates) [107] (Scheme 1). Alternatively, oxidatively modified glutathione (glutathione sulfenate $(\mathrm{GSOH})$, nitrosoglutathione (GSNO), or glutathione thiolsulfinate $(\mathrm{GS}(\mathrm{O}) \mathrm{SG})$ ) can react with protein thiolate. Furthermore, a distance of $\leq 6.2 \AA$ between thiols strongly predicts intra-protein disulfide bond formation [108]. The reversal of S-glutathionylation is achieved mainly enzymatically via glutaredoxin (Grx), which selectively dethiolates pSSGs through a GSH-dependent mechanism.

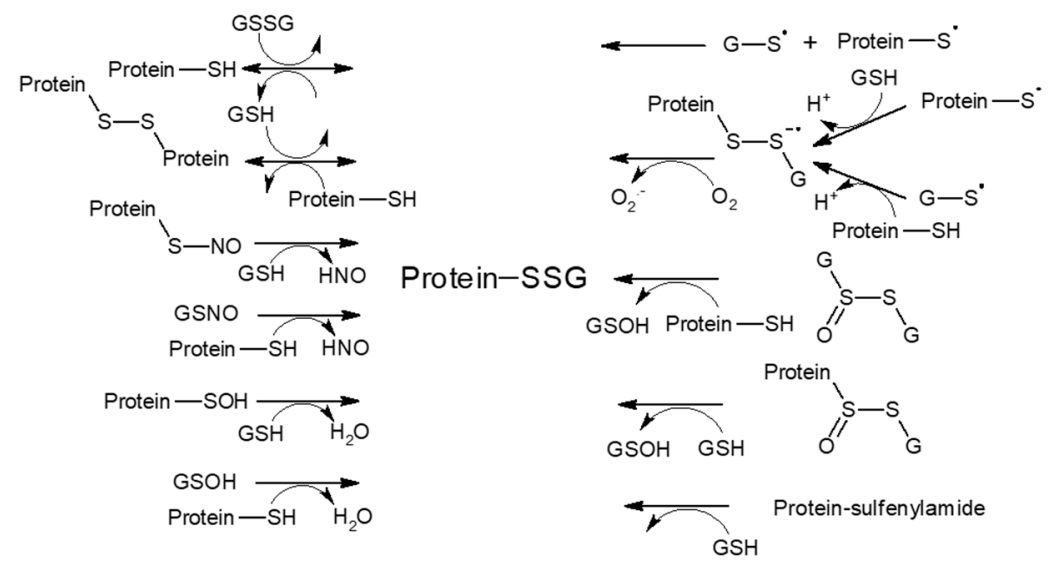

Scheme 1. Reaction mechanisms potentially involved in glutathionylation (adapted from Gallogly et al. [107]).

Studies on the yeast 20S proteasome revealed that glutathionylation of Cys76 and Cys221 in the $\alpha 5$ subunit participates in regulating the gating of the $20 \mathrm{~S}$ proteasome through conformational changes $[109,110]$. In particular, Cys76 was suggested to control gate opening, while Cys221 (the only cysteine located on the surface of the yeast proteasome) was proposed to be its negative regulator. Moreover, the mutations $\alpha 5-$ Cys76S and/or $\alpha 5-C y s 221 S$, associated with the gate in a closed conformation, attenuated the viability and lifespan of S. cerevisiae compared to the wild type counterpart [111]. Despite partial inhibition of the chymotrypsin-like and caspase-like activities of the $20 S$ proteasome by S-glutathionylation, the rate of degradation of oxidized proteins increased. Thus, the increased proteolysis due to S-glutathionylation is primarily governed by the $20 \mathrm{~S}$ gate opening despite a partial decrease in site-specific activity (caused by allosteric modification of the catalytic sites). Nevertheless, a biphasic response to S-glutathionylation was observed for mammalian proteasomes, showing an increase in chymotrypsin-like activity at low concentrations of GSH or GSSG and a decrease at high levels of GSH and GSSG [112]. Furthermore, S-glutathionylation of the yeast $20 S$ was found to be controlled by glutaredoxin- 2 and cytosolic thioredoxins through a mechanism involving Grx-2 entry into the $20 \mathrm{~S}$ core particle and its degradation [113]. Grx-2 showed increased ubiquitination in yeast cells grown under oxidative conditions. Overall, enhancement of the 20S function through S-glutathionylation-directed gate opening may represent an adaptive mechanism of cells in response to oxidative stress. Moreover, increased reversible cysteine thiol oxidation, followed by the formation of internal disulfide bonds, correlated with disassembly of the yeast 26S proteasomal complex [114]. The exposure of HEK293 cells and neutrophils to $\mathrm{H}_{2} \mathrm{O}_{2}$ and $\mathrm{GSH}$, as well as the in vivo conditions associated with inactivated catalase, were shown to decrease the $26 \mathrm{~S}$ proteasome peptidase activity caused by the S-glutathionylation of Rpn1 and Rpn2 subunits in the $19 \mathrm{~S}$ regulator [115]. These data corroborate the findings that during oxidative stress, the pool of $20 \mathrm{~S}$ proteasomes expands through their uncoupling from the regulatory complex 19S [116], which also has higher susceptibility to oxidation compared to 20S [117], and 20S proteasomal degradation dominates over ubiquitin- and ATP-dependent proteolysis. Accordingly, S-glutathionylation was also shown to 
downregulate other components of the ubiquitin-proteasome pathway. The inhibition of E1 and E2 enzymes under conditions of an increased GSSG:GSH ratio in RPE cells, associated with the formation of E1-protein-mixed disulfides, pointed to a redox regulation of E1 and E2 activities in response to oxidant insult [118].

\subsubsection{S-Nitrosylation and Other S-Modifications}

S-nitrosylation is a covalent attachment of the NO moiety to a sulfhydryl group of cysteine residues. Similar to S-glutathionylation, S-nitrosylation belongs to the major modifications involved in the redox-dependent signaling and regulation of protein functions, which also provide protection of the protein thiol group against further oxidation. The chemistry that forms S-nitroso-cysteine involves nitrosylation via $\mathrm{N}_{2} \mathrm{O}_{3}$ (formed from $\mathrm{NO}$ produced by $\mathrm{NO}$ synthases), metal catalysis, and a trans-S-nitrosylation reaction with the initially formed GSNO or other pSNO proteins, principally S-nitrosothioredoxin [119].

S-nitrosylation of the proteasome might be a mechanism by which NO exerts its regulatory effects on vasculature. Using the biotin switch approach with a novel tandem mass tag CysTMT ${ }^{6}$ combined with LC/MS/MS analysis revealed S-nitrosylation at 13 sites on 10 proteasome subunits from human pulmonary arterial endothelial cells (Rpt1 (Cys389), Rpt4 (Cys170, Cys347), Rpt5 (Cys387, Cys396), Rpn2 (Cys806), Rpn6 (Cys222), Rpn9 (Cys114), $\alpha 1$ (Cys154, Cys161), $\alpha 7$ (Cys42), $\beta 3$ (Cys19), and S15 (Cys81) [104,120]. S-nitrosylation of the proteasomal subunits was suggested to engage in cell cycle regulation and the inhibition of vascular smooth muscle cell proliferation, thereby preventing the development of neointimal hyperplasia [121]. Ten cysteine residues in the core particle of the $26 \mathrm{~S}$ proteasome from rat vascular smooth muscle cells were suggested to undergo reversible S-nitrosylation, thereby inhibiting all three enzymatic activities [121]. This effect was independent of the guanylyl cyclase/cGMP and adenylate cyclase/cAMP signaling pathways. Moreover, NO exposure also differentially modulated $\alpha$ and $\beta$ subunit expression in the sub-cellular localization of those subunits. In particular, the upregulation of constitutive $\alpha 1$ and inducible $\beta 1, \alpha 5$, and $\alpha 6$ subunits could be an adaptive mechanism that limits the overall inhibition of the proteasome by NO in vascular cells.

S-nitrosylation also differentially regulates the stability of substrate proteins against degradation by the ubiquitin-proteasome system. For instance, S-nitrosylation of phosphodiesterase 5 at Cys220 in a failing human heart reduces phosphodiesterase 5 activity and targets it toward proteasomal degradation, thus preventing its detrimental effects [122]. On the other hand, the S-nitrosylation of Bcl-2 at two cysteine residues (Cys158 and Cys229) by endogenous NO prevents its degradation by the ubiquitin-proteasome system (UPS), indicating a key mechanism for the control of apoptotic cell death and cancer development [123].

S-alkylation by endogenous electrophiles might also confer inhibition of the $26 \mathrm{~S}$ proteasome and provides a putative anti-inflammatory mechanism mediated by 15 -deoxy- $\Delta^{12,14}$-prostaglandin $\mathrm{J}_{2}$ $\left(15 \mathrm{~d}-\mathrm{PGJ}_{2}\right)$, a secondary product of lipid peroxidation. Treatment of human aortic endothelial cells

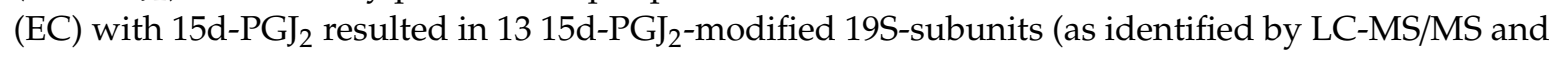
confirmed further by immunoprecipitation experiments for Rpn1, Rpn2, Rpn3, and Rpn6 subunits) [124]. This modification is produced by the Michael addition of cysteine thiolate to the $\alpha$, $\beta$-unsaturated carbonyl group located in the cyclopentenone ring form (Section 3.2.1), yielding inhibition of proteasome activity, confirmed by a decrease in chymotrypsine-like (ChTL) peptidase activity and the accumulation of ubiquitinated proteins. Consequently, this modification results in the inhibition of the degradation of the $26 \mathrm{~S}$ proteasome targets, IkB- $\alpha$ and p105, as well as NF- $\mathrm{kB}$ nuclear translocation in EC in response to inflammogen and suppression of the adhesion and migration of monocytes toward activated EC.

A decrease in redox potential and over-oxidation of regulatory protein thiols with attendant changes in sensitivity and co-ordination among regulatory mechanisms have been suggested as critical mechanisms involved in organismal ageing [125]. Proportional to this hypothesis, both reversible and irreversible oxidation, such as the sulfinylation or sulfonylation (formation of $\mathrm{Cys}-\mathrm{SO}_{2} \mathrm{H}$ or $\mathrm{Cys}-\mathrm{SO}_{3} \mathrm{H}$, respectively) of cysteine sulfhydryls at catalytic sites, can confer the downregulation of enzyme 
activity. The $20 \mathrm{~S}$ proteasome from aged F344BN rat fast-twitch skeletal muscle showed significantly less degradation of oxidized calmodulin [126]. However, the activity of aged 20S was partially rescued by DTT, implying the oxidation of functionally significant cysteines. A study by Zong et al. showed that upon paraquat treatment, cysteine thiols at the subunits $\alpha 2, \beta 1, \beta 3$, and $\beta 5 \mathrm{i}$ of the murine cardiac proteasomes were oxidized at higher levels [127]. However, the reversibility of these modifications has not been elucidated. Nevertheless, the presence of species such as cystine, sulfenic, sulfinic, and sulfonic acid has been suggested.

\subsubsection{Poly-ADP Ribosylation}

The poly(ADP-ribose) polymerase (PARP) family of proteins catalyse the synthesis of polymers of ADP-ribose covalently attached to specific Lys/Glu/Asp/Arg/Cys amino acid residues in acceptor proteins using nicotinamide adenine dinucleotide $\left(\mathrm{NAD}^{+}\right)$as a substrate $[128,129]$. PARP1 and PARP2 proteins may act as DNA damage sensors that follow binding to strand breaks, poly(ADP-ribosyl)ate themselves, and nuclear acceptor proteins that regulate the function of the altered proteins. The activation of nuclear 20S proteasome in K562 leukemia cells in response to hydrogen peroxide-induced damage was shown to be associated with its poly-ADP ribosylation yielding enhanced ChTL peptidase activity and the degradation of oxidized histones [130,131]. This modification was found to be dependent on the binding occurring between the nuclear 20S proteasome, poly-ADP ribose, and poly-ADP ribose polymerase in response to oxidative stress. Furthermore, pre-treatment of HT22 cells with PARP-1 and proteasome inhibitors delayed the repair of single strand breaks and oxidative DNA base damage [131]. Interestingly, PARP-1 was also shown to be selective for poly-ADP ribosylate non-oxidized histones and, therefore, protect them from unwanted degradation. In contrast, the decrease in the poly(ADP-ribosyl)ation of oxidized histones makes them available for proteasomal degradation via the PARP-1-activated proteasome.

Overall, poly-ADP ribosylation of the $20 \mathrm{~S}$ proteasome may be a mechanism defending the nucleus of a tumor cell against oxidative stress contributing to the repair mechanisms near the strand breaks. Consistently, the increased poly-ADP ribosylation of certain targets has also been suggested to be involved in the development of resistance to chemotherapies [129]. These findings point to the need for potent PARP inhibitors for successful chemotherapies that combat resistance. Nevertheless, PARP-1 was shown to associate with the nuclear proteasome in activated microglial cells, thus conferring protection through increased activity of the nuclear proteasome and the enhanced turnover of oxidized proteins [132]. Hence, since the activated microglia were selectively vulnerable to PARP1 pharmacological inhibitors, these can have potential benefits in therapies for neuroinflammatory diseases.

\subsubsection{Phosphorylation}

The subunits of the $20 \mathrm{~S}$ and $\mathrm{i} 20 \mathrm{~S}$ proteasomes and their regulators are extensively phosphorylated at the Ser, Thr, and Tyr residues, resulting in modulation of the proteolytic activity, assembly, and localization of the proteasomal complexes (reviewed in [103,104,133-135]). Phosphorylation has been discovered on every subunit. Most phosphorylation sites can be found on the Rpn2 subunit, whereas Rpn15 bears only one phospho-site [135]. The critical role of phosphorylation in the regulation of proteasomal activity is supported by the evidence that diverse kinases (calmodulin-dependent protein kinase II (CaMKII), polo-like kinase 1 (Plk1), and casein kinase II (CK II)) are co-purified with the proteasome. Phosphorylation of the proteasome may also acquire its regulatory role in a cellular-compartment-dependent manner since the phospho-Ser/Thr phosphatase, ubiquitin-like domain-containing C-terminal domain phosphatase 1 (UBLCP1), was shown to upregulate proteasomal activity (documented as enhancing all three proteolytic activities and polyUb-protein degradation) only in the nucleus and not in the cytosol [136].

Mechanistically, phosphorylation favors the interaction between the $20 \mathrm{~S} \alpha$ ring and ATPase ring in the $19 \mathrm{~S}$ regulatory complex. In this regard, CK II was shown to phosphorylate several Ser, Tyr, and Tyr 
residues on the $\alpha 2, \alpha 3$, and $\alpha 7$ subunits, yielding an increase of all three proteolytic activities of the $20 \mathrm{~S}$ proteasome [137-140]. This may be associated with enhanced assembly of the $26 \mathrm{~S}$ proteasome, likely mediated through phosphorylation-promoted electrostatic interactions located at the contact interface between the $20 \mathrm{~S}$ proteasome and the regulatory complex. In favor of this assumption, the phosphorylation of $\alpha 7$ at Ser243 and Ser250 was not related to changes in the degradation of the peptide or protein substrate by the unassembled 20S proteasome [141]. On the other hand, $\gamma$-IFN-stimulated destabilization of the $26 \mathrm{~S}$ proteasomes and immunoproteasome assembly with the PA28 regulator were accompanied by the dephosphorylation of subunit $\beta 7$ [139]. PA28 is also phosphorylated at the $\alpha$ and $\beta$ subunits, whereas its dephosphorylation results in a decrease in the ChTL activity of the PA28-20S complexes [142].

Plk1 was found to phosphorylate the $\alpha 3$ and $\alpha 7$ subunits in purified 20S proteasomes, as well as in the CA46 and HEK cells associated with increased ChTL activity [143].

Multiple sites in the 20S proteasome were shown to be phosphorylated by cAMP-dependent protein kinase A [144]. However, the significance of many of these sites has yet to be established. Phosphorylation of Ser residues by PKA in the $\alpha 1, \alpha 2, \alpha 3, \beta 2, \beta 3$, and $\beta 7$ subunits and Thr residues in the $\alpha 3, \beta 3$, and $\beta 7$ subunits resulted in an increase of all three peptidase activities of the murine cardiac $20 \mathrm{~S}$ proteasome [145]. In turn, protein phosphatase 2A attenuated Ser phosphorylation of the $\alpha 1, \alpha 3, \alpha 6$, and $\beta 2$ subunits and phosphorylation of the $\alpha 1$ subunit and the $\alpha 6$ subunit associated with a decrease of proteolytic activities. A neuroprotective role for phosphorylation of $20 \mathrm{~S} \mathrm{CP}$ has been suggested since PKA stimulated $\beta$-amyloid precursor protein secretion from HEK cells, pointing to its contribution to the $\alpha$-secretase pathway [146].

Phosphorylation of $\alpha$ - and Rpt-subunits can also modify 26S's function by affecting ATPase activity, which regulates $\alpha$-gate opening in the 20S CP, as well as substrate unfolding and translocation. During substrate cleavage, the ATPases' $C$ termini dock into pockets between the $\alpha$-subunits and yield opening of the gated channel for substrate entry $[133,147]$. Consistently, increased degradation of the GFP-fusion substrate requiring ubiquitination (GFP-CL1) and one not requiring ubiquitination (ornithine decarboxylase) was found upon phosphorylation of the 19S subunit Rpt6 via CaMKII and protein kinase A (PKA) $[148,149]$. Moreover, the 445 subunit in the $26 \mathrm{~S}$ complex is directly associated with the $20 \mathrm{~S}$ proteasome subunit $\alpha 2$ in a manner dependent on a protein kinase, which is tightly associated with or contained in the regulatory complex [150].

The $26 \mathrm{~S}$ proteasome is also dynamically phosphorylated during the cell cycle at the Thr25 of the 19S subunit Rpt3 mediated by dual-specificity tyrosine-regulated kinase 2 (DYRK2), whereas blocking Rpt3-Thr25 phosphorylation markedly impairs proteasome activity (as confirmed by decreased peptidase activities and degradation of the total proteins, GFP-degron fusion proteins targeted to Ub-dependent or independent degradation, and ATPase activity), promotes the accumulation of cell cycle inhibitors $\mathrm{p} 21^{\mathrm{Cip} 1}$ and $\mathrm{p} 27^{\mathrm{Kip} 1}$, and hampers cell proliferation and tumor growth [151]. The proposed mechanism consists of Rpt3-Thr25 phosphorylation-mediated enhanced substrate translocation. Furthermore, the kinase Aurora B is now also identified as an enhancer of the activity of the $26 \mathrm{~S}$ proteasome in cell cycle regulation [152]. Although specific phosphorylation sites have not been detected, Aurora B strongly interacted with the $26 \mathrm{~S}$ proteasome subunits, Rpn1/2.

The Rpn6 subunit, even without phosphorylation, seems to play a critical regulatory role and may enhance the stability or formation of the 26S proteasomes [153]. Consistently, phosphorylation at Rpn6(Ser14) enhanced the degradation of several substrate proteins degraded by a Ub-dependent mechanism, including the hydrophobic degron (GFP-CL1), the $\mathrm{N}$-end rule system (Ub-R-GFP), the ubiquitin-fusion degradation (UFD) pathway (Ub ${ }^{\mathrm{G} 76 \mathrm{~V}}$-GFP), and a few short-lived endogenous proteins $[154,155]$. The hormones (such glucagon or epinephrine) and conditions that increase cAMP rapidly (such as exercise and fasting) also augment proteasome activity and the cellular capacity to clear damaged and preexisting regulatory proteins. Raising the cAMP levels activating PKA also slightly increased the amount of double-capped $26 \mathrm{~S}$ proteasomes, which implies that Rpn6 phosphorylation increases the association and stabilization of these complexes [154]. Activation of 
proteasomes via this mechanism may be useful in treating proteotoxic diseases since PKA activation stimulated the degradation of various aggregation-prone proteins, including mutant FUS (Fused in sarcoma), SOD1 (superoxide dismutase 1), TDP43 (TAR DNA-binding protein 43), and tau [155], and reduced the levels of aggregated tau protein and improved cognitive function in a mouse model of tautopathy [156].

Rpn3 is also a target of CK II. However, this modification seems to be involved in the turnover of the proteasomes [157]. Phosphorylation at Rpn (Ser6) did not change peptidase activity nor degradation of ornithine decarboxylase (ODC) and the ubiquitinated inhibitor of apoptosis 1 (Ub-cIAP1) through the old proteasomes. However, the old proteasomes exhibited increased deubiquitinating activity, which is likely due to their elevated association with Usp14. Furthermore, the increased cytosolic localization of old proteasomes was suggested to be important for their turnover mechanism.

Paradoxically, phosphorylation can also negatively regulate the activity of the proteasome, as this modification by tyrosine kinases c-Abl and Arg at the $\alpha 4$ (Tyr153) subunit reduced the chymotrypsin-like activities of the $20 \mathrm{~S}$ and $26 \mathrm{~S}$ proteasomes, as well as ${ }^{35}$ S-labeled protein degradation [158]. In addition, expression of the $\alpha 4(\mathrm{Y} 153 \mathrm{~F})$ mutant decreased the stability of p53, p27, cyclin $\mathrm{A}$, and cyclin $\mathrm{E}$ and induced G1/S cell cycle arrest, suggesting the role of c-Abl/Arg in cell cycle regulation. Furthermore, Aiken et al. [159] hypothesized that phosphorylation could represent a supplementary regulatory mechanism of the proteasome in response to oxidative stress. This theory is substantiated by the findings that in $\mathrm{H}_{2} \mathrm{O}_{2}$ - or etoposide-exposed mouse fibroblasts, activity of the $26 \mathrm{~S}$ proteasome is inhibited due to the phosphorylation of Rpt 5 by apoptosis signal-regulating kinase 1 (Ask1), a kinase activated by thioredoxin- 1 in response to oxidative stress. This was further confirmed by a decrease in all three peptidase activities of the proteasome, the degradation of GFP-reporters, ATPase activity, and increased endogenous IкB $\alpha$ in TNF $\alpha$-stimulated cells overexpressing ASK1, as well as further assays with cells expressing truncation and catalytically inactive ASK1 mutants [160]. The proteasome-interacting protein Ecm29, involved in the proteasome's quality control system and responsible for $26 \mathrm{~S}$ proteasome disassembly and increased resistance of yeast cells to oxidative stress [161], required the phosphorylated tail of $\alpha 7$ by CKII for its association with proteasomes [162,163]. In addition, the activities of other kinases (PKA, CaMKII, c-Abl, and Arg) were also shown to be modulated by oxidative stress. Furthermore, Rpn2 was found to be phosphorylated at Thr273 in response to osmotic stress by p38 mitogen-activated protein kinase (MAPK), resulting in a decrease of all three peptidase activities of the $26 \mathrm{~S}$ proteasome, and stabilization of the GFP-degron fusion proteins targeted to Ub-dependent or independent degradation [164]. This modification can cause a conformational change in Rpn2, which might be transmitted to its interacting Rpt subunits (including Rpt3, Rpt4, and Rpt6), leading to their $C$ termini inhibiting the $\alpha$-gate opening.

In summary, phosphorylation can regulate the proteasome either positively-at which point it is engaged in processes such as cell cycle progression or the prevention of disease protein aggregation-or negatively, playing a role under stress conditions and promoting disassembly of the $26 \mathrm{~S}$ proteasome, accompanied by endorsement of cell maintenance processes or apoptosis induction.

\subsubsection{O-GlcNAcylation}

O-linked-N-acetylglucosaminylation (O-GlcNAcylation), modification by a single O-linked $\beta-N$-acetylglucosamine moiety at Ser or Thr residues, is proposed as a nutrient sensor that is regulated by an opposing pair of enzymes O-linked $\mathrm{N}$-acetylglucosamine (GlcNAc) transferase (OGT) and 3-O-(N-acetyl-D-glucosaminyl)-L-serine/threonine $\mathrm{N}$-acetylglucosaminyl hydrolase (OGA), adding and removing, respectively, the modifications from proteins. O-GlcNAcylation of the Rpt2 subunit is associated with inhibition of the chymotrypsin-like proteolytic activity of the nuclear extract from glucose-starved/forskolin-treated NRK cells (activated extract), 26S (but not 20S) proteasomes and stabilization of the substrate, transcription factor Sp1, and a decrease in the ATPase activity of purified proteasomes [165]. Moreover, the inhibition of peptidase activity appeared to depend on substrate hydrophobicity since the cleavage of the hydrophilic chymotryptic substrate 
Z-Gly-Gly-Leu-7-amido-4-methylcoumarin (Z-GGL-AMC) was not suppressed. This mechanism can link proteasomes to metabolic stimuli such as the post-absorptive insulin-stimulated flux of glucose into skeletal muscle and diminution of proteasome-mediated amino acid release coinciding with a decreased need of body for gluconeogenesis.

Moreover, the subunits of 20S CP can also undergo O-GlcNAcylation accompanied by a decrease in proteolytic activity in response to glycemic stimulus. Using only a ChTL peptidase assay, Overath et al. [166] showed that the exposure of murine fibroblasts to elevated glucose induced a transient decrease in proteasomal activity accompanied by an increase in O-GlcNAcylation of the $20 S$ proteasome [166]. The same study revealed O-GlcNAcylation sites at the hydroxyl groups of serine residues at the subunits $\alpha 1$ (Ser5), $\alpha 5$ (Ser198), $\alpha 4$ (Ser130), and $\beta 6$ (Ser208 and Ser57) in the $20 \mathrm{~S}$ proteasomes isolated from the spleen, liver, and brain. The occurrence of particular subunit modifications was tissue- and proteasome-subtype-specific. In this regard, modifications of $\alpha 1$ and $\alpha 5$ were only detected in spleen (immuno) proteasomes, whereas the O-GlcNAcylation of $\beta 6$ (Ser208) was found only in brain proteasomes. As for S-glutathionylation and phosphorylation, a link to cellular redox status has also been suggested for proteasomal regulation via O-GlcNAcylation. The increased occupancy of O-GlcNAcylation sites in spleen immunoproteasomes compared to constitutive forms was suggested to be responsible for their protective effect against cytokine-induced oxidative damage. Interestingly, increased OGT levels in myocytes were found to attenuate oxidative stress, whereas elevated OGA had the opposite effect [167].

Increased O-GlcNAcylation is also directly linked to insulin resistance and hyperglycemia-induced glucose toxicity, two hallmarks of diabetes and diabetic complications [168]. Certain proteins with substantial changes in O-GlcNAc site occupancy between different glycemic states may serve as a sensitive diagnostic tool for the early detection of diabetes. From among total $35 \mathrm{O}-$ GlcNAc sites on human erythrocyte proteins identified by mass spectroscopic analysis, one O-GlcNAc site was detected at the $\alpha 5$ subunit on the proteasomes. However, this site showed only a mildly increased occupancy in response to diabetic conditions [169].

Furthermore, crosstalk between O-GlcNAcylation and phosphorylation (these two modifications often mutually exclusively take place at the same or adjacent sites) has been suggested as a regulatory mechanism of the UPS pathway [170]. Five regulatory particle subunits and at least nine CP subunits were recognized in the highly purified $26 \mathrm{~S}$ proteasome of the Drosophila melanogaster by two different monoclonal antibodies specific to O-linked N-GlcNAc-modified proteins, as well as by wheat germ agglutinin, which is specific for the N-GlcNAc sugar side-chain [171]. From among the identified subunits, strong staining was detected for the ATPase subunits Rpt1, Rpt2, and Rpt3 which were also phosphorylated.

Additionally, the modification of a substrate protein by O-GlcNAc often increases its resistance against proteasomal degradation. O-GlcNAcylation also regulates ubiquitination in response to metabolic needs, as many proteins in the ubiquitination pathway (such as ubiquitin precursors, E1, E2, E3 enzymes, and deubiquitinases) have been shown to bind OGT or undergo O-GlcNAcylation [172].

\subsection{6. $\mathrm{N}^{\alpha}$ - and $\mathrm{N}^{\varepsilon}$-Acetylation}

The acetylation of $\alpha$-amino groups of $\mathrm{N}$-terminal residues in proteins is likely to be an irreversible modification and may serve as a degradation signal. However, acetylation of the $\epsilon$-amino groups of Lys side chains is reversible and may have regulatory functions. The regulatory role of acetylation may be complementary to phosphorylation, as both modifications usually occur at distinct regions. Large-scale proteomic analyses revealed lysine acetylation of different proteasomal subunits $[173,174]$.

Using high resolution LC-MS/MS, the acetylation of nine N-termini (at $\alpha 1-7, \beta 3$, and $\beta 4$ ) and seven internal lysine residues ( $\alpha 1$ (Lys104), $\alpha 5$ (Lys203), $\alpha 6$ (Lys30), $\alpha 6$ (Lys115), $\beta 3$ (Lys77), $\beta 6$ (Lys203), and $\beta 7$ (Lys201)) was identified in the 20S proteasomes in the murine myocardium [175]. Furthermore, using histone deacetylase (HDAC) inhibitors, a positive correlation between acetylation and proteolytic function was confirmed in both healthy and diseased cardiac tissue. Enhancement 
of $20 \mathrm{~S}$ proteasomal trypsin-like activity coincided with the acetylation of five lysine residues at the subunits $\alpha 6$ (Lys30, Lys115), $\beta 3$ (Lys77), $\beta 6$ (Lys203), and $\beta 7$ (Lys201) induced upon HDAC inhibition and was explained by a lysine-acetylation-induced conformational change in the $20 \mathrm{~S}$ proteasomes that renders the catalytic centers more accessible to substrates. Since HDAC inhibitors diminished both $\beta 2$ and $\beta 7$ cytosolic levels, Lys acetylation appears to also alter proteasome redistribution by shuttling proteasomes out of the cytosolic compartment.

The acetylation modifying enzymes appear to also interact with the PA28 activator. The cAMP response element-binding protein (CREB)-binding-protein-dependent acetylation of the PA28 $\gamma$ (REG28 $\gamma$ ) activator at Lys195 increased the interaction between PA28 $\gamma$ monomers occurring between helixes 2 and 4 , likely by inducing favorable changes in conformation and facilitated heptamerization [176]. This modification increased PA28 $\gamma$ activity in the proteasomal degradation of the target substrates, including cyclin-dependent kinase inhibitor p21, determining the cell cycle progression and proliferation of HEK293 cells. On the other hand, silent information regulator 1 (SIRT1) was suggested to bind and deacetylate PA28 $\gamma$, which inhibits heptamerization or triggers its disassembly. In turn, the $N$ - $\alpha$-acetyltransferase 10 protein (Naa10p) was shown to associate directly with PA28 $\alpha$ through the DLRAFYAE motif and, in the case of PA28 $\beta$, in a PA28 $\alpha$-dependent manner, resulting in the suppression of the chymotrypsin-like activity of the 20S complex with $11 \mathrm{~S}$ RP [177]. However, Naa10p activity was not required for its inhibitory effect, and it was speculated that the inhibitory mechanism might involve binding with Naa10p causing steric hindrance against substrate entry.

By contrast, during biogenesis of the $20 \mathrm{~S}$ proteasome, $\mathrm{N}^{\alpha}$-acetylation may induce irreversible inactivation of the Thr1 N-terminus and block substrate binding, which is prevented by the presence of $\mathrm{N}$-terminal $\beta$-subunit propeptides [178]. The propeptides are removed only after the two proteasome half-mers (built with one $\alpha$-ring and one $\beta$-ring) have paired, thus preventing access by $\mathrm{N}^{\alpha}$-acetyltransferases [179].

Lys acetylation was also recognized as a signal increasing the stability of regulatory transcription factors (such as p53, runt-related transcription factor 3 (Runx3), steroidogenic factor-1 (SF-1), ETS-related protein 81 (ER81), and forkhead box O4 (FOXO4)) through diverse mechanisms including competition with ubiquitination, conformational changes, and shielding from E3s [180]. Furthermore, acetylation of the E3 ubiquitin ligase, murine double minute 2 (Mdm2), interferes with its activity [181]. By contrast, the Lys acetylation of substrate proteins can also accelerate their degradation through modified communication with interacting proteins (such as E3 ubiquitin ligase, Mdm2, and HSP90) [180].

\subsubsection{Ubiquitination}

Lysine residues also represent sites of ubiquitination, an important signal targeting substrate proteins for degradation by UPS, thereby opposing the most common stabilization effect of acetylation. Ubiquitination involves the covalent attachment of a monomer or a lysine-linked polymer of ubiquitin, a 76-amino acid protein with a highly stable structure, to the $\varepsilon$-amino group of the Lys of the target protein controlled by the coordinated action of the E1, E2, and E3 enzymes. Since the proteasome itself is degraded by the UPS pathway, it is conceivable that ubiquitination is found on most of its subunits. However, this modification can also play a regulatory role. Monoubiquitination, unlike polyubiquitination, does not provide a signal for degradation; instead, it can serve as a signal for, e.g., DNA repair or gene silencing [182]. Monoubiquitination of the proteasomal $\alpha 2$ subunit (and possibly other $\alpha$ subunits) was suggested to inhibit the proteasome either directly or through the binding of a modified form of the $\alpha 2$ subunit to $\delta$-aminolevulinic acid dehydratase (ALAD) in place of the 195 regulatory cap [183]. Moreover, treatment with the HDAC inhibitor induced acetylation of ubiquitinated $\alpha 2$ subunits and translocation of the ALAD-proteasome (with acetylated/ubiquitinated- $\alpha 2$ ) complex to nuclei, shedding light on a putative mechanism possibly involved in the inhibition of tumor growth. 
The substrate-recognizing subunit Rpn10 is also mono-ubiquitinated at three Lys residues within the Von Willebrand factor type A (VWA) domain (Lys71, Lys84, and Lys99), as well as Lys268 located at the C-terminus of the protein in vivo [184]. This modification regulates the capacity of Rpn10 to interact with substrates by inhibiting Rpn10's ubiquitin-interacting motif (UIM) and may serve as a regulatory mechanism controlling the recruitment of proteasomal substrates. Interestingly, the levels of mono-ubiquitination in yeast, controlled by Rsp5, a member of the neuronal precursor cell-expressed developmentally downregulated 4 (Nedd4) ubiquitin-protein ligase family, and ubiquitin carboxyl-terminal hydrolase 2 (Ubp2), a deubiquitinating enzyme, are decreased under conditions of proteolytic stress (such as heat and cold or the presence of Cd). Moreover, the Rsp5-dependent dissociation of Rpn10 was demonstrated to promote its dissociation from the proteasome and increase interaction of the $26 \mathrm{~S}$ proteasome with Dsk2 (dual-specificity protein kinase 2), a protein linked to the ubiquitin-like/ubiquitin-associated (UBL/UBA) family of ubiquilins, considered to be key regulators of neurological and cognitive functions [185]. Crystallographic data coupled with cryo-electron microscopy analysis provided high-resolution insight into the disassembly process of Rpn10 from the proteasome, involving Lys 84 ubiquitylation-promoted steric clashes with Rpn9, thereby facilitating the cyclic activity of Rpn10 [186]. In the proposed model, both the proteasomal and cytosolic Ub-receptor harvest ubiquitylated proteins for proteasomal destruction, and the cytosolic form of Rpn10 shuttles ubiquitylated proteins to Rpn10-free proteasomes.

Rpn10 was also shown to be poly-ubiquitinated by a range of E3 ligases, including multimeric and monomeric really interesting new gene (Ring) finger E3s (muscle Ring-finger protein-1 (MuRF1), Siah2, Parkin, anaphase promoting complex (APC), and SKP1-Cullin 1-F-box protein $\beta$-transducin repeat-containing protein (SCF $\beta$ TRCP1), U-box E3, carboxy-terminus of Hsc70 interacting protein (CHIP), and homologous to E6-associated protein (E6AP) C-terminus (HECT) domain E3s (E6AP and Nedd4), and is rapidly degraded in vivo [187]. The high affinity of Rpn10 to poly-Ub chains is critical for its ubiquitination by diverse E3s, as the ubiquitination of Rpn10 results from its binding to ubiquitin chains on the E3 (after self-ubiquitination) or on the substrate. Additionally, the poly-ubiquitination, but not mono-ubiquitination, of E3 allowed Rpn10 to bind and accelerated its ubiquitination. The proposed mechanism involved the binding of Rpn10 to the growing $\mathrm{Ub}$ chain on the E3, whose ubiquitination occurs because of its proximity to the highly reactive $\mathrm{Ub}$ thioester, followed by the release of Rpn10 after multiple rounds of ubiquitination.

However, the polyubiquitination of proteasomal subunits may not be unconditionally related to their degradation. Rpn13 is poly-ubiquitinated by the proteasome-associated E3, ubiquitin protein ligase E3C (Ube3c, yeast ortholog Hul5), in response to proteolysis inhibition (induced by proteasome inhibitors, heat shock, and arsenite) [188]. This modification causes a substantial drop in the capacity of the $26 \mathrm{~S}$ proteasome for Ub-dependent proteolysis. However, proteasomal activity toward hydrolyzing peptides and non-ubiquitinated proteins is not affected. Two bortezomid-sensitive ubiquitination sites were identified in the Rpn13 of $26 \mathrm{~S}$ purified proteasomes corresponding to Lys21 and Lys34, which are located at the N-terminal end of the Ub-binding Pru domain in Rpn13. This autoinhibitory mechanism likely prevents obstructed proteasomes from binding further $\mathrm{Ub}$-conjugates or irreversible aggregates and causing potential damage to the particle under the conditions of proteotoxic stress.

Thus, mono-ubiquitination of the proteasomal $\mathrm{Ub}$ receptors can enhance proteasome processivity and interaction with specific substrates under a physiological state. However, polyubiquitination under proteotoxic conditions could be associated with a loss of their function or promotion of their degradation.

\subsubsection{Other N-Modifications (SUMOylation, N-Myristoylation, N-Methylation)}

SUMOylation is the covalent modification of a target protein by SUMO (small ubiquitin-related modifiers), a ubiquitin-like protein, through the chronological action of E1 (activation of Smt3p 1 (Aos1)/ubiquitin activating enzyme 2 (Uba2)) and E2 (ubiquitin carrier protein 9, Ubc9) enzymes. Most targets also require a SUMO ligase or E3 enzyme to facilitate their SUMOylation. SUMOylation 
is reversed by SUMO-specific deconjugating enzymes termed ubiquitin-like protease/sentrin-specific proteases (Ulp/SENPs).

SUMO-conjugation is mostly involved in the cellular stress response [104]. Eight subunits, $\alpha 3, \alpha 5$, $\beta 4$, Rpn1, Rpn2, Rpn6, Rpn10, and Rpn12, were identified as substrates for SUMO2 modification in $\mathrm{U} 2 \mathrm{OS}$ cells via tandem affinity purification. In addition, two subunits, $\alpha 5$ and $\beta 4$, showed increased SUMO conjugation in response to heat stress conditions [104,189].

SUMOylation of a critical lysine of the Rpn2 subunit adjacent to the binding domain of the ubiquitin receptor Rpn13 subunit negatively controls the interaction and association of Rpn2 with Rpn13 [190]. Lys932 is a major SUMO acceptor whose conjugation regulates Rpn13 binding. Rpn2 becomes SUMO2/3-modified via the SUMO E3 enzyme, protein inhibitor of activated STAT Y (PIASy), preventing Rpn13 docking. This is opposed by xSENP1 removing SUMOylation from Rpn2, enabling Rpn13 loading and the degradation of key proteasomal substrates, such as cyclin B, resulting in mitotic exit. However, only a small pool of the proteasomes has been shown to be inhibited by Rpn2 SUMOylation. One of the hypotheses is that this modification might be important for the local regulation of proteasomal activity like that coupled to the observed chromosome localization. In addition, the association of xSENP1 with Rpn2 within 19S RP is an optimal location to cleave SUMO chains from proteins that are targeted for proteasomal degradation by SUMO-targeted ubiquitin ligases (STUbLs).

Analogously, a quantitative proteomic approach coupled with an immunofluorescence analysis suggested that increased SUMOylation of the proteasome in response to proteotoxic stress (promoted by its pharmacological inhibition) can serve as a tag to direct its nuclear translocation and colocalization with promyelocytic leukemia (PML) protein nuclear bodies, a site of protein degradation [191]. The location and distribution of most of the modified residues on the outer surface of the proteasome subunits likely implies that SUMOylation may affect protein-protein interactions.

$\mathrm{N}$-myristoylation can also serve as a tag directing the proteasomal complex to the nucleus. Kimura et al. showed that the nucleo-cytoplasmic localization of yeast $26 \mathrm{~S}$ proteasomes can be dynamically controlled through N-terminal myristoylation of the 19S subunit (Rpt2), which was suggested to be a mechanism involved in stress response [192,193]. Mechanistically, the myristoylated N-terminus of Rpt2 in the 26S proteasome extends outside the complex and can be engaged in interactions with the membrane structures of the nuclear envelope. However, it is likely not involved in nuclear import itself. N-myristoylation did not appear to affect peptidase activities. However, it might represent a mechanism involved in nuclear protein quality control preventing protein aggregation and clearing short-lived critical regulatory proteins in the nucleus.

Furthermore, the methylation of Lys and Arg can play a critical role in a variety of processes, such as the control of the intracellular localization of a protein, signaling transduction, and protein-protein interactions [194]. N-Methylation sites were discovered in proteasomes from archeal halophilic bacteria, from mouse cardiac tissue, liver cells, and in the human $20 S$ proteasome following methanol exposure in vitro [104]. Matrix-assisted laser desorption/ionization time-of-flight/time-of-flight (MALDI-TOF/TOF) MS analysis revealed that the N-terminal Pro residue of the yeast Rpt1 subunit can be un-modified, mono-methylated, or di-methylated [195]. N-methylation of Rpt1 and/or its Pro ${ }^{3}$-Lys ${ }^{4}$ sequence might be important in cell growth or for oxidative and canavanine-induced stress tolerance in yeast. However, neither N-terminal methylation nor the $\mathrm{N}$-terminal $\mathrm{Pro}^{3}-\mathrm{Lys}^{4}$ sequence was conserved throughout evolution. Hence, their biological significance may differ in each protein or species due to the amino acid sequences of other regions and/or conformations of proteins. Nevertheless, the proteomic study also showed the tissue-specific methylation of the mammalian $20 \mathrm{~S}$ proteasome. In particular, the mouse heart $\beta 6$ subunit was found to be monomethylated on Arg, whereas $\alpha 2$ from the liver was found to be dimethylated on Lys [196]. A study by Osna et al. [197], pointing to the involvement of changes of proteasome methylation in ethanol toxicity in liver cells, shed some light on the biological relevance of these modifications. In their study, defects in Lys N-methylation of the $25 \mathrm{kDa}$ subunit of hepatic proteasome were found to be associated with a decrease of the proteasome ChTL peptidase activity following ethanol treatment, independently of ethanol-induced 
oxidative stress. Lys methylation and peptidase inhibition were responsive to an altered methyl donor:acceptor substrate ratio (S-adenosylmethionine (SAM):S-adenosylhomocysteine (SAH)), even in purified commercial $20 \mathrm{~S}$ proteasome preparations. The authors proposed that the $20 \mathrm{~S}$ proteasomal subunit(s) and/or other proteins that form a tight complex and are co-purified with $20 \mathrm{~S}$ proteasome possess (a) SAM-dependent methyltransferase-like activity and (b) are sensitive to SAH inhibition. Moreover, the activity of immunoproteasome was found to be more sensitive to inhibition by decreasing the SAM:SAH ratio. This was further corroborated by lowered the antigen presentation in hepatitis $\mathrm{C}$ structural protein $\left(\mathrm{HCV}^{+}\right)$mice elicited by ethanol feeding [198]. Thus, $\mathrm{N}$-methylation of the liver $20 \mathrm{~S}$ proteasome may play a role in preventing the pathological formation of protein aggregates (such as ethanol-induced Mallory bodies) and defects in the antigen presentation by liver cells. Nevertheless, the N-modifications may generally play roles in the nuclear translocation of the proteasome as a part of the defense mechanism in response to cellular stress.

Table 2. (a) Posttranslational modifications of proteasome: S-modifications and poly-ADP ribosylation; (b) Posttranslational modifications of proteasome: Phosphorylation; (c) Posttranslational modifications of proteasome: Phosphorylation (continued) and O-GlcNAcylation; (d) Posttranslational modifications of proteasome: $\mathrm{N}$-acetylation and ubiquitination; (e) Posttranslational modifications of proteasome: N-SUMOylation, N-myristoylation and N-methylation.

(a)

\begin{tabular}{|c|c|c|c|c|c|c|}
\hline PTM & Subunit & Substrate & Stimuli/Mechanism & Model & Effect & Ref. \\
\hline \multirow{2}{*}{ 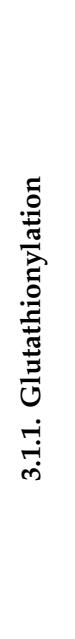 } & $\alpha 5\left(\mathrm{Cys}^{76}, \mathrm{Cys}^{221}\right)$ & $\begin{array}{l}\text { BSAox-DNPH, } \\
\text { casein-FITC, } \\
\text { Grx, FPS }\end{array}$ & $\begin{array}{c}\text { respiratory } \\
\text { conditions, } \\
\text { Grx, cytosolic } \\
\text { Trxs,proteolytic } \\
\text { inhibitors, } \\
\text { GSH/GSSG, Cys }\end{array}$ & $\begin{array}{c}\text { Yeast, rat liver } \\
\text { epithelium cells, } \\
\text { purified 20S PS } \\
\text { from yeast, rabbit } \\
\text { reticulocytes and } \\
\text { human } \\
\text { erythrocytes, yeast } \\
\text { cells with mutated } \\
(\Delta N \alpha 3 \alpha 7 \text {, } \\
\alpha 5-C 76 S, 5-C 221 S) \\
20 S \text { PS }\end{array}$ & $\begin{array}{c}\text { Positive and } \\
\text { negative } \\
\text { regulation of } \\
\alpha \text {-gate opening } \\
\uparrow \text { degradation of } \\
\text { protein } \\
\text { substrate, } \\
\downarrow \text { ChTL } \\
\uparrow \text { ChTL \{mmolar } \\
\text { GSH, GSSG, } \\
\text { Cys\} }\end{array}$ & [109-113] \\
\hline & Rpn1, Rpn2 & FPS & $\mathrm{GSH} / \mathrm{H}_{2} \mathrm{O}_{2}$ & $\begin{array}{c}\text { HEK } 293 \text { cells, } \\
\text { neutrophils; lung } \\
\text { extracts from mice } \\
\text { with inactivated } \\
\text { catalase; purified } \\
\text { human 20S and } \\
\text { 26S PS }\end{array}$ & $\downarrow$ ChTL $\downarrow$ TL & [115] \\
\hline \multirow{2}{*}{ 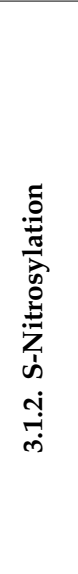 } & 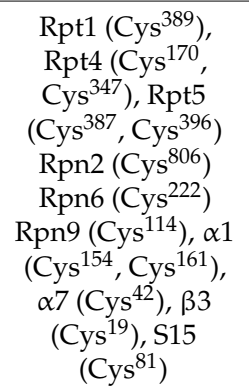 & - & $\begin{array}{c}\text { NO donors } \\
\text { (CysS-NO, } \\
\text { GS-NO) }\end{array}$ & $\begin{array}{l}\text { Human } \\
\text { pulmonary } \\
\text { arterial } \\
\text { endothelial cells } \\
\text { and lysates }\end{array}$ & - & [120] \\
\hline & $\begin{array}{l}\text { 20S PS (10 } \\
\text { cysteines) }\end{array}$ & FPS & $\begin{array}{c}\text { NO-donors (e.g., } \\
\text { SNAP, GS-NO) } \\
\text { DTT } \\
\text { cGMP/cAMP } \\
\text { analogues }\end{array}$ & $\begin{array}{l}\text { Rat vascular } \\
\text { smooth muscle } \\
\text { cells }\end{array}$ & $\begin{array}{l}\downarrow \text { ChTL } \downarrow \text { TL } \downarrow \text { CL } \\
\uparrow \beta 1, \beta 1 i, \alpha 5, \alpha 6\end{array}$ & [121] \\
\hline
\end{tabular}




\begin{tabular}{|c|c|c|c|c|c|c|}
\hline PTM & Subunit & Substrate & Stimuli/Mechanism & Model & Effect & Ref. \\
\hline 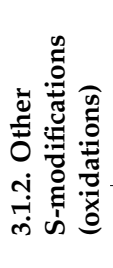 & $\beta 1, \beta 2, \beta 5$ & CaMox, FPS & Ageing & $\begin{array}{l}\text { Aged F344BN rat } \\
\text { fast-twitch } \\
\text { skeletal muscle- } \\
\text { homogenates and } \\
\text { purified PS }\end{array}$ & $\begin{array}{c}\downarrow \text { ChTL } \downarrow \text { TL } \downarrow \text { CL } \\
\downarrow \text { CaMox } \\
\text { degradation } \\
\text { restored by DTT }\end{array}$ & [126] \\
\hline 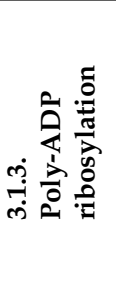 & 20S PS & $\begin{array}{c}\text { FPS } \\
{\left[{ }^{3} \mathrm{H}\right] \mathrm{Leu}-\text { and }} \\
{\left[{ }^{3} \mathrm{H}\right] \text {-histones }} \\
\text { Fluorescamine- } \\
\text { proteins } \\
{\left[{ }^{35} \mathrm{~S}\right]-\text { Met- }} \\
\text { proteins }\end{array}$ & $\begin{array}{c}\text { PARP1 } \\
\mathrm{H}_{2} \mathrm{O}_{2}, \mathrm{TNF} \alpha \\
\text { Lactacystin, } \\
\text { MG-132 } \\
\text { 3-ABA, PJ-34 }\end{array}$ & $\begin{array}{c}\text { Primary human } \\
\text { fibroblasts, PC12, } \\
\text { RAW264.7, K562, } \\
\text { BV2, PARP } \\
\text { expressing cells; } \\
\text { Isolated histones, } \\
\text { nuclei and 20S PS }\end{array}$ & $\begin{array}{c}\uparrow \text { ChTL } \\
\uparrow \text { degradation of } \\
\text { radio-labelled } \\
\text { and } \\
\text { fluorescamine- } \\
\text { proteins } \uparrow 20 S \text { PS } \\
\text { and PARP } \\
\text { association }\end{array}$ & [130-132] \\
\hline
\end{tabular}

ChTL, chymotrypsin-like activity; TL, trypsin-like activity; CL, caspase-like activity; FPS, fluorogenic peptide substrate; PS, proteasome; RP, regulatory particle; BSAox-DNPH, oxidized BSA BSAox derivatized with dinitrophenylhydrazine; GSH, glutathione; GSSG, glutathione disulfide; Cys-NO, S-nitroso cysteine; GS-NO, S-nitroso glutathione; CaMox, oxidized calmodulin; DTT, 1,4-Dithiothreitol; IкB, inhibitor of nuclear factor kB; Grx-2, glutaredoxin-2; Trxs, thioredoxins; SNAP, S-Nitroso-N-acetylpenicillamine; 15d-PGJ 2 , 15-deoxy- $\Delta^{12,14}$-prostaglandin $\mathrm{J}_{2} ; \mathrm{PJ}-34, \mathrm{~N}$-(6-oxo-5,6-dihydrophenanthridin-2-yl)-(N-dimethylamino) acetamide hydrochloride; 3-ABA, 3-aminobenzamide; PARP1, poly(ADP-ribose) polymerase 1; 3-ABA, PJ-34, PARP inhibitors; lactacystin, MG-132, PS inhibitors.

(b)

\begin{tabular}{|c|c|c|c|c|c|c|}
\hline PTM & Subunit & Substrate & Stimuli/Mechanism & Model & Effect & Ref. \\
\hline \multirow{5}{*}{ 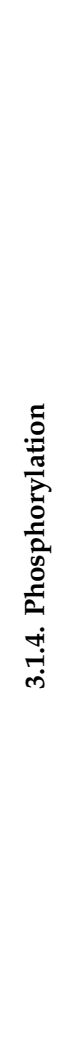 } & $\begin{array}{c}\alpha 2, \alpha 3 \text { (Ser or Thr) } \\
\alpha 7 \text { (Tyr) }\end{array}$ & FPS & $\begin{array}{c}\text { CKII, cGMP } \\
\text { PP, PP inhibitors }\end{array}$ & $\begin{array}{l}\text { L-132 human } \\
\text { embryonic lung } \\
\text { cells, Rat-1, COS } \\
\text { cells, yeast, } \\
\text { purified 20S and } \\
\text { 26S PS }\end{array}$ & $\begin{array}{c}\uparrow 26 \mathrm{~S} \text { PS } \\
\text { assembly } \\
\uparrow \mathrm{ChTL}(\uparrow \mathrm{Km}), \\
\uparrow \mathrm{TL} \uparrow \mathrm{CL}\end{array}$ & [137-140] \\
\hline & $\begin{array}{c}\alpha 7\left(\operatorname{Ser}^{258}, \operatorname{Ser}^{263}\right. \\
\left.\operatorname{Ser}^{664}\right)\end{array}$ & - & CKII & $\begin{array}{c}\text { Purified yeast } \\
\text { 20S PS } \\
\alpha 7, \text { Rpt5 and Ecm } \\
\text { truncation and } \\
\text { deletion mutants }\end{array}$ & $\begin{array}{c}\uparrow 26 \mathrm{~S} \text { PS } \\
\text { association with } \\
\text { Ecm }\end{array}$ & {$[162,163]$} \\
\hline & $\alpha 7\left(\operatorname{Ser}^{243}, \operatorname{Ser}^{250}\right)$ & $\begin{array}{l}\text { FPS, myelin } \\
\text { basic protein }\end{array}$ & p & $\begin{array}{c}\text { NRK cells, } \\
\text { purified 20PS } \\
\text { \{rat liver\} } \\
\text { Recombinant } \\
\text { pTHC8, C8.1, C8.2, } \\
\text { C8.3, C8 S243A, } \\
\text { and C8 S243,250A } \\
\text { proteins }\end{array}$ & $\begin{array}{l}\text { No changes in } \\
\text { proteolysis of } \\
\text { FPS or protein } \\
\text { substrate }\end{array}$ & [141] \\
\hline & $\alpha 7, \alpha 3$ & FPS & $\begin{array}{c}\text { Plk, } \\
\text { PP, PP inhibitors }\end{array}$ & $\begin{array}{l}\text { Purified 20S PS, } \\
\text { 20S precipitated } \\
\text { from CA46 and } \\
\text { HEK cells, cells } \\
\text { expressing } \\
\text { HA-K82R mutant }\end{array}$ & $\uparrow$ ChTL & [143] \\
\hline & $\begin{array}{c}\alpha 1, \alpha 2, \alpha 3, \beta 2, \beta 3 \\
\beta 7 \text { (Ser) } \\
\alpha 1, \alpha 3, \beta 3, \beta 7 \\
\text { (Thr) }\end{array}$ & FPS & PKA/PP2A & $\begin{array}{l}\text { Purified murine } \\
\text { cardiac 20PS }\end{array}$ & $\uparrow C h T L \uparrow T L \uparrow C L$ & [145] \\
\hline
\end{tabular}




\begin{tabular}{|c|c|c|c|c|c|c|}
\hline PTM & Subunit & Substrate & Stimuli/Mechanism & Model & Effect & Ref. \\
\hline & 28-30-kDa subunit & $\begin{array}{c}\text { FPS, } \beta \text {-amyloid } \\
\text { precursor } \\
\text { protein }\end{array}$ & $\begin{array}{c}\text { PKA, } \\
\text { forskolin, } \\
\text { 8-bromo cAMP }\end{array}$ & HEK293 cells & $\begin{array}{l}\uparrow \mathrm{ChTL}, \uparrow \mathrm{APP} \alpha \\
\text { secretion }\end{array}$ & [146] \\
\hline & Rpt6 $\left(\operatorname{Ser}^{120}\right)$ & $\begin{array}{c}\text { GFP-CL1 } \\
\{\text { in vivo }\}, \text { FPS } \\
\{\text { in vitro }\}\end{array}$ & $\begin{array}{l}\text { PKA, } \\
\text { Forskolin, } \\
\text { rolipram }\end{array}$ & HEK293, NRK cells & $\begin{array}{c}\uparrow C h T L \uparrow T L \uparrow C L \\
\uparrow \text { degradation } \\
\text { GFP-CL1 }\end{array}$ & [148] \\
\hline & Rpt6 & $\begin{array}{l}\text { paGFP-CL1, } \\
\text {-ODC }\end{array}$ & $\begin{array}{l}\text { CMPK II, } \\
\text { bicuculline }\end{array}$ & $\begin{array}{l}\text { Rat hippocampal } \\
\text { neurons }\end{array}$ & $\begin{array}{c}\uparrow \text { degradation } \\
\text { GFP-CL1 and } \\
\text { GFP-ODC }\end{array}$ & [149] \\
\hline & p45/Sug1/Rpt6 & - & p45 kinase & $\begin{array}{c}\text { Purified cardiac } 26 S \\
\text { PS }\end{array}$ & $\begin{array}{l}\text { } \text { interaction } \\
\text { with } \alpha 2\end{array}$ & [150] \\
\hline & Rpt3 $\left(\mathrm{Thr}^{25}\right)$ & 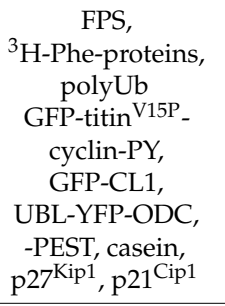 & DYRK2 & $\begin{array}{c}\text { HEK293T, } \\
\text { MDA-MB-468, HaCaT } \\
\text { cells, MEFs, T25A } \\
\text { knock-in and DYRK2 } \\
\text { knockout cells, mouse } \\
\text { brain, purified 26S PS } \\
\text { from cells }\end{array}$ & $\begin{array}{c}\uparrow C h T L \uparrow T L \uparrow C L \\
\uparrow D e g r a d a t i o n \text { of } \\
\text { proteins, } \\
\text { degron-reporters } \\
\text { and ATP; } \\
\uparrow S \rightarrow \text { M phase in } \\
\text { cell cycle }\end{array}$ & [151] \\
\hline & Rpn1 & $\begin{array}{c}\text { FPS, } \\
\text { NLS-GFP-CL1 } \\
\text { and } \\
\text { NLS-UbG76V_GFP }^{\text {N-GF }}\end{array}$ & UBLCP1 & $\begin{array}{c}\text { ZR751 breast cancer } \\
\text { and HEK293Tcells, } \\
\text { HaCaT } \\
\text { double-stable lines }\end{array}$ & $\begin{array}{c}\uparrow \text { nuclear ChTL } \\
\uparrow \text { nuclear 26S PS } \\
\text { assembly } \\
\uparrow \text { degradation } \\
\text { NLS-GFP-CL1 } \\
\text { and } \\
\text { NLS-UbG76V_GFP }\end{array}$ & [136] \\
\hline
\end{tabular}

ChTL, chymotrypsin-like activity; TL, trypsin-like activity; CL, caspase-like activity; FPS, fluorogenic peptide substrate; PS, proteasome; CKII, casein kinase II; cGMP/AMP, cyclic guanosine/adenosine monophosphate; NRK, normal rat kidney; Plk, polo-like kinase; PP, protein phosphatase; PKA, protein kinase A; HEK293T, human embryonic kidney 293T cells; APP $\alpha, C$-terminally truncated fragment of $\beta$ APP; MEFs, mouse embryonic fibroblasts; DYRK2, tyrosine-regulated kinase 2; CMPKII, calcium/calmodulin-dependent protein kinase II; UBLCP1, ubiquitin-like domain-containing C-terminal domain phosphatase 1; Ub, ubiquitin; GFP, green fluorescence protein; GFP-CL1, CL1 short degron fused to the C terminus of GFP; GFP-ODC, ornithine decarboxylase degron on the C terminus of GFP; UBL-YFP-ODC and -PEST, substrates degraded in a Ub-independent manner; NLS, nuclear localization signal connected to GFP-CL1 or $\mathrm{Ub}^{\mathrm{G} 76 \mathrm{~V}}$-GFP; polyUb GFP-titin ${ }^{\mathrm{V} 15 \mathrm{P}}$-cyclin-PY and $\mathrm{Ub}^{\mathrm{G} 76 \mathrm{~V}}$-GFP, Ub-dependent reporter-degron fusion proteins; paGFP, pa (photoactivation) variant of GFP.

(c)

\begin{tabular}{|c|c|c|c|c|c|c|}
\hline PTM & Subunit & Substrate & Stimuli/Mechanism & Model & Effect & Ref. \\
\hline \multirow{3}{*}{ 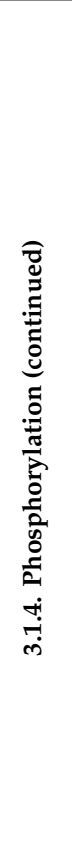 } & PA28 $\alpha, \beta$ & FPS & $\begin{array}{c}\text { Alkaline } \\
\text { phosphatase }\end{array}$ & $\begin{array}{l}\text { Rabbit } \\
\text { reticulocytes, } \\
\text { human } \\
\text { erythrocytes }\end{array}$ & $\uparrow$ ChTL & [142] \\
\hline & Rpn6 (Ser $\left.{ }^{14}\right)$ & $\begin{array}{c}\text { FPS, GFP-CL1, } \\
\text { Ub-R-GFP, } \\
\mathrm{Ub}^{\mathrm{G} 76 \mathrm{~V}} \text {-GFP, } \\
{ }^{32} \mathrm{P}^{-} \mathrm{Ub}_{5} \text {-DHFR, } \\
\mathrm{Ub}_{\mathrm{n}} \text {-Sic1, } \\
\left.{ }^{3} \mathrm{H}\right] \mathrm{Phe} \text { and } \\
\left.{ }^{3} \mathrm{Tyr}\right] \text {-proteins, } \\
\text { mutant FUS, } \\
\text { SOD1, TDP43, } \\
\text { and tau }\end{array}$ & $\begin{array}{c}\text { PKA, } \\
\text { forskolin, } \\
\text { rolipram, } \\
\text { dibutyryl cAMP, } \\
\text { glucagon, } \\
\text { epinephrin, } \\
\text { exercise, food } \\
\text { deprivation }\end{array}$ & $\begin{array}{l}\text { HEK293, C2C12, } \\
\text { SH-SY5Y, H9C2, } \\
\text { renal cells, } \\
\text { hepatocytes, Rpn6 } \\
\text { mutants, purified } \\
\text { PS from rTg4510 } \\
\text { mice, human and } \\
\text { rat muscles } \\
\text { and liver }\end{array}$ & $\begin{array}{c}\uparrow C h T L \uparrow T L \uparrow C L \\
\uparrow \text { degradation } \\
\text { short lived but } \\
\text { not long lived } \\
\text { proteins, } \\
\text { polyUb- and } \\
\text { aggregation-prone } \\
\text { proteins, ATP }\end{array}$ & [154-156] \\
\hline & $\alpha 4\left(\operatorname{Tyr}^{153}\right)$ & $\begin{array}{c}\text { FPS, }{ }^{35} \text { S-labeled } \\
\text { proteins }\end{array}$ & c-Abl, Arg & $\begin{array}{l}\text { 293T, MCF-7, } \\
\text { MCF-7/C-Abl(K290R), }^{-1} \text { c-abl }^{-/-} \text {arg }^{-/--/-} \\
\text {MEFs, cells } \\
\text { expressing } \alpha 4 \\
\text { Y153F or c-Abl } \\
\text { (K290R) mutant, } \\
\text { purified 26S PS }\end{array}$ & $\begin{array}{c}\downarrow \text { ChTL, } \\
\downarrow^{32} \mathrm{~S} \text {-labeled } \\
\text { proteins } \\
\text { degradation, } \\
\uparrow \text { destabilisation } \\
\text { of p53, p27, } \\
\text { cyclin A, and } \\
\text { cyclin E and } \\
\text { G1/S cell cycle } \\
\text { arrest in 293T } \alpha 4 \\
\text { Y153F mutants }\end{array}$ & [158] \\
\hline
\end{tabular}




\begin{tabular}{|c|c|c|c|c|c|c|}
\hline PTM & Subunit & Substrate & Stimuli/Mechanism & Model & Effect & Ref. \\
\hline & Rpt5 & $\begin{array}{c}\text { FPS, polyUb } \\
\text { lysosyme, } \\
\text { Ub }^{\mathrm{G} 76 \mathrm{~V}_{-}} \text {-GFP, } \\
\text { GFP-ODC, } \\
\text { GFP-CL1, } \\
\text { IkB } \alpha, \text { ATP }\end{array}$ & ASK1 & $\begin{array}{l}\text { HeLa, HEK293, } \\
\text { neuroblastoma } \\
\text { N2a, C6 glioma } \\
\text { cells, cells } \\
\text { expressing } \\
\text { truncation and } \\
\text { catalytically } \\
\text { inactive ASK1 } \\
\text { mutants }\end{array}$ & $\begin{array}{c}\uparrow \text { apoptosis } \\
\downarrow \text { ChTL } \downarrow \text { TL } \downarrow \text { CL } \\
\downarrow \text { Degradation of } \\
\text { total proteins, } \\
\text { I } \mathrm{B} \alpha \text {, reporters } \\
\text { and ATP } \\
\text { hydrolysis }\end{array}$ & [160] \\
\hline & Rpn2 (Thr' $\left.{ }^{273}\right)$ & $\begin{array}{c}\mathrm{Ub}^{\mathrm{G} 76 \mathrm{~V}_{-}} \text {GFP, } \\
\text { Ub-R-GFP, } \\
\text { GFP-CL1, } \\
\text { GFP-ODC, } \\
\text { endogenous } \\
\text { IкB } \alpha\end{array}$ & $\begin{array}{l}\text { Osmotic stress } \\
\text { p38 MAPK }\end{array}$ & $\begin{array}{l}\text { HeLa expressing } \\
\text { constitutively } \\
\text { active form of p38 } \\
\text { activator MKK6, } \\
\text { T273A mutants, } \\
\text { purif. 26S PS }\end{array}$ & 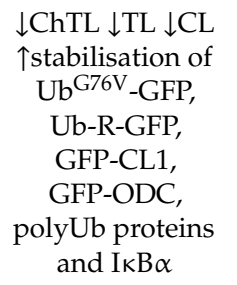 & [164] \\
\hline & Rpn3 (Ser $\left.{ }^{6}\right)$ & $\begin{array}{c}\text { FPS, } \\
\text { ubiquitin-AMC, } \\
{ }^{35} \text { S-ODC, } \\
{ }^{35} \text { S-Ub-cIAP1 }\end{array}$ & $\mathrm{CKII} \alpha^{\prime}$ & $\begin{array}{c}\text { MEFs, HeLa, } \\
\text { HEK293T cells } \\
\text { Rpn11-Flag/EGFP } \\
\text { MEFs infected } \\
\text { with } \\
\text { Cre-retrovirus }\end{array}$ & $\begin{array}{c}\uparrow \text { deubiquitinaton } \\
\text { and } \downarrow \text { nuclear } \\
\text { localisation of } \\
\text { old proteasomes, } \\
\text { no change in } \\
\text { proteolysis of } \\
\text { FPS and } \\
35 \text { S-ODC, } \\
{ }^{35} \text { S-Ub-cIAP1 }\end{array}$ & [157] \\
\hline \multirow{3}{*}{ 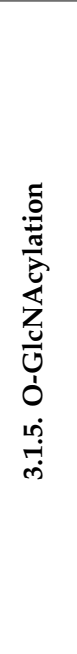 } & Rpt2 & $\begin{array}{c}\text { FPS, } \\
\text { transcription } \\
\text { factor SP1, } \\
\text { GFP-degron, } \\
\text { ATP }\end{array}$ & OGT/O-GlcNAcase & $\begin{array}{l}\text { Nuclear extract } \\
\text { from } \\
\text { glucose-starved/ } \\
\text { forskolin-treated } \\
\text { NRK cells, } \\
\text { purified 20S and } \\
26 S \text { PS, } \\
\text { OGT siRNA cells }\end{array}$ & $\begin{array}{c}\downarrow \text { generation of } \\
\text { SpX from SP1, } \\
\downarrow \text { ChTL } \\
\text { \{suc-LLVY-AMC\}, } \\
\text { unchanged TL } \\
\text { and ChTL } \\
\text { \{Z-GGL-AMC\} } \\
\downarrow \text { ATPase activity } \\
\downarrow \text { GFP-degron in } \\
\text { OGT siRNA } \\
\text { cells }\end{array}$ & [165] \\
\hline & $\begin{array}{c}\alpha 1\left(\mathrm{Ser}^{5}\right), \alpha 5 \\
\left(\mathrm{Ser}^{198}\right), \alpha 4 \\
\left(\mathrm{Ser}^{130}\right), \beta 6\left(\mathrm{Ser}^{208}\right. \\
\left.\text { and } \mathrm{Ser}^{57}\right)\end{array}$ & FPS & $10 \mathrm{mM}$ glucose & $\begin{array}{l}\text { Murine fibroblast } \\
\text { cells, } \\
\text { 20S PS purified } \\
\text { from spleen, liver, } \\
\text { and brain tissues }\end{array}$ & $\downarrow$ ChTL & [166] \\
\hline & $\alpha 5$ & - & diabetes & $\begin{array}{l}\text { Human } \\
\text { erythrocytes }\end{array}$ & $\begin{array}{c}\uparrow O-G l c N A c \text { site } \\
\text { occupancy }\end{array}$ & [169] \\
\hline
\end{tabular}

ChTL, chymotrypsin-like activity; TL, trypsin-like activity; CL, caspase-like activity; FPS, fluorogenic peptide substrate; PS, proteasome; PKA, protein kinase A; forskolin, rolipram, compounds raising cAMP by stimulating adenylate cyclases or by inhibiting phosphodiesterase 4, resp.; MEFs, mouse embryonic fibroblasts; HEK293, human embryonic kidney 293 cells; Ub, ubiquitin; ASK1, apoptosis signal-regulating kinase 1; CKII $\alpha^{\prime}, \alpha^{\prime}$ subunit of casein kinase II; FUS, fused in sarcoma; SOD1, superoxide dismutase 1; TDP43, TAR DNA-binding protein; O-GlcNAcylation, O-linked-N-acetylglucosaminylation; OGT, O-linked N-acetylglucosamine (GlcNAc) transferase; O-GlcNAcse, 3-O-(N-acetyl-D-glucosaminyl)-L-serine/threonine N-acetylglucosaminyl hydrolase; SP1, transcription factor specificity protein 1; GFP-CL1, CL1 short degron fused to the C terminus of GFP; Ub-R-GFP, Ub-dependent reporter-degron fusion substrate, N-end rule system; Ubn-Sic1, Ub-conjugated substrate and inhibitor of the cyclin-dependent protein kinase CDC28 (Sic1); ${ }^{32} \mathrm{P}_{-} \mathrm{Ub}_{5}$-DHFR; ${ }^{32} \mathrm{P}$-labeled pentaUb-conjugated dihydrofolate reductase; c-Abl and Arg, tyrosine kinases; GFP-ODC, ornithine decarboxylase degron on the C terminus of GFP; $\mathrm{Ub}^{\mathrm{G} 76 \mathrm{~V}}$-GFP, Ub-dependent reporter-degron fusion substrate; ${ }^{35} \mathrm{~S}$-Ub-cIAP1, ${ }^{35} \mathrm{~S}$-labeled Ub-conjugated inhibitor of apoptosis 1 protein; Ub-AMC, Ubiquitin 7-amido-4-methylcoumarin; $\mathrm{I} \kappa \mathrm{B} \alpha$, inhibitor of nuclear factor $\kappa \mathrm{B} \alpha$. 
(d)

\begin{tabular}{|c|c|c|c|c|c|c|}
\hline PTM & Subunit & Substrate & Stimuli/Mechanism & Model & Effect & Ref. \\
\hline \multirow{4}{*}{ 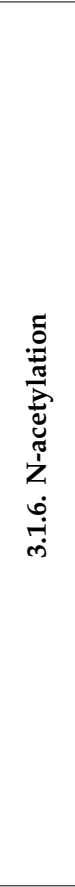 } & $\begin{array}{c}\left.\alpha 6{\left(\mathrm{Lys}^{30}, \mathrm{Lys}^{115}\right)}{ }^{115}{ }^{77}\right), \beta 6 \\
\left(\mathrm{Lys}^{203}\right), \beta 7 \\
\left(\mathrm{Lys}^{201}\right)\end{array}$ & FPS & $\begin{array}{l}\text { Acute } / / R \text { injury, } \\
\text { end-stage heart } \\
\text { failure, HDAC } \\
\text { inhibitors }\end{array}$ & $\begin{array}{l}\text { Human and mice } \\
\text { cardiac tissue; } \\
\text { purified cardiac } \\
\text { 20S PS }\end{array}$ & $\begin{array}{c}\uparrow \mathrm{TL} \downarrow \mathrm{TL} \text { after } \mathrm{I} / \mathrm{R} \\
\text { restored by } \\
\text { HDAC inhibitors }\end{array}$ & [175] \\
\hline & PA28 $\gamma\left(\right.$ Lys $\left.^{195}\right)$ & $\begin{array}{l}\mathrm{p} 21, \mathrm{HCV} \\
\text { core protein }\end{array}$ & CBP/SIRT & $\begin{array}{l}\text { HEK293/293T, } \\
\text { H1299, HeLa, } \\
\text { A549 cells } \\
\text { HEK293 cells } \\
\text { expressing } \\
\text { PA28 } \gamma \text {-K195R } \\
\text { mutant }\end{array}$ & $\begin{array}{c}\uparrow \text { degradation p21 } \\
\text { and HCV core-173; } \\
\uparrow \text { PA28 } \\
\text { heptamerization } \\
\text { and cell cycle } \\
\text { progression }\end{array}$ & [176] \\
\hline & PA28 $\alpha, \beta$ & $\begin{array}{c}\text { FPS } \\
\text { \{Cell-based } \\
\text { bioluminescent } \\
\text { assays and } \\
\text { standard } \\
\text { in vitro } \\
\text { assay\} }\end{array}$ & $\begin{array}{l}\text { Naa10p protein } \\
\text { independent on its } \\
\text { activity }\end{array}$ & $\begin{array}{c}\text { RKO, H1299, } \\
\text { PG cells, } \\
\text { shNaa10p, } \\
\text { siPA28 } \alpha \text { cells, cells } \\
\text { expressing mutant } \\
\text { Naa10p (R82A) or } \\
\text { overexpressing } \\
\text { Naa10p; purified } \\
\text { PS complexes }\end{array}$ & $\downarrow$ ChTL & [177] \\
\hline & $\beta 1, \beta 2, \beta 5$ & FPS & $\begin{array}{c}\mathrm{N} \text {-acetyltransferase } \\
\text { ARD1-NAT1 }\end{array}$ & $\begin{array}{l}\text { Yeast, } \beta \text {-subunit } \\
\text { propeptide and } \\
\text { NAT1 deletion } \\
\text { mutants }\end{array}$ & $\begin{array}{l}\text { Corresponding } \\
\downarrow \text { ChTL } \downarrow \text { TL } \downarrow C L ; \\
\text { growth defects }\end{array}$ & [178] \\
\hline \multirow{3}{*}{ 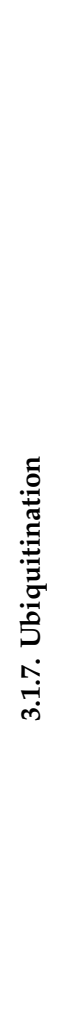 } & $\begin{array}{c}\alpha 2 \\
\{\text { mono-ubiquitination\} }\end{array}$ & FPS & $\begin{array}{l}\text { Binding to } \delta \text {-ALAD, } \\
\text { HDAC inhibitor } \\
\text { (SAHA) }\end{array}$ & $\begin{array}{c}\text { Human prostate } \\
\text { cancer DU145, } \\
\text { LNCaP and PC-3 } \\
\text { cells, ALAD } \\
\text { overexpressing } \\
\text { cells }\end{array}$ & $\begin{array}{c}\downarrow C h T L \\
\text { Interaction with } \\
\delta \text {-ALAD; } \\
\uparrow \text { Interaction with } \\
\delta \text {-ALAD, } \\
\text { acetylation and } \\
\text { nuclear } \\
\text { translocation in } \\
\text { response to SAHA }\end{array}$ & [183] \\
\hline & $\begin{array}{c}\text { Rpn10 }\left(\text { Lys }^{84},\right. \\
\text { Lys }^{268}, \text { Lys }^{71}, \\
\text { Lys }^{99} \text { ) } \\
\text { \{mono-ubiquitination\} }\end{array}$ & cyclin B & $\begin{array}{c}\text { Rsp5/Ubp2; } \\
\text { Rpn10-conjugated } \\
\text { Ub clashes with } \\
\text { Rpn9 leading to } \\
\text { disassembly of } \\
\text { Rpn10:Rpn9 } \\
\text { complex }\end{array}$ & $\begin{array}{c}\text { Yeast; } \\
\text { rsp5, ubp2, Rpn10, } \\
\text { Dsk2 mutants; } \\
\text { Purified 26S PS }\end{array}$ & $\begin{array}{c}\downarrow \text { affinity to } \\
\text { polyUb substrates; } \\
\downarrow \text { cyclin B } \\
\text { degradation; } \\
\text { Dissoc. of } \\
\text { Rpn10/interaction } \\
\text { with Dsk2 } \\
\text { 26S PS “Rpn10 } \\
\text { low/Dsk2 high” } \\
\text { state; } \\
\text { iprocessivity of } \\
\text { PS through } \\
\text { cytosolic Rpn10 }\end{array}$ & $\begin{array}{l}{[184-} \\
186]\end{array}$ \\
\hline & $\begin{array}{l}\text { Rpn10 (multiple } \\
\text { sites; Lys }{ }^{74}, \text { Lys }^{122} \\
\text { Lys }^{262}, \text { Lys }^{365} \\
\text { ubiquitinated by } \\
\text { both MuRF1 and } \\
\text { E6AP) \{poly- } \\
\text { ubiquitination\} }\end{array}$ & - & $\begin{array}{c}\text { Ring finger E3s } \\
\text { (MuRF1, Siah2, } \\
\text { Parkin, APC, } \\
\text { SCFßTRCP1), U-box } \\
\text { E3 (CHIP), HECT } \\
\text { domain E3s (E6AP } \\
\text { and Nedd4)/UbcH5 }\end{array}$ & $\begin{array}{l}\text { Purified WT and } \\
\text { mutant proteins }\end{array}$ & $\begin{array}{l}\text { Polyubiquitination, } \\
\text { release and } \\
\text { degradation of } \\
\text { Rpn10 }\end{array}$ & [187] \\
\hline
\end{tabular}




\begin{tabular}{|c|c|c|c|c|c|c|}
\hline PTM & Subunit & Substrate & Stimuli/Mechanism & Model & Effect & Ref. \\
\hline & $\begin{array}{c}\text { Rpn13 }\left(\text { Lys }^{21}\right. \\
\text { Lys }^{34} \text { ) } \\
\text { \{poly-ubiquitination\} }\end{array}$ & $\begin{array}{c}\text { FPS, } \\
{ }^{32} \mathrm{P}_{-U b_{5}-\mathrm{DHFR}} \\
{ }^{32} \mathrm{P}-\mathrm{Ub}_{\mathrm{n}}-\mathrm{Sic1}, \\
{ }^{32} \mathrm{P} \text {-casein }\end{array}$ & $\begin{array}{c}\text { Ube3c } \\
\text { PS inhibitors } \\
\text { Heat shock } \\
\text { Arsenite }\end{array}$ & $\begin{array}{c}\text { HEK293F cells, } \\
\text { cells stably } \\
\text { expressing } \\
\text { Dss1/Sem1, } \\
\text { Ube3c siRNA } \\
\text { transfected cells, } \\
\text { cells re-expressing } \\
\text { Ube3c; Purified } \\
\text { 26S PS }\end{array}$ & $\begin{array}{l}\downarrow \mathrm{Ub}_{5} \text {-DHFR, } \\
\text { Ub } b_{n} \text {-Sic1 } \\
\text { degradation; } \\
\text { Unchanged } \\
\text { ChTL and casein } \\
\text { degradation; } \\
\downarrow 26 \mathrm{~S} \text { PS binding } \\
\text { to Ub }{ }_{5} \text {-DHFR }\end{array}$ & {$[188]$} \\
\hline
\end{tabular}

ChTL, chymotrypsin-like activity; TL, trypsin-like activity; CL, caspase-like activity; FPS, fluorogenic peptide substrate; PS, proteasome; $\mathrm{Ub}$, ubiquitin; I/R, ischemia/reperfusion; HDAC, histone deacetylases; HCV core protein, hepatitis $C$ virus core protein; CBP, cAMP response element-binding protein (CREB); Naa10p, $N$ - $\alpha$-acetyltransferase 10 protein; $\delta$-ALAD, $\delta$-aminolevulinic acid dehydratase; Ub, ubiquitin; SAHA, suberoylanilide hydroxamic acid; ubp2, ubiquitin carboxyl-terminal hydrolase 2; DSK2, dual-specificity protein kinase 2; Ring, really interesting new gene; MuRF1, muscle Ring-finger protein-1; APC, anaphase promoting complex; SCF $\beta$ TRCP1, SKP1-Cullin 1-F-box protein $\beta$-transducin repeat-containing protein; CHIP, carboxy-terminus of Hsc70 interacting protein; HECT, homologous to E6-associated protein (E6AP) C-terminus; Nedd4, neuronal precursor cell-expressed developmentally downregulated $4 ;{ }^{32} \mathrm{P}-\mathrm{Ub}_{5}$-DHFR, ${ }^{32} \mathrm{P}$-labeled pentaUb-conjugated dihydrofolate reductase; ${ }^{32} \mathrm{P}-\mathrm{Ub}_{\mathrm{n}}-\mathrm{Sic} 1,{ }^{32} \mathrm{P}$-labeled $\mathrm{Ub}$-conjugated substrate and inhibitor of the cyclin-dependent protein kinase CDC28 (Sic1); Ube3c, Ub protein ligase E3C; Dss1 (Sem1), Ub receptor of 26S PS.

(e)

\begin{tabular}{|c|c|c|c|c|c|c|}
\hline PTM & Subunit & Substrate & Stimuli/Mechanism & Model & Effect & Ref. \\
\hline \multirow{3}{*}{ 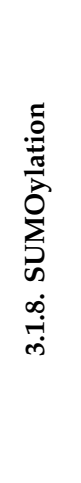 } & $\alpha 5, \beta 4$ & - & Heat shock & U2OS cells & - & [189] \\
\hline & $\begin{array}{c}\text { Rpn2 } \\
\left(\text { Lys }^{932}\right)\end{array}$ & Cyclin B & PIASy/xSENP1 & $\begin{array}{c}\text { Xenopus egg } \\
\text { extract } \\
\text { Purified WT and } \\
\text { mutant proteins }\end{array}$ & $\begin{array}{c}\text { Decrease in } \\
\text { association of Ub } \\
\text { receptor Rpn13 with } \\
\text { Rpn2, } \downarrow \text { cyclin B } \\
\text { degradation, delayed } \\
\text { anaphase progression } \\
\text { and mitotic arrest }\end{array}$ & [190] \\
\hline & $\begin{array}{l}41 \text { modified } \\
\text { Lys residues }\end{array}$ & - & MG132 & $\begin{array}{l}\text { HEK293 stably } \\
\text { expressing } \\
\text { SUMO3m, SUMO } \\
\text { interacting motif } \\
\text { (SIM) mutants }\end{array}$ & $\begin{array}{l}\text { Nuclear translocation } \\
\text { and colocalization } \\
\text { with PML NB }\end{array}$ & [191] \\
\hline
\end{tabular}

\begin{tabular}{|c|c|c|c|c|c|c|}
\hline 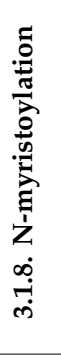 & Rpt2 $\left(\mathrm{Gly}^{2}\right)$ & $\begin{array}{l}\text { FPS, } \\
\text { CFP-Ubi4, } \\
\text { Gcn4 }\end{array}$ & $\begin{array}{c}\text { N-myristoyltransferase } \\
\text { Canavanine, } \\
\text { elevated } \\
\text { temperature }\end{array}$ & $\begin{array}{c}\text { Yeast, Cells } \\
\text { expressing } \\
\text { rpt2-G2A, and } \\
\text { rpt2-G2 } \Delta \text { mutants }\end{array}$ & $\begin{array}{l}\text { Nuclear translocation } \\
\uparrow \text { degradation nuclear } \\
\text { polyUb proteins and } \\
\text { Gcn4; Unchanged } \\
\text { peptidase activity or } \\
\text { 26S assembly; } \\
\text { Cytoplasmic PS } \\
\text { aggregates, and } \\
\downarrow \text { growth in } \\
\text { mutant cells }\end{array}$ & {$[192,193]$} \\
\hline \multirow[b]{2}{*}{ 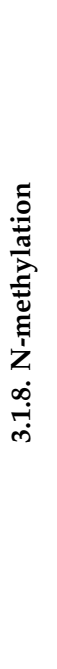 } & Rpt1 $\left(\mathrm{Pro}^{3}\right)$ & - & $\begin{array}{l}\mathrm{N} \text {-methyltransferase } \\
\text { Canavanine, } \mathrm{H}_{2} \mathrm{O}_{2}\end{array}$ & $\begin{array}{c}\text { Yeast } \\
\text { Cells expressing } \\
\text { PK-deleted Rpt1 } \\
\text { mutants }\end{array}$ & $\begin{array}{c}\downarrow \text { growth, and } \uparrow \\
\text { sensitivity to stress in } \\
\text { mutant cells }\end{array}$ & [195] \\
\hline & $\begin{array}{l}\text { Lys in } 25 \mathrm{kDa} \\
\text { subunit }\end{array}$ & FPS, CYP2E1 & $\begin{array}{c}\text { N-methyltransferases } \\
\text { EtOH } \\
\text { SAM:SAH, IFN- } \gamma, \\
\text { Tubercidin }\end{array}$ & $\begin{array}{l}\text { Huh7CYP cells, } \\
\text { liver cytosolic and } \\
\text { nuclear extracts, } \\
\text { HCV+ mice and } \\
\text { hepatocytes, } \\
\text { purified 20S PS }\end{array}$ & $\begin{array}{c}\downarrow \text { ChTL larger } \\
\text { reduction in } \\
\text { nuclear PS } \\
\uparrow C Y \text { 2E1 stabilization } \\
\uparrow \text { LMP7 ( } \beta 5 \mathrm{i}) \text { (HCV+, } \\
\text { HCV-) } \\
\downarrow \text { PA28 } \alpha \text { (HCV+, } \\
\text { HCV-) } \\
\downarrow \text { LMP2 ( } \beta 1 \mathrm{i}) \text { (HCV+) } \\
\downarrow \text { Ecm29, UCHL5 } \\
\text { (HCV+, HCV-) } \\
\downarrow \text { SAM:SAH } \\
\downarrow \text { SIINFEKL } \\
\text { presentation } \\
(\text { HCV+>HCV-) }\end{array}$ & {$[197,198]$} \\
\hline
\end{tabular}


ChTL, chymotrypsin-like activity; TL, trypsin-like activity; CL, caspase-like activity; FPS, fluorogenic peptide substrate; PS, proteasome; Ub, ubiquitin; PML NB, promyelocytic leukemia protein nuclear bodies; Gcn4, transcription factor General Control Nonderepressible; CFP-Ubi4, tetraUb-conjugated cyan fluorescent protein (CFP) reporter; SUMO3m, 6xHis-SUMO3-Q87R-Q88N; CYP2E1, cytochrome P450 2E1; PIASy/xSENP1, SUMO E3 enzyme, protein inhibitor of activated STAT Y/SUMO deconjugating enzyme sentrin-specific protease; canavanine, an arginine analogue, restricting growth; Ecm29, main proteasome-interacting protein responsible for stress-triggered remodeling of the 26S proteasome; UCHL5, ubiquitin carboxyl-terminal hydrolase isozyme L5; SIINFEKL-TE, ovalbumin peptide cleaved by the PS to SIINFEKL; PK, Pro $^{3}$-Lys ${ }^{4}$; SAM, S-adenosyl; SAH, S-adenosyl-L-homocysteine; tubercidin, inhibitor causing accumulation of SAH by blocking S-adenosylhomocysteine hydrolase activity

\subsection{Covalent Modifications of Amino Acid Side Chains by Strong Oxidants and Electrophiles}

Upon exposure to increased amounts of strong electrophiles and oxidants derived largely from cellular oxidative metabolism, proteasomal complexes can undergo reactions ranging from site-directed oxidative modifications to irreversible oxidative damage (Table 3a-b). Generally, the chemical reactions of proteins with electrophiles occur preferably in electron-rich nucleophilic groups, i.e., the nitrogen of the amino-, imidazole-, and guanidine groups of Lys, His, and Arg, respectively; the oxygen nucleophiles of the hydroxyl-, phenolic-, and carboxyl groups of Ser, Thr, Tyr, Glu, and Asp, respectively; and the -SH group of Cys and the thioether group of Met $[199,200]$. These modifications include the introduction of carbonyl groups, the nitration of tyrosines, the formation of adducts with reactive aldehydes or non-enzymatic glycation, and glycoxidation. Severe oxidative damage may also lead to cleavage of the polypeptide backbone [201]. Non-specific and irreversible oxidative damage targeting nucleophilic groups at the catalytic sites of a functional protein can, on average, result in a decline in the protein's activity. Exposure to strong oxidizing agents $\left(\mathrm{OCl}^{-} / \mathrm{HOCl}, \mathrm{ONOO}^{-}\right)$or elevated levels of $\mathrm{H}_{2} \mathrm{O}_{2}$ was shown to yield a decline in the proteolytic activities of two forms of the proteasome, 26S and 20S (able to catalyze the removal of oxidized proteins), in isolated proteasome preparations and K562 cell lysates [83]. Again, the $26 \mathrm{~S}$ proteasome complex was more vulnerable to oxidative damage compared to the 20S, which substantiates its role in cellular antioxidant defense. Interestingly, inhibition of the ATP-dependent chymotrypsin-like peptidase activities of the $26 \mathrm{~S}$ proteasome were shown to occur at oxidant concentrations several times lower than those required for the maximum degradation of ferritin oxidized by the $20 \mathrm{~S}$ proteasome. Consistently, the 195 ATPase subunit Rpt 3 of the $26 \mathrm{~S}$ proteasome in human neuroblastoma cells showed strong sensitivity to oxidation [202].

\subsubsection{Protein Carbonylation}

Protein carbonylation is the introduction of aldehyde or ketone groups into protein via oxidation. Primary protein carbonylation can occur through the direct metal-catalyzed oxidation of amino acid side chains, particularly on Lys, Arg, Pro, Thr, His, and Trp residues or via ROS-mediated polypeptide backbone cleavage through the $\alpha$-amidation pathway or $\beta$-scission [203,204]. Secondary carbonylation involves the Michael addition reaction of nucleophilic groups on the amino acid side chains with reactive aldehyde and Schiff base formation via the reactions of reducing sugars with Arg and Lys (Section 3.2.3). Increased carbonyl modifications at the $\alpha 2, \alpha 4, \alpha 6$, and $\beta 3$ subunits of the purified murine cardiac $20 S$ proteasome were detected following paraquat treatment via two-dimensional electrophoresis [127]. Threonine 94 of the proteasome subunit $\beta 7$ (DSTMLGASGDYADFQYLK) was identified by MS as a site of primary carbonylation after derivatization using biotin hydrazide. However, using human diseased tissues and a murine model [205,206], the oxidation of Rpt5 subunit of the 26S proteasome was assigned a significant role in cardiovascular disorders, as this subunit plays a critical role in the assembly and activation of the $26 \mathrm{~S}$ proteasome [207]. Increased carbonylation of Rpt5 was suggested to be involved in the dysfunction of murine myocardial UPS following ischemia-reperfusion [205]. Remarkably, oxidative damage to the other 19S RP subunits was not observed. Moreover, carbonylation of the $20 \mathrm{~S}$ proteasome subunits was also not detected. This is, again, in agreement with the proposed lower vulnerability of the ATP-independent $20 \mathrm{~S}$ proteasome to oxidative damage compared to the $26 \mathrm{~S}$ 
proteasome [83]. The carbonylation of Rpt5 was also increased in failing compared to nonfailing human hearts [206]. This oxidative modification coincided with a drop in both ATP-dependent (and less affected ATP-independent) ChTL peptidase activity, the accumulation of total oxidized and polyUb proteins, and certain UPS targets—such as Bax [205], p53, and Akt [206]—in both human and murine cardiac tissue.

However, the anti-DNPH pull-down experiment suggested that both Rpt3 and Rpt5 account for the oxidation signal in murine myocardial tissue [205]. Correspondingly, exposure of the SH-SY5Y cells to the intracellular oxidative stress promoted by endogenous reactive electrophile, 15-deoxy- $\Delta^{12,14}$-prostaglandin $\mathrm{J}_{2}\left(15 \mathrm{~d}-\mathrm{PGJ}_{2}\right)$ significantly increased carbonylation of the $19 \mathrm{~S}$ ATPase subunit Rpt3. This was associated with a decrease in its ATPase activity and the proteolytic activity of the 26S proteasome [202]. Moreover, selective oxidation of Rpt3 was also detected upon in vitro oxidation of the purified $26 \mathrm{~S}$ proteasome under metal-catalyzed oxidation.

As already mentioned, $15 \mathrm{~d}-\mathrm{PGJ}_{2}$ is also likely to inhibit the proteasome through a mechanism by which $15 \mathrm{~d}-\mathrm{PGJ}_{2}$ directly binds the proteasome. Hence, $15 \mathrm{~d}-\mathrm{PGJ}_{2}$ can also indirectly carbonylate the proteasome via the Michael addition of specific Cys thiolates at 13 subunits of 19S RP to the $\alpha$, $\beta$-unsaturated ketone structure of $15 \mathrm{~d}-\mathrm{PGJ}_{2}$ (Scheme 2) [124]. Michael addition with 4-hydroxy-trans-2nonenal (HNE) (Section 3.2.2) is also a type of secondary carbonylation.

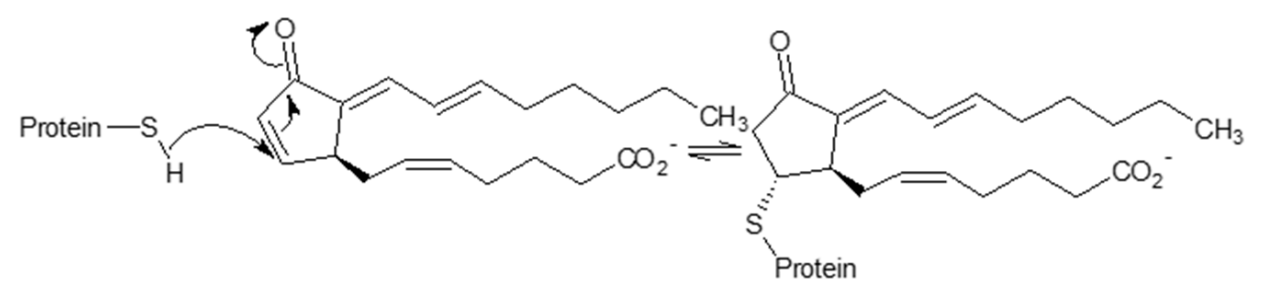

Scheme 2. Mechanism of the covalent modification of thiol-containing proteins by $15 \mathrm{~d}-\mathrm{PGJ}_{2}$ via Michael-type nucleophilic addition.

\subsubsection{HNE Modification}

The lipid-peroxidation-derived product, 4-hydroxy-trans-2-nonenal (HNE), as an $\alpha, \beta$-unsaturated carbonyl compound, typically undergoes a 1,4-addition reaction (Michael addition) with Lys, His, and Cys residues and Schiff base formation involving a 1,2-addition reaction with lysine (Scheme 3). However, the HNE adducts with Arg, Thr, and Trp residues have also been detected in proteins [208]. The reactivity of the side chain amino acids toward HNE was suggested to have the following order: Cys $>>$ His $>$ Lys [209]. The Michael HNE adduct is generally a more prevalent protein modification (accounting for more than $99 \%$ of HNE-induced modifications in proteins) compared to a labile lysine- $\varepsilon$-amino Schiff base. The 1,4-addition reaction of lysine residues to HNE exerts larger reversibility compared to the formation of more stable His- and Cys-HNE Michael adducts [210]. However, the reversibility of an addition reaction and the instability of some HNE-derived protein adducts, often complicating their analysis, can likely confer a regulatory function, particularly under conditions of acute oxidative stress. In this regard, a faster recovery of $\alpha 7-\mathrm{HNE}$ adducts on the protesome was observed compared to general HNE adducts in both FF95 cells and purified $20 \mathrm{~S}$ proteasome preparations, pointing to enhanced instability of this modification [211]. 


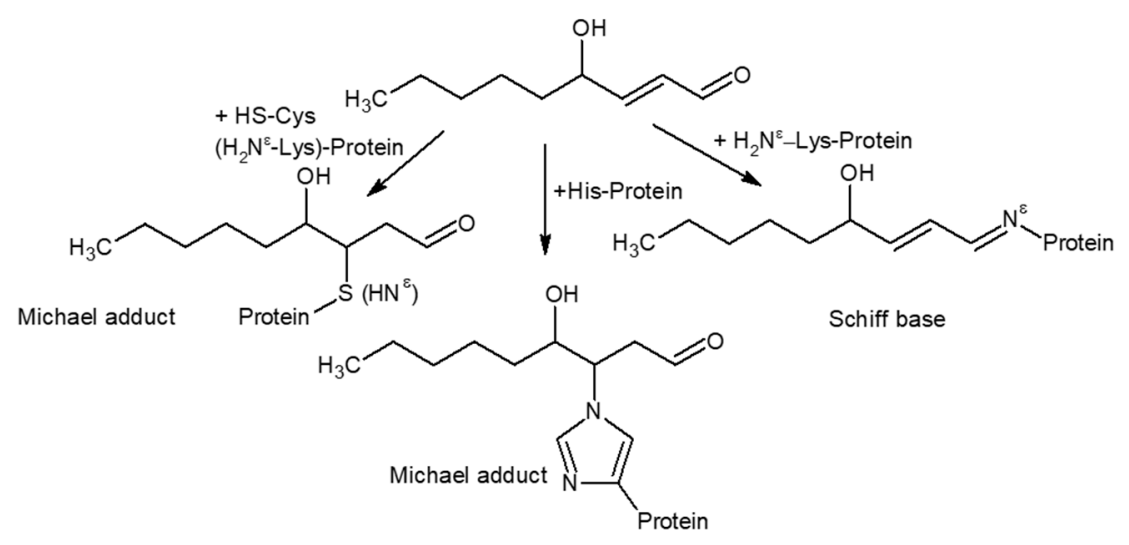

Scheme 3. Formation of Michael adduct and Schiff base from amino acid side chains in proteins by HNE.

Nevertheless, the damaging effects arising from HNE protein modifications have been recognized for a number of proteins, where HNE causes an alteration of protein structure and/or the inhibition of protein functions [212,213]. In addition, HNE-protein adducts might contribute to the pathogenesis of diseases but may also serve as biomarkers [214]. Modification of the proteasomal subunits by 4-hydroxy-nonenalyation was found to be associated with a functional decline in a range of pathological and experimental conditions, including ischemia-reperfusion [215] and cerebral ischemia [216], in homogenates of injured kidney tissue [217], in aged human lymphocytes [218], and in tissues from aged rats [219], or in purified liver proteasomal preparation [220]

HNE modification mostly affects the $\alpha$ subunits that may interfere with the substrate accessibility of the catalytic core and/or impact catalytic activities by influencing the interactions between $\alpha$ and catalytic $\beta$ subunits. Furthermore, HNE does not seem to modify RP nor profoundly disassemble the $26 \mathrm{~S}$ proteasome $[215,218]$. The study by Okada et al. [217] showed that the HNE-modified proteins were significantly ubiquitinated. Moreover, the proteolytic activities of the proteasomes in the tissues from disease models were diminished in accordance with the accumulation of oxidized, HNE-, or Ub-modified proteins [215,217]. These findings indicate the involvement of the proteasomes in the removal of HNE-modified proteins, as well as the crucial role of the ubiquitin/proteasome system in the metabolism of HNE-conjugated proteins in vivo. Chymotrypsin-like activity appeared to be less affected in in vivo models of I/R [215] and ferric nitrilotriacetate-elicited renal toxicity [217]. By contrast, purified proteasomes from rat liver showed increased sensitivity to ChTL activity inhibition at low-concentrations of HNE, at time coinciding with modification of the $\alpha 6$ unit by 4-hydroxy-nonenalyation [220]. This can also be explained by the increased content of inducible subunit $\beta 5 \mathrm{i}(70 \%)$ in the liver proteasome, showing increased vulnerability to oxidative damage compared to the constitutive form [221]. HNE-adducts on $\beta$-subunits were not found, likely, due to the limited sensitivity of the detection method. Nevertheless, ChTL activity might also be affected by interaction of $\beta 5$ with its adjacent neighbor, HNE-modified $\alpha 6$. Consistently, impaired chymotrypsin-like activity was observed in aged tissues [218,219], correlated with increased HNE-modification of the $\beta 5$ i subunit detected in leukocyte-enriched fractions of human blood appearing around the age of 40 years [218]. Ageing has also been shown to be accompanied by an increase of inducible subunits in certain tissues, mostly due to progression of low-grade chronic inflammation [222].

Overall, 4-hydroxy-nonenalyation shows a generally suppressive effect on proteasomal activity. However, a particular mechanism might be tissue-dependent and possibly affected by the inflammatory disease state.

\subsubsection{Glycation and Glycoxidation}

Diabetic complications and aging are accompanied by the accumulation of end-stage products of the Maillard or browning reaction, also known as advanced glycation (or glycoxidation) end products (AGEs), which cause structural and functional changes to tissue proteins [223]. The initial 
stage involves a glycation reaction primarily between the free $\varepsilon$-amino groups of a lysine in proteins with the carbonyl group, e.g., for the reducing sugar, thereby forming a Schiff base that rearranges spontaneously to a more stable ketoamine, Amadori product [224]. These substances may undergo further conversions, which are more complex and generate a wide range of reactive carbonyl and dicarbonyl compounds, both free and protein-bound, in non-oxidative and oxidative (glycoxidative) reactions. The intermediate glycation products may then react with proteins to form AGEs, i.e., stable, irreversible adducts (such as pyrraline, $\mathrm{N}^{\varepsilon}$-(carboxymethyl)lysine, $\mathrm{N}^{\varepsilon}$-(carboxyethyl)lysine) and crosslinks (such as pentosidine and imidazolium compounds)). The glycation of cysteine can also generate irreversible AGEs, such as S-(carboxyethyl)cysteine, through the formation of highly reversible hemithioacetal intermediates.

Chronic and strong hyperglycemia conditions in the cell culture and in vivo were reported to impair proteasome peptidase activity $[225,226]$. The modifications of several $20 \mathrm{~S}$ proteasome $\beta$ subunits with the reactive carbonyl compound methylglyoxal (MGO) (the major intracellular precursor of AGEs) were suggested as the underlining mechanism of the high glucose effect [225]. In particular, MGO-derived hydroimidazolone adducts with $\beta 2$ subunit were confirmed in tissue homogenates from three different diabetic models, including nondiabetic glyoxalase 1-knockdown mice, indicating that increased MGO alone is sufficient to cause proteasome dysfunction. In addition, various MGO-derived AGEs were detected at the $\beta 2, \beta 4$, and $\beta 5$ subunits (in particular, methylimidazolone [ $N$-acetyl- $N$-(5-hydro-5-methyl)-4-imidazolone], $N^{\varepsilon}$-(carboxyethyl)lysine, and argpyrimidine, (Scheme 4)) in the purified $20 \mathrm{~S}$ proteasomes incubated with $\mathrm{MGO}$, although no detectable modification of the $\beta 5$ subunit was found in vivo. Moreover, increased MGO was suggested to also reduce the protein levels of the polyubiquitin receptor 19S Rpn10 making the polyUb proteins accumulate in tissues under a chronic hyperglycemia state. Nevertheless, as suggested by the same authors, the upregulation of chymotryptic-like activity can occur in the acute phase of high glucose (3-5 days), pointing to a biphasic manner of influence of proteasomal activity via hyperglycemia. The study by Moheimani et al. [227] reported the consistent elevation of proteasomal activities induced by short-term exposure to the reactive carbonyl compounds, glyoxal, methylglyoxal, and glycoaldehyde, in J774A.1 cell extracts. By contrast, proteasomal activity was differentially inhibited by a higher concentration of bovine serum albumin (BSA) pre-glycated by reactive aldehydes and glucose. Hence, inhibition can likely arise from the effects of glucose-derived AGEs on $26 \mathrm{~S}$ proteasome activity, exerting the following order of sensitivity to inhibition: caspase-like $>$ chymotrypsin-like $>$ trypsin-like. The nucleophilic attack of the $\gamma$-hydroxyl group of threonines of the $\beta$ catalytic subunits on the electron-deficient groups in glycated BSA was suggested as one of the mechanisms of proteasomal inhibition [227]. By analogy, the nucleophilic attack of the oxygen from $\mathrm{N}$-terminal catalytic threonine to an electron-deficient atom is also the mechanism for covalent proteasomal inhibitors [228]. Interestingly, some of the major classes of these inhibitors share structural elements with reactive electrophilic compounds produced by glucose or lipid oxidation in vivo. The representative compounds include, e.g., aldehyde MG123, $\alpha^{\prime}, \beta^{\prime}$-epoxyketone epoxomycin, and syrbactins bearing the $\alpha, \beta$-unsaturated carbonyl moiety. The inhibitory reaction of aldehyde and glyoxal inhibitors is reversible. For ketoaldehydes, the mechanism involves the formation of a six-membered heterocycle containing hemiketal and imine bonds (a Schiff base derived from the N-terminal amino group of Thr-1). Michael addition is also involved in the inhibitory effects of syrbactins [229].

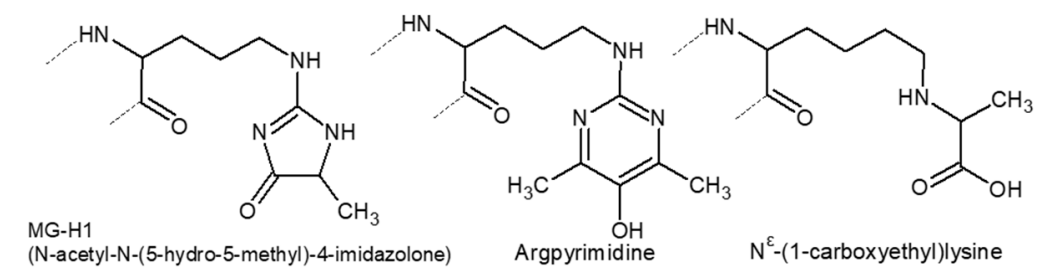

Scheme 4. Structures of AGEs detected in the purified 20S proteasomes incubated with MGO. 


\subsubsection{Tyrosine Nitration}

Tyrosine nitration is a covalent oxidative modification of tyrosine residues mediated by nitric oxide-derived species such as $\mathrm{NO}_{2}$ and peroxynitrite $\left(\mathrm{ONOO}^{-}\right)$[230]. Reaction occurs via a two-step mechanism involving a tyrosyl radical formation (arising from the one-electron oxidation of the phenolic ring of Tyr by $\cdot \mathrm{OH}, \mathrm{NO}_{2}, \mathrm{CO}_{3} \cdot{ }^{-}$radicals, oxo-metal compounds $\left(\mathrm{O}=\mathrm{Mn}^{\mathrm{IV}}\right)$, compounds I and II of hemoperoxidases, or lipid-derived radicals) followed by its reaction with $\mathrm{NO}_{2}$ to form 3-nitrotyrosine (Scheme 5) [230,231]. Peroxynitrite does not directly react with tyrosine residues; however, the peroxynitrite-derived radicals $\cdot \mathrm{OH}, \mathrm{NO}_{2}$, and $\mathrm{CO}_{3} \cdot{ }^{-}$play an essential role in tyrosine oxidation and nitration. Protein 3-nitrotyrosine is an established biomarker of oxidative stress in vivo, observed in such pathologies as neurodegeneration, cardiovascular disease, and cancer. Remarkably, this irreversible modification can result in dramatic changes in protein structure and can mediate not only the loss, but also the gain, of a new functionality of the affected protein [230].

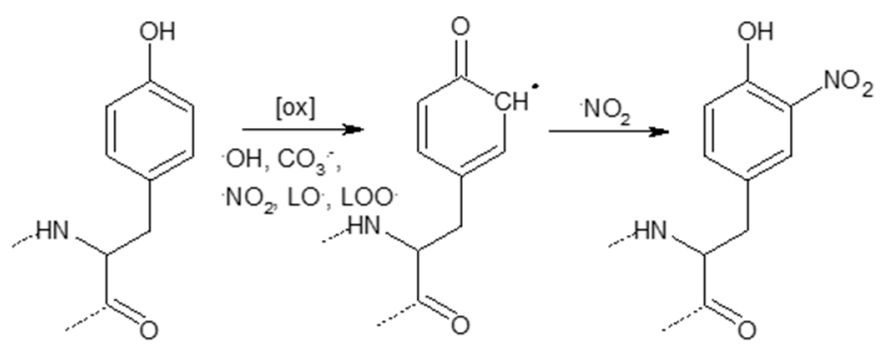

Scheme 5. Tyrosine nitration through intermediate tyrosyl radical formation followed by a nitration reaction (LOO, LO-—lipid-derived radicals, lipid-peroxy-radicals, and lipid-alkoxy-radicals, respectively).

Two-dimensional electrophoresis revealed that the murine cardiac $20 \mathrm{~S}$ proteasome can exist under physiological conditions modified by nitrotyrosine at subunits $\alpha 1, \alpha 2, \alpha 7, \beta 1, \beta 3, \beta 5$, and $\beta 7$, in line with the important signaling role of nitric oxide, especially in cardiac tissue [127]. Exposure to peroxynitrite $\left(\mathrm{ONOO}^{-}\right)$, a powerful oxidant, may not lead unequivocally to the loss of proteasomal catalytic activity. However, its upregulation can also trigger pathological consequences. The increased $26 \mathrm{~S}$ proteasomal activity observed in the purified proteasome preparations, endothelial cells, and mouse models of hypertension, diabetes, and dyslipidemia was shown to be related to the $\mathrm{ONOO}^{-}$-mediated protein tyrosine nitration of 19S RP $[232,233]$. This was accompanied by the accelerated degradation of molecules (such as thioredoxin, GTP cyclohydrolase I, and tetrahydro-L-biopterin) that are essential for endothelial homeostasis and the suppression of oxidative stress, thereby resulting in concomitant endothelial dysfunction. The proposed mechanism of activation involves the promotion of $26 \mathrm{~S}$ assembly through the introduction of 3-nitrotyrosine modification into the 19S RP subunit, Rpt4. However, it was not excluded that modification of the substrate proteins by $\mathrm{ONOO}^{-}$could also promote their selective recognition and degradation by the proteasome [234], a mechanism that may also contribute to the enhanced downregulation of crucial protective enzymes. 
Table 3. (a) Posttranslational modifications of proteasome: Carbonylation and 4-hydroxynonenalyation;

(b) Posttranslational modifications of proteasome: Glycation and tyrosine nitration.

(a)

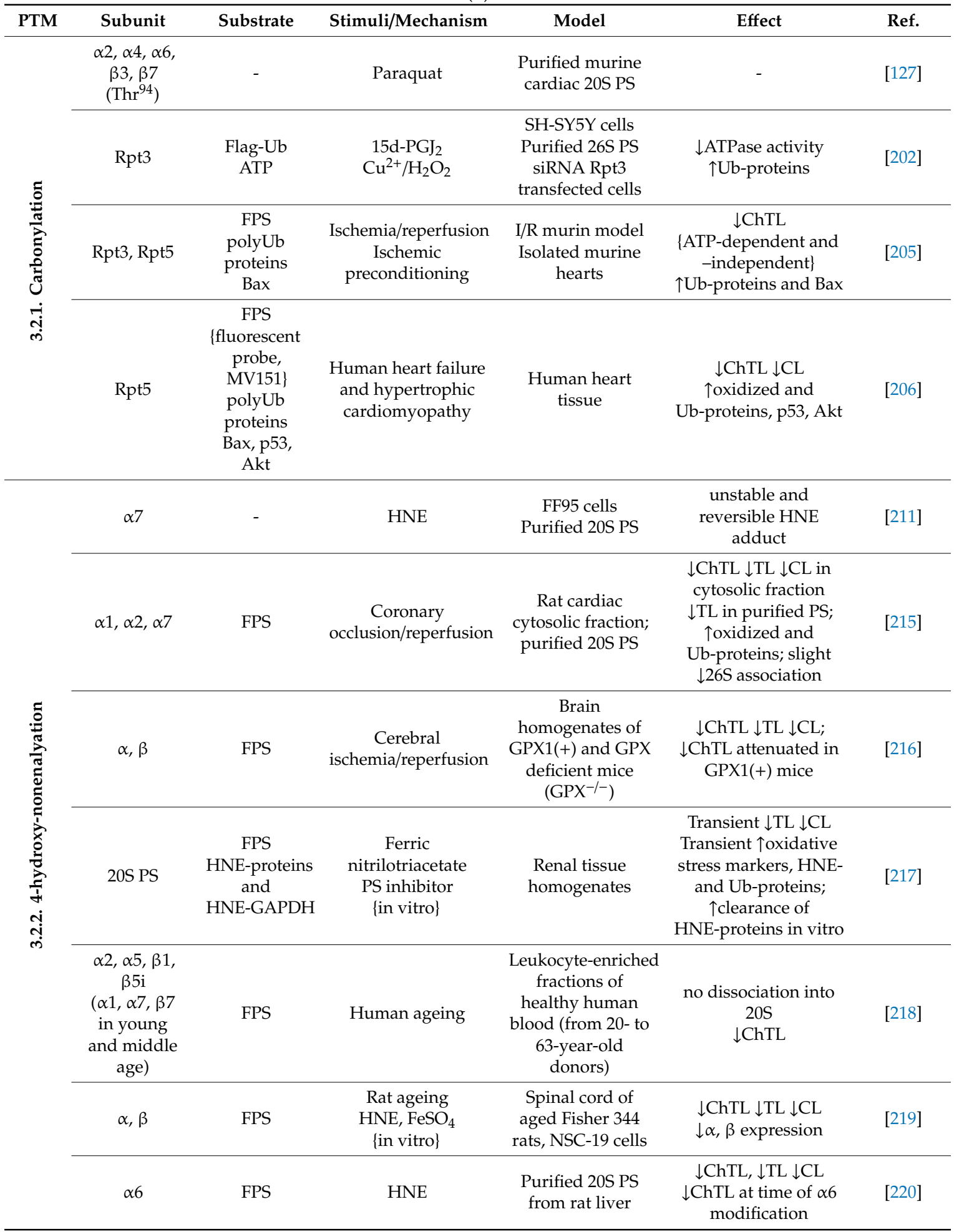

ChTL, chymotrypsin-like activity; TL, trypsin-like activity; CL, caspase-like activity; FPS, fluorogenic peptide substrate; $\mathrm{PS}$, proteasome; $\mathrm{RP}$, regulatory particle; $\mathrm{I} / \mathrm{R}$, ischemia/reperfusion; $15 \mathrm{~d}-\mathrm{PGJ} \mathrm{J}_{2}, 15$-deoxy- $\Delta^{12,14}$-prostaglandin $\mathrm{J}_{2}$; HNE, 4-hydroxy-2-nonenal; GPX, glutathione peroxidase; $\mathrm{Ub}$, ubiquitin; Bax, proapoptotic protein; Akt, protein kinase $\mathrm{B}$. 
(b)

\begin{tabular}{|c|c|c|c|c|c|c|}
\hline PTM & Subunit & Substrate & Stimuli/Mechanism & Model & Effect & Ref. \\
\hline \multirow[t]{2}{*}{ 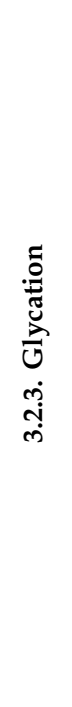 } & $\begin{array}{l}\beta 2\{\text { in vivo }\} \\
\beta 2, \beta 4, \beta 5 \\
\{\text { in vitro\} }\end{array}$ & FPS & $\begin{array}{c}\text { AGE-BSA, MGO, } \\
\text { GA \{purified PS\} } \\
\text { HG, MGO, GO, GA } \\
\text { \{cells\} }\end{array}$ & $\begin{array}{c}\text { C57BL/6 WT mice, } \\
\text { diabetic Ins2 }{ }^{\text {Akita }}, \\
\text { GLO1-knockdown } \\
\text { (GLO1-KD), and } \\
\text { STZ diabetic and } \\
\text { GLO1-knockdown } \\
\text { diabetic } \\
\text { (GLO1-KD-STZ) } \\
\text { mice; } \\
\text { EA-hy.926 and } \\
\text { bovine retinal } \\
\text { endothelial cells, } \\
\text { purified 20S PS } \\
\text { from cells }\end{array}$ & $\begin{array}{c}\downarrow \text { ChTL in cells } \\
\downarrow \text { ChTL in purified PS } \\
\text { \{no effect of AGE-BSA\} } \\
\downarrow \text { ChTL } \downarrow \text { TL } \downarrow \text { CL } \\
\text { \{kidney diab. Ins2 }{ }^{\text {Akita }} \\
\text { mice } \\
\downarrow \text { ChTL \{aorta diab } \\
\text { Ins2 } 2^{\text {Akita }} \text { mice\} } \\
\downarrow C h T L\{\text { kidney } \\
\text { GLO1-KD, STZ diab. } \\
\text { and GLO1-KD-STZ\} } \\
\uparrow \text { Ub-proteins in vivo } \\
\text { and in vitro } \\
\downarrow 19 S \text { Rpn10 }\{\text { in vivo\} } \\
\downarrow 19 S \text { RP }\{\text { in vitro\} }\end{array}$ & [224] \\
\hline & - & FPS & $\begin{array}{c}\text { HG, MGO, GO, GA, } \\
\text { AGE-BSA \{BSA } \\
\text { pre-glycated with } \\
\text { glucose, MGO, GO, } \\
\text { GA\} }\end{array}$ & $\begin{array}{l}\text { J774A.1 mouse } \\
\text { macrophage cell } \\
\text { extracts }\end{array}$ & $\begin{array}{c}\uparrow C h T L \uparrow T L \uparrow C L \\
\{\mathrm{MGO}, \mathrm{GO}, \mathrm{GA}\} \\
\downarrow C h T L \downarrow C L \uparrow T L \\
\{\text { AGE-BSA }\}\end{array}$ & [227] \\
\hline \multirow{4}{*}{ 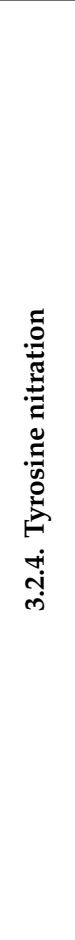 } & $\begin{array}{c}\alpha 1, \alpha 2, \alpha 7, \\
\beta 1, \beta 3, \beta 5, \\
\beta 7\end{array}$ & - & - & $\begin{array}{l}\text { Purified murine } \\
\text { cardiac 20S PS }\end{array}$ & - & [127] \\
\hline & Rpt4 & $\begin{array}{c}\text { FPS } \\
\text { Endogenous } \\
\text { BH4, } \\
\text { GTPCH and } \\
\text { Trx }\end{array}$ & $\begin{array}{l}\text { STZ, Angiotensin II, } \\
\text { HFD, MG132 } \\
\text { \{in vivo\}; ONOO-, } \\
\text { uric acid, L-NAME, } \\
\text { MG132 \{in vitro\}, } \\
\text { Tempol, MG132, } \\
\text { SNP, Ach }\{\text { ex vivo\} }\end{array}$ & $\begin{array}{l}\text { C57BL/6J WT, } \\
\text { LDLr }^{-/-} \text {knockout } \\
\text { and PA700/S10B } \\
\text { knockdown mice; } \\
\text { HUVEC WT and } \\
\text { p67-DN Nox cells, } \\
\text { purified 26S PS }\end{array}$ & $\begin{array}{c}\uparrow \text { ChTL } \\
\text { \{ATP-dependent\} } \\
\uparrow 26 S \text { PS assembly } \\
\downarrow \text { Levels of BH4, } \\
\text { GTPCH I and Trx } \\
\downarrow \text { Ach-induced vessel } \\
\text { relaxation } \\
\text { Restorative effect of } \\
\text { antoxidants and PS, } \\
\text { Nox, NOS inhibition }\end{array}$ & {$[232,233]$} \\
\hline & 20S PS & $\begin{array}{c}\text { FPS, } \\
\beta \text {-casein }\end{array}$ & $\mathrm{ONOO}^{-}$ & $\begin{array}{c}\text { Bovine brain 20S } \\
\text { PS and thymus } \\
\text { 20S iPS }\end{array}$ & $\begin{array}{c}\uparrow C h T L \uparrow C L \uparrow B r A A P \\
\downarrow T L: 20 S \text { PS } \\
\downarrow C h T L \downarrow C L \downarrow \text { BrAAP: } \\
20 S \text { iPS } \\
\downarrow \beta \text {-casein degradation } \\
\text { by iPS }\end{array}$ & [221] \\
\hline & $\begin{array}{c}20 \mathrm{~S} \text { PS } \\
\{\text { high level } \\
\left.\mathrm{ONOO}^{-}\right\}\end{array}$ & FPS & $\begin{array}{l}\text { Molsidomine } \\
\{\text { in vivo }\} \\
\text { ONOO }^{-} \\
\text {SIN-1 } \\
\text { SNAP }\end{array}$ & $\begin{array}{l}\text { Mouse liver, Hep } \\
\text { G2 cells, liver } \\
\text { soluble fractions, } \\
\text { crude and purified } \\
\text { PS preparations }\end{array}$ & $\begin{array}{c}\uparrow \text { ChTL }\{\text { low level } \\
\left.\text { ONOO }^{-}\right\} \\
\downarrow \text { ChTL }\{\text { high level } \\
\left.\text { ONOO }^{-}\right\} \\
\text {ChTL stimulated by } \\
\text { ATP and PA28 }\{\text { low } \\
\left.\text { level } \mathrm{ONOO}^{-}\right\}\end{array}$ & [235] \\
\hline
\end{tabular}

ChTL, chymotrypsin-like activity; TL, trypsin-like activity; CL, caspase-like activity; FPS, fluorogenic peptide substrate; PS, proteasome; iPS, immunoproteasome; RP, regulatory particle; AGE-BSA, pre-glycated bovine serum albumin; MGO, methylglyoxal; GO glyoxal; GA, glyceraldehyde; HG, high glucose; GLO1, glyoxalase I; Ub, ubiquitin; BH4, tetrahydro-L-biopterin; GTPCH, GTP cyclohydrolase I; Trx, thioredoxin; STZ, streptozotocin; HFD, high fat diet; Ach, acetylcholine; p67-DN Nox, overexpression of a dominant-negative form of the p67 NADPH oxidase subunit; NOS, NO synthase; BrAAP, branched amino acid preferring peptidase (occurs at sites in the 20S PS catalyzing ChTL and CL activities); SIN-1, 3-morpholinosydnonimine hydrochloride; SNAP, S-Nitroso-N-acetylpenicillamine; molsidomine, a sydnonimine acting as a heterocyclic direct NO donor; L-NAME, $\mathrm{N}^{\omega}$-Nitro-L-arginine methyl ester; $\mathrm{LDLr}^{-/}$, LDL receptor knockout mice; PA700/S10B, siRNA knockdown of PA700/S10B of the 26S PS.

However, higher concentrations of peroxynitrite were shown to modify the $20 \mathrm{~S}$ core particle proteasome, resulting in the alteration of its proteolytic activities [221]. In this regard, the constitutive and inducible forms of the $20 \mathrm{~S}$ proteasome isolated from bovine brain and thymus, respectively, showed differential sensitivities to peroxynitrite-induced oxidation, measured as 3-nitrotyrosines and tryptophan residue oxidation [221]. The inducible proteasomes possessing a larger accessible 
hydrophobic surface showed more profound oxidative modifications, resulting in a decrease in proteolytic functions, shown as a suppressed $\beta$-casein degradation rate, as well as reduced peptidase activities. By contrast, an increase in peptidase activities was documented for the less oxidized constitutive form but without affecting its caseinolytic activity. Furthermore, lower concentrations of peroxynitrite or its donor SIN-1 enhanced proteasome activity, whereas higher levels caused it to decline, as confirmed in Hep G2 cells, mouse liver, liver soluble fractions, and crude and purified proteasome preparations [235]. It has been suggested that a low amount of $\mathrm{ONOO}^{-}$generated under mild oxidative stress induces slight conformational changes in the active sites of the $20 \mathrm{~S}$ proteasome, which facilitates the stimulatory effects of PA28 and 19S, thereby enhancing proteasome activity. High concentrations of $\mathrm{ONOO}^{-}$generated under severe oxidative stress might, however, strongly affect the conformation of the $20 \mathrm{~S}$ proteasome, thus limiting the accessibility of either PA28 or 195 regulatory particles to the $20 \mathrm{~S}$ proteasome.

Hence, the sensitivity of the proteasome to peroxynitrite seems to be tissue-specific, dose-dependent, and likely affected by the relative content of the constitutive proteasome to that of the immunoproteasome in certain organs.

\section{Proteasome and Protein Aggregates}

Protein folding is a process that occurs both co-translationally and post-translationally, driven by the formation of hydrophilic interactions within a polypeptide chain, the collapse of hydrophobic regions, and the burial of electrostatic interactions [236,237]. The folded conformation of a protein (with exposed hydrophilic surface and hidden hydrophobic patches) represents the most thermodynamically favorable state. However, under certain circumstances, unfolded conformation can be promoted. This leads to a state where intermolecular interactions become dominant over intramolecular ones, resulting in the aggregation of proteins. The aggregation process resembles the reactions of chain polymerization, where the sites of aggregate growth represent the active centers of a chain reaction [238]. In vivo, the misfolding of proteins can be promoted either by biological factors (e.g., genetic mutation, erroneous translation, and transcription) or induced through physical changes in the environment (such as fluctuations in $\mathrm{pH}$ and temperature or oxidative and osmotic stress) [239]. Furthermore, aggregation can arise from the misincorporation of a protein into membranes or the disassembly of subunits in protein complexes, thereby allowing the interaction of normally unexposed hydrophobic domains.

Degenerative disorders, such as Huntington's, Parkinson's, and Alzheimer's disease; systemic amyloidosis; spinocerebellar ataxia; cystic fibrosis; and prion encephalopathies are collectively called 'conformational diseases' due to their common characteristic, the presence of a structural alteration of specific proteins that enhances their propensity to aggregate. There might be diverse structural presentations of aggregates, including amorphous ones. However, the highly ordered fibrillar deposits termed 'amyloids' represent the most common form of aggregates in these diseases. The common physicochemical features of amyloids include a fibrillar morphology (long, unbranched, and often twisted structures a few nanometers in diameter), a predominantly $\beta$-sheet secondary structure, insolubility in common solvents and detergents, and protease resistance. The aggregation process is promoted by an increase in the concentration of disease proteins and is also facilitated by their covalent modification (e.g., phosphorylation of $\alpha$-synuclein or its oxidative modification during the ageing process) [240]. The 'seeding-nucleation polymerization model' describes how amyloid aggregates are formed in vivo [241-243]. During the initial, 'lag' or 'nucleation phase', a thermodynamically unfavorable process occurs when the monomers undergo self-association into $\beta$ sheet structures, thus creating globular oligomeric species termed 'nuclei' or 'seeds'. The following 'growth phase' is characterized by the fast recruitment of monomers and the formation of species with diverse sizes, including protofibrils. Protofibrils, species with a curved morphology, further organize into protofilaments that finally pack into mature fibrils. The addition of preformed nuclei or seeds can accelerate the nucleation step, even if the seeds are heterologous. During the last 'saturation phase', 
a dynamic equilibrium is established between monomeric species and high-molecular-weight fibrils. This model describes the formation of highly ordered amyloid fibrils; however, amorphous species can also arise from the initial oligomeric complexes. These amorphous aggregates usually comprise different proteins, with each protein not necessarily associated with a diseased state. However, the amyloid fibrils and oligomers are typically composed of one disease protein, and dynamic interconversions between individual types of aggregated assemblies have been suggested to occur [236]. However, in living systems, these interconversions appear to be controlled by diverse molecular chaperones and proteolytic enzymes. A study employing size exclusion chromatography and MS-based proteomics suggested that the aggregation of oxidized proteins can be very different from the polymerization process commonly associated with neurodegenerative diseases [244]. This likely involves the adsorption of oxidatively damaged proteins onto the surface of existing, native protein complexes, thus compromising their function.

Although the aggregation of identical or very similar polypeptides is a more favorable process [245], heterologous aggregation can also proceed in a cooperative way [239]. Moreover, aggregated non-disease proteins generated over the course of ageing have been proposed to induce disease protein aggregation, likely via a so-called 'cross-seeding mechanism' [246]. The amorphous insoluble aggregates represent disordered protein assemblies. These assemblies have been termed, similar to the amorphous assemblies observed in bacteria, 'inclusion bodies', to distinguish them from highly ordered amyloids. Nevertheless, bacterial inclusion bodies have been shown to contain amyloid-like structures and possess amyloid-like properties [247]. Considerable evidence suggests that intermediate soluble oligomers and protofibrils are more toxic than insoluble mature assemblies. The presence of hydrophobic patches on proteins facilitating their interaction with the membrane, membrane proteins, or other macromolecules has been suggested as a reason for the enhanced toxicity of these intermediates [248,249]. However, these hydrophobic patches are hidden when oligomers become associated within high-molecular-weight aggregates.

The aggregated crosslinked proteinaceous material termed 'lipofuscin' belongs to the main forms of intracellular inclusions. Lipofuscin accumulates during physiological ageing as a consequence of physiological trade-offs and random damage. Because of its gradual accumulation over one's lifetime, lipofuscin has long been known as the autofluorescent 'ageing pigment' or 'wear and tear pigment' [250]. Lipofuscin is mainly present in postmitotic cells, such as cardiomyocytes and neurons. The electron microscopy of neuronal lipofuscin revealed its biphasic structure consisting of an electron-dense pigment matrix associated with electron-lucent lipid droplets [251]. The ultrastructure of the pigment matrix is usually described as granular. In neurons, however, it is mainly composed of more or less tightly packed trilaminar linear formations [251]. Pentilinear short curved structures were detected in the neuronal lipofuscin of animal species. In humans, however, lipofuscin showed brain region-specific appearances, likely reflecting distinct metabolic features of specific neurons. Thus, the structural and chemical features of lipofuscin may be closely connected to the particular oxidative and glycolytic metabolism of distinct cells and their turnover of the produced enzymes, transmitters, or other messenger molecules. The chemistry of lipofuscin formation involves mostly iron-catalysed oxidation and polymerization reactions. These involve proteins and lipids originating from the auto- or hetero-phagocytosed materials present in the lysosomal lumen [252]. Covalently cross-linked proteins comprise 30-70\% of lipofuscin content, and the second main components are lipids $(20-50 \%)$. Starting from the fifth decade of life, lipofuscin-bound sugar residues were also detected in human samples $[253,254]$. The content of metals, including $\mathrm{Fe}, \mathrm{Cu}, \mathrm{Zn}, \mathrm{Al}, \mathrm{Mn}$, and $\mathrm{Ca}$, can reach up to $2 \%$. The cross-links originate from condensation reactions between the amino groups and carbonyls of the aldehydic products of lipid peroxidation or carbohydrates. These reactions represent the initial steps in the formation of structures, such as 1,4-dihydropyridines or 2-hydroxy-1,2-dihydropyrrol-3-ones, which are responsible for the autofluorescent properties of lipofuscin. The presence of cross-linked peptides favors lipofuscin's resistance to degradation and accumulation over time [255]. Alternatively, these crosslinks can be generated through the interactions of tyrosyl or tryptophanyl radicals [256]. 
Although it is mainly localized to the lysosomes, lipofuscin can also be formed in the cytosol in a lysosome- and autophagy-independent manner [257]. Analogously, the formation of cytosolic lipofuscin involves the oxidative and crosslinking reactions that interfere with proteolytic and disaggregation processes. By contrast, the autophagy process was shown to mediate its sequestration into the lysosomes. This indicates that the lysosomal storage of lipofuscin might be a putative cellular defence mechanism reducing its cytotoxic effects in the cytosol [257]. Inclusion bodies may also serve a protective function by increasing the degradation of the aggregated protein species if these fail to be handled by chaperones and proteasomal complexes. These structures, mostly found in cultured eukaryotic cells, are typically located at the perinuclear region. They are termed 'aggresomes' and provide the sequestration of aggregated, misfolded, and toxic proteins through a process controlled via dynein/dynactin-mediated microtubule-based transport [258-260]. The findings in the field of the biogenesis of aggresomes also argue against the generally accepted view of aggregation in vivo as a passive process and emphasize the characteristics of the active ATP- and ubiquitin-requiring processes. The aggresomes facilitate the autophagic clearance of protein aggregates at the microtubule organizing centre where autophagosomes and lysosomes are concentrated. The aggresome/autophagy pathway features ubiquitin-dependent machinery and involves several regulatory proteins, including histone deacetylase 6 (HDAC6), E3 ubiquitin-protein ligase Parkin, deubiquitinating enzyme Ataxin-3, and the ubiquitin-like protein Ubiquilin-1. The intermediate filament proteins, such as vimentin form the cage-like structures encircling the aggresomes, contribute to the stability of the aggresomes and likely regulate their interactions [261]. Corresponding to microtubule-mediated transport, other cytoskeleton-related proteins, such as actin and tubulin, were also shown to associate with aggresomes. The cellular chaperones and components of the UPS, including ubiquitinating enzymes, proteasome subunits, and proteasome activators, are recruited to the aggresomes for enhanced protein folding and degradation within these structures [262]. The proteasome, via its deubiquitinating enzyme subunit Rpn11/PSMD14/Poh1, which is resident in the 19S proteasome regulatory particle, was shown to stimulate aggresome clearance by producing unanchored free ubiquitin chains that bind and activate HDAC6. HDAC6, in turn, induces an actinomyosin system that promotes the deaggregation and autophagic clearance of the aggresome [263].

Several studies provided evidence for the similarities between the aggresomes and intracellular inclusions typically seen in protein deposition diseases. The centrosome markers $\gamma$-tubulin and pericentrin, components of UPS; heat shock proteins, such as HSP70 and HSP90; and regulatory proteins of the aggresome machinery-Ubiquilin-1, HDAC6, Parkin, Ataxin-3-are also present in the pathological inclusion bodies [264-267]. The overexpression of proteins such as Parkin, $\alpha$-synuclein, and huntingtin, which are associated with neurodegenerative diseases, was shown to cause aggresome formation in proteasome-impaired cells [268-270]. Lewy bodies, the intracytoplasmic inclusions in Parkinson's disease, were also shown to share some commonalities with aggresomes [271]. These similarities included biogenesis through the microtubule-mediated transport of ubiquitinated proteins to the centrosome where they coalesce, as well as the tendency to afford cytoprotective effects. Furthermore, Lewy body formation has been suggested to be an aggresome-related adaptive event in response to increasing levels of abnormal proteins in neurons. In this regard, Lewy bodies were hypothesized to be non-functional aggresomes that failed due to excessive protein production or defects of the proteasomal components within these structures [271].

Aside from these findings, initial studies have suggested that the impairment of UPS provides one of the mechanisms through which protein aggregates can exert their proteotoxic effects [272]. The simplest model predicts that aggregates will inhibit the proteasome through direct interactions and that this inhibition depends on the aggregated structure in general, not on the unique structural motif of an aggregated protein [272,273]. Consistently, co-immunoprecipitation experiments and analyses of post-mortem brain tissue have revealed accumulated ubiquitinated substrates colocalized in inclusion bodies together with UPS components [273-276]. These findings are suggestive of an unsuccessful attempt of the cells to defeat aggregation through engagement with degradation processes. 


\subsection{Inhibition vs. Immobilization}

In biotechnologies, the confinement of an enzyme to a polymer carrier support is termed 'enzyme immobilization'. An immobilized molecule is one whose movement in space has been restricted either completely or to a small and limited region via attachment to a solid structure. Besides synthetic polymer materials, biomaterials made from proteins such as collagen, albumin, and ferritin, serve as efficient carrier matrices [277]; interestingly, amyloid fibrils produced from insulin, crystalline, and $\alpha$-synuclein also represent promising nanoscaffolds for use in biotechnologies [278-280]. In this regard, bacterial inclusion bodies, which are functional and non-toxic amyloids occurring in recombinant bacteria, have also been considered promising functional materials for a broad spectrum of applications [281,282]. Moreover, in general, the enzymes in cellular systems are proposed to be in an immobilized state through association with highly organized cellular materials. This was suggested to result in modification of their catalytic features compared to the free enzymes in a solution [283].

The general principles used for enzyme fixation to insoluble support include entrapment, physical adsorption (involving weak forces, including hydrogen bonds and van der Waals forces), ionic binding, and covalent or affinity binding [284]. The interactions used for immobilization can be reversible (in the case of physical adsorption, ionic linkages and affinity binding) or irreversible (in the case of stable covalent binding and the entrapment method). Reverse processes can be achieved via changes in the $\mathrm{pH}$, temperature, or ionic strength of the solution. For comparison, both irreversible and reversible sequestration of the proteasome and other protein components into aggregates have been reported $[285,286]$. It can be speculated that some of these mechanisms may also likely apply to interactions of the proteasome with the aggregated protein matrix. As already mentioned in Sections 3.1 and 3.2, the proteasome can expose reactive groups, such as thiol-moieties and carbonyls. Moreover, these groups may also be present on the surface of the aggregated protein matrix. Interestingly, the bifunctional reactive carbonyl compound glutaraldehyde represents a frequently used cross-linker in immobilization biotechnologies. Furthermore, the reversible covalent immobilization of enzymes can also be achieved via the introduction of disulfide bonds. Correspondingly, covalent binding of the proteasome to highly glycated BSA resulting in proteasomal inhibition was suggested by Moheimani et al. [227]. By contrast, the treatment of lipofuscin with reducing agents such as DTT or $\mathrm{NaBH}_{4}$ was not shown to alter its inhibition effect on proteasomal activity, thus excluding the possibility of a reaction with hydroperoxides or aldehydes on the lipofuscin surface [287].

On the surface of the lipofuscin, fixation of the enzyme on a metal-chelated matrix is also a basic technique for enzyme immobilization. This fixation is based on the ability of the nucleophilic group in the protein side chains of Cys, His, and Trp to substitute weakly bonded ligands in the complexes of metals such as $\mathrm{Cu}, \mathrm{Zn}, \mathrm{Fe}, \mathrm{Ni}$, and Ca precipitated on the surface of a polymer carrier [288]. In principle, the transition metal ions are considered strong Lewis acids and interact with strong Lewis bases, such as nitrogen and oxygen. The proteins involved in several age-dependent neurodegenerative disorders ( $\beta$ amyloid and $\tau$ protein in Alzheimer's disease, $\alpha$-synuclein in Parkinson's disease, the prion protein in Prion disease, huntingtin with an expansion of the polyglutamine (polyQ) repeat region near the N-terminus in Huntington disease, SOD1 in amyotrophic lateral sclerosis, frataxin in Friedreich's ataxia, and $\alpha$-B-crystallin in cataracts) were suggested to present ligands for $\mathrm{Cu}^{2+}$ or $\mathrm{Fe}^{3+}$ ions $[289,290]$. For illustration, the three histidine residues in amyloid $\beta$ are all involved in metal coordination, along with an oxygen ligand resulting in the formation of strongly reducing metalloproteins. The incorporation of traces of transition metals by the aggregates extensively promotes redox chemical reactions, resulting in the enhancement of their cytotoxicity. Similarly, the iron inclusions of lipofuscin were postulated to result in a redox-active surface catalyzing the Fenton reaction [291]. Consequently, these observations raise the question of whether the metal sequestration by protein aggregates could also facilitate the proteasome's confinement to its surface.

In many instances, the lower activity of an immobilized enzyme or the deterioration of other catalytic features compared to the soluble enzyme is observed. A decrease in enzyme activity following its immobilization is often attributed to conformational changes in the enzyme structure, steric hindrance 
in the immediate vicinity of the enzyme molecules and prevention of interactions with other enzyme molecules, rigidification of conformation, diffusional effects, interactions between substrate and the scaffold, or unfolding of the enzyme on its surface [292,293]. Inactivation may also occur as a result of adsorption interactions involving active site residues. In that case, the active site may be sterically blocked, and the activity may be totally or partially lost. By analogy, an interaction involving a catalytic site with relatively soluble aggregated or aggregation-prone proteins and consequent 'clogging' or 'choking' of the proteasome was also shown to be the cause of proteasomal inhibition [294]. The nanogold-labeled amyloid $\beta$ peptide was shown to be bound within the inner catalytic compartment of the proteasome [295]. However, in cases of larger aggregates, the binding of the proteasome to the lateral surface and its subunits may be a sterically more favorable process. In this regard, by employing a $\beta$-sheet-rich prion protein, Andre and Tabrizi [296] proposed a general model for proteasome interactions with the aggregated misfolded proteins in neurodegenerative diseases (Figure 2). Based on this hypothesis, through binding to the lateral surface, the protein aggregates can exert an antagonistic effect on $20 S \alpha$-gate opening governed by the 19S subunits and and thus favor a closed conformation. Conversely, the selective binding of Rpt5/S6', a subunit of the $19 \mathrm{~S}$ regulator binding polyubiquitinated proteins, to aggregated $\alpha$-synuclein was suggested to mediate blocking of the $26 \mathrm{~S}$ proteasome [297]. As monomeric $\alpha$-synuclein showed a less potent inhibitory effect on the degradation of proteasomal substrates, further hypotheses regarding the cause of inhibition were derived from the steric properties of large aggregated structures. These included the prevention of unfolding proteins associated with proteasomal degradation and physical blocking of the pore of the 19S cap. Similarly, neither unphosphorylated recombinant $\tau$ nor phosphorylated isolated $\tau$ proteins were capable of inhibiting proteasome activity [273]. However, such inhibition was only achieved with high-molecular-weight paired helical filaments assembled from the $\tau$ protein.

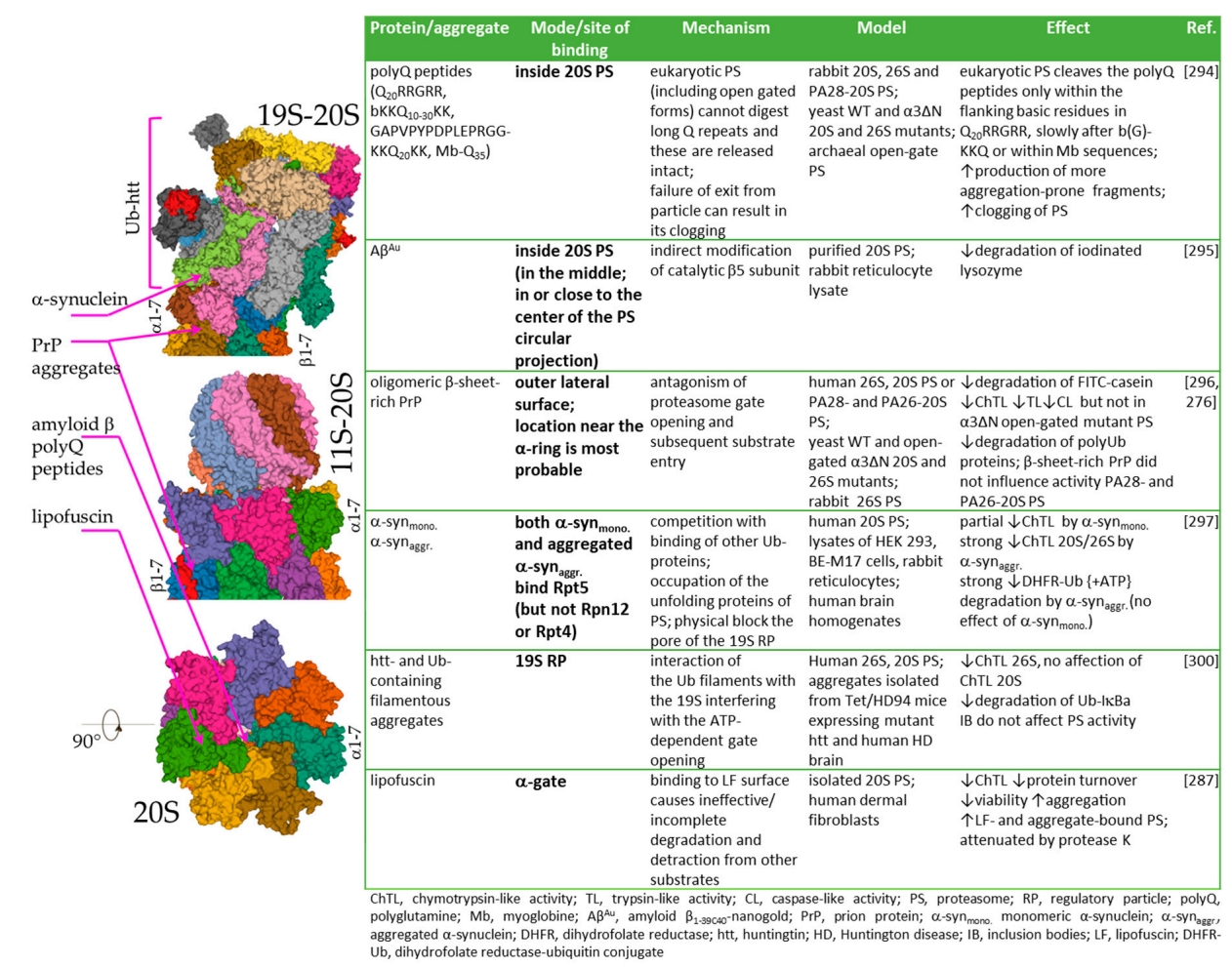

Figure 2. Proposed mechanisms of interaction of the proteasome with aggregated proteins. Aggregated proteins as well as monomers were shown to interact with the lateral side of CP or the 19S regulatory particle. PolyQ repeats lacking $\mathrm{Ub}$ modification or amyloid $\beta$ peptide can occupy the internal proteasome cavity. Images are from the RCSB PDB (rcsb.org) of PDB ID: 5A5B [65,66], 6XMJ [65,298], $1 G 0 U[65,299]$. 
The properties of the aggregate surface could be a key factor for the inhibitory effect. The ubiquitincontaining filamentous aggregates of the polyQ-containing protein, huntingtin, specifically inhibited the activity of the 26S, but not 20S, proteasome in a non-competitive manner [300]. The inhibition mechanism involved interaction of the ubiquitylated sites with subunits of the $19 \mathrm{~S}$ caps. On the other hand, a lack of the poly-ubiquitin modification in the aggregates of synthetic polyQ peptides was likely responsible for the deficiency of the interference with the 26S proteasome's function [301]. In analogy, affinity binding via pre-coupling of the support to an affinity ligand is also one of the physical methods used for the immobilization of enzymes. This principle utilizes the selectivity between complementary biomolecules, and its key advantages include selectivity of interactions and control over the orientation of the immobilized enzyme. Similarly, binding of the proteasome to hydrophobic oligopeptides exposed on the surface of lipofuscin was proposed to be responsible for lipofuscin's inhibition [287]. However, a reduction in affinity sites with protease $\mathrm{K}$ treatment decreased proteasomal inhibition and binding to lipofuscin. The hydrophobic nature of the affinity binding sites likely also affects enzyme activity. Hydrophobic supports have been generally recognized as materials that have a very negative impact on immobilized enzyme activity because of uncontrolled enzyme-support interactions. In particular, the interactions of reversibly exposed hydrophobic pockets within enzymes featuring hydrophobic surfaces were suggested to lead to the stabilization of the denatured conformation of the enzyme [302].

Physical phenomena related to the heterogenic enzymic environment, such as local changes in $\mathrm{pH}$ or substrate concentration, represent possible additional factors contributing to the modified performance of an immobilized enzyme [283]. Due to partitioning effect, the polymeric carrier can either attract or repel the substrates, inhibitors, effectors, or products. The most common example is the partitioning of ionic species to poly-ionic matrices, which occurs in low ionic strength solutions. In this way, the polyanionic polymers may attract not only cationic substrates but also protons, resulting in a lower local $\mathrm{pH}$ around the enzyme. Processes such as an increase in the local concentration of a protein substrate, neutralization of its positive charges, and changes in its conformation were suggested to be driving forces behind the protein aggregation induced by polyanionic biopolymers, including heparan, anionic lipids, and nucleic acids [303,304]. In addition, local changes in $\mathrm{pH}$ in the proximity of the carrier (arising from such processes as the local reactions of an enzyme, partitioning effects, and diffusional limitations of $\mathrm{H}^{+}$) can also result in a shift of the $\mathrm{pH}$ optimum of the immobilized enzyme.

Diffusional effects can be observed in cases of a slow diffusion rate of molecules in an unstirred solution and are critical in case of the high activity of an immobilized enzyme [305,306]. These effects result in the establishment of a concentration gradient of substrates and products in the enzyme microenvironment. External diffusional limitations are caused by the rate of diffusion of the substrate being restricted in the film of the poorly mixed fluid's surrounding support, the so-called 'Nernst-Planck layer', and can be diminished by increasing the stirring rate. These diffusional constraints also likely have an impact in a cellular milieu representing an unstirred system. Due to the microenvironment's effects, especially in the case of diffusion-controlled reactions, the immobilized enzyme can adopt complex non-Michaelian kinetic behavior, whose kinetics are generally referred to as 'apparent' kinetics. If diffusional limitations are absent, the 'inherent' kinetic parameters are obtained. Here, partition effects still play a significant role. However, in the absence of partition effects, the 'intrinsic' kinetic parameters apply, which are comparable to the parameters of the soluble enzyme.

\subsection{Proteasome Immobilisation In Vivo: Detriments vs. Benefits?}

In biotechnologies, the main advantage of immobilizing an enzyme that sometimes outweighs the adverse effects on its activity is stabilization of the enzymes, which is linked to increased enzymatic conformational rigidity. In this way, the immobilized enzyme may gain improved stability against $\mathrm{pH}$ and temperature fluctuations, as well as denaturing agents, resulting in an increase of its lifetime. For instance, an amyloid hydrogel made of $\alpha$-synuclein protein fibrils was shown to protect entrapped horseradish peroxidase from a loss of activity due to multiple catalysis and heat treatments [280]. 
For proteases, immobilization can also prevent autolysis through a restriction of intramolecular interactions [307]. Proteasomal intramolecular autolysis assists in the maturation process of core particles, removing the propeptides attached to the Thr1 in precursor $\beta$ subunits, which then serve as $\mathrm{N}$-terminal nucleophiles in substrate hydrolysis [308]. Nevertheless, the autolytic breakdown of purified proteasomes was also described in response to urea-induced damage, likely due to conformational changes, which is suggestive of a specific regulatory mechanism in vivo [309]. Moreover, the degradative process was enhanced by ATP.

Nevertheless, immobilization can also result in enhancement of the catalytic activity of an enzyme. This can be achieved by stabilizing a more active conformation. For instance, the immobilization of lipases on hydrophobic surfaces can lead to the stabilization of an open conformation and interfacial activation [310]. In certain cases, immobilization has been reported to prevent or at least diminish enzyme inhibition via blocking or distortion of the inhibition site. In the case of multisubunit enzymes, immobilization can also prevent subunit dissociation. The attachment of enzymes to the appropriate surface can also constrict their activity at a particular site and thus greatly enhance their local concentration. In this regard, redistribution of the components of the proteasome from the total cellular environment into huntingtin aggregates was shown [311]. However, this led to limited degradation of important proteasomal substrates.

Furthermore, immobilization may greatly alter the physicochemical properties of the enzyme surroundings, modifying the hydrophobicity or hydrophilicity of the environment, which can result in a partition of different compounds away from or towards the enzyme. This effect was shown to be associated even with protection of the enzyme against oxidative reactions by lowering the local concentration of oxygen or $\mathrm{H}_{2} \mathrm{O}_{2}[312,313]$.

As reviewed in this work (Scheme 6, Sections 3.1 and 3.2), a range of covalent oxidative modifications plays a role in the regulation of proteasomal activity. In this regard, based on the nature of an aggregate surface, hydrophobic, and hydrophilic ROS can be differentially attracted into the proximity of an immobilized proteasome, resulting in an increase of selectivity in the insertions of regulatory oxidative modifications or protection against oxidative damage.

As already mentioned, increasing evidence points to the cytoprotective propensity of large insoluble inclusions called 'aggresomes', which are developed mostly in cultured eukaryotic cells [314,315] and the inclusion bodies present in bacteria [281,282] or typically seen in neurodegenerative diseases [316-318]. By contrast, interventions that block aggresome formation slow down the rate of the turnover of misfolded proteins and enhance their cytotoxicity [314]. Consistently, the components of UPS recruited to aggresomes were shown to retain their catalytic activity. The proteasomes, as well as other important proteins-such as HSP70 and the transcriptional coactivator, CREB-binding protein (CBP), and molecular chaperones-were found to be dynamically and reversibly recruited into polyQ inclusion bodies [319]. Interestingly, these recruited proteasomes remained catalytically active and accessible to substrates. Other proteins, such as HSP70, have also been shown to be reversibly associated with polyQ protein aggregates [320]. The rapid association and dissociation of HSP70 at the growing aggregate surface was proposed as an important factor for preventing proteins from becoming irreversibly sequestered in aggregates. By analogy, a range of enzymes-including reductases, oxidases, kinases, phosphorylases, aldolases, lyases, synthases, and lipases, in the form of inclusion bodies or mammalian aggresomes-were shown to retain their activities as self-immobilized particulate catalysts [281,321,322]. In addition, inclusion body-based scaffold proteins applied to the in vivo surface immobilization of an enzyme also represent promising particulate catalysts [323]. 


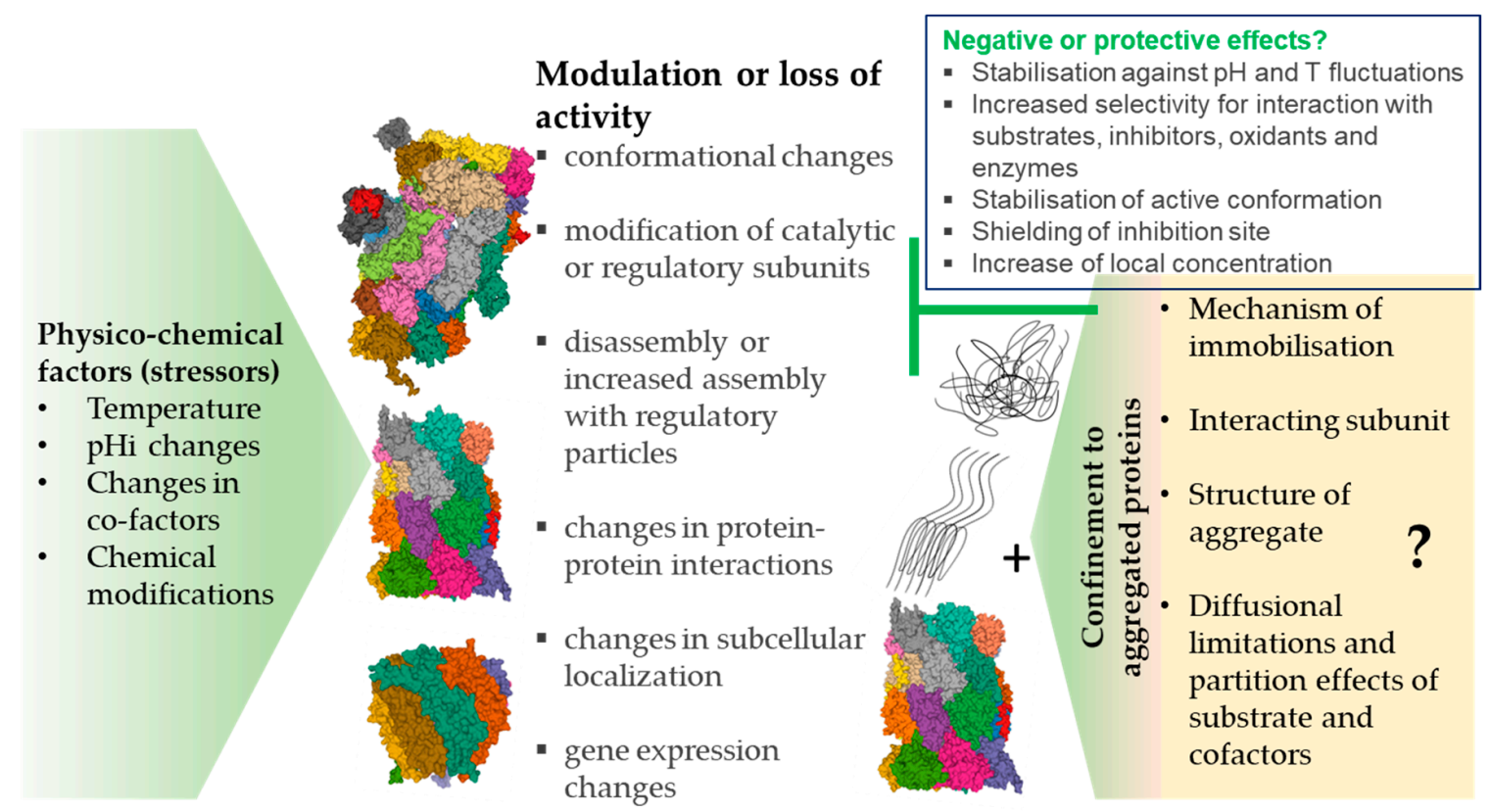

Scheme 6. The physico-chemical effects of the intracellular environment on the function of the proteasome and the contribution of interaction with aggregates. Interaction with protein aggregates can contribute to the spectrum of physico-chemical influences depending on the type of aggregated protein scaffold. Insoluble aggregates might potentially afford some beneficial effects on the proteasome, including stabilization against microenvironment changes and reactions with inhibitors and oxidants. Images are from the RCSB PDB (rcsb.org) of PDB ID: 6RGQ [64,65], 5A5B [65,66], 5MX5 [65,67].

Moreover, experiments with purified proteasomes, cell lines, and animal models have not uniformly pointed to compromising effects of the pathological aggregates in protein deposition diseases on the function of the proteasome. Indeed, decreased, unchanged, and even increased proteasomal activity has been reported (reviewed in [324]). In some cases, these outcomes can be explained by the limitations arising from the experimental design, such as liberation of the proteasome from protein aggregates over the course of an in vitro assay [37]. However, insight into the molecular properties of the aggregated proteinaceous 'carrier' and the processes at the interface of the aggregate-aqueous medium also likely contribute to understanding the effects of protein aggregation on the biological functioning of the proteasome and other enzymes.

\section{Summary and Remaining Questions}

The biological causes of the modulation of the function of the proteasome in physiological processes and pathologies include modulation of the gene expression of its subunits [53,54,57-62], ubiquitin mutation [325], enzymatic post-translantional modifications, and indirect effects related to protein aggregation, such as a global decline in proteolysis [301]. However, the changes in the physico-chemical characteristics of the cellular environment, such as $\mathrm{pH}$ or temperature fluctuations, reactions with products of oxidative metabolism, and processes occurring at the solid-water interface, might also significantly contribute to its altered performance. Immobilization techniques were successfully used in the case of other proteases (such as trypsin, lumbrokinase, and chymotrypsin) for biomedical application, as well as in the food industry, yielding enhanced stability or even increased activity of the fixed enzymes [284]. Moreover, confinement to a silica nanocarrier through non-covalent interactions was introduced as an effective approach for intracellular delivery of the purified proteasomes retaining their proteolytic activity [326]. Thus, in analogy with artificial systems, investigating the intermolecular interactions between the proteasomal system and protein aggregates while also considering the structure and hydrophobicity of the 'carrier', the presence of reactive groups or sequestered metal ions, partitioning and diffusional processes, and the production of enzyme activity and stability, 
could contribute to the elucidation of the pathogenic mechanisms associated with altered proteolysis or a regulatory mechanism aimed at protecting protein homeostasis in cells.

Author Contributions: Conceptualization, L.R.; Writing—original draft preparation, L.R and E.C.; Writing—review and editing, L.R and E.C.; Supervision, L.R.; Funding acquisition, L.R. All authors have read and agreed to the published version of the manuscript.

Funding: The study was supported by VEGA 2/0041/17. This work was supported by the Slovak Research and Development Agency under the Contract no. APVV-18-0336.

Conflicts of Interest: The authors declare no conflict of interest.

\section{References}

1. Morozov, A.V.; Karpov, V.L. Proteasomes and Several Aspects of Their Heterogeneity Relevant to Cancer. Front. Oncol. 2019, 9, 761. [CrossRef]

2. Bard, J.A.M.; Goodall, E.A.; Greene, E.R.; Jonsson, E.; Dong, K.C.; Martin, A. Structure and Function of the 26S Proteasome. Annu. Rev. Biochem. 2018, 87, 697-724. [CrossRef]

3. Sherman, D.J.; Li, J. Proteasome Inhibitors: Harnessing Proteostasis to Combat Disease. Molecules 2020, 25, 671. [CrossRef]

4. Enenkel, C. Proteasome dynamics. Biochim. Biophys. Acta Bioenerg. 2014, 1843, 39-46. [CrossRef]

5. Kish-Trier, E.; Hill, C.P. Structural Biology of the Proteasome. Annu. Rev. Biophys. 2013, 42, 29-49. [CrossRef]

6. Orlowski, M.; Wilk, S. Catalytic Activities of the 20 S Proteasome, a Multicatalytic Proteinase Complex. Arch. Biochem. Biophys. 2000, 383, 1-16. [CrossRef]

7. Stadtmueller, B.M.; Hill, C.P. Proteasome Activators. Mol. Cell 2011, 41, 8-19. [CrossRef]

8. Grice, G.L.; Nathan, J.A. The recognition of ubiquitinated proteins by the proteasome. Cell. Mol. Life Sci. 2016, 73, 3497-3506. [CrossRef]

9. $\quad$ Lasker, K.; Förster, F.; Bohn, S.; Walzthoeni, T.; Villa, E.; Unverdorben, P.; Beck, F.; Aebersold, R.; Sali, A.; Baumeister, W. Molecular architecture of the $26 \mathrm{~S}$ proteasome holocomplex determined by an integrative approach. Proc. Natl. Acad. Sci. USA 2012, 109, 1380-1387. [CrossRef]

10. He, J.; Kulkarni, K.A.; Da Fonseca, P.C.; Krutauz, D.; Glickman, M.H.; Barford, D.; Morris, E.P. The Structure of the 26S Proteasome Subunit Rpn2 Reveals Its PC Repeat Domain as a Closed Toroid of Two Concentric $\alpha$-Helical Rings. Structure 2012, 20, 513-521. [CrossRef]

11. Shi, Y.; Chen, X.; Elsasser, S.; Stocks, B.B.; Tian, G.; Lee, B.-H.; Zhang, N.; De Poot, S.A.H.; Tuebing, F.; Sun, S.; et al. Rpn1 provides adjacent receptor sites for substrate binding and deubiquitination by the proteasome. Science 2016, 351, aad9421. [CrossRef] [PubMed]

12. Husnjak, K.; Elsasser, S.; Zhang, N.; Chen, X.; Randles, L.; Shi, Y.; Hofmann, K.; Walters, K.J.; Finley, D.; Dikic, I. Proteasome subunit Rpn13 is a novel ubiquitin receptor. Nat. Cell Biol. 2008, 453, 481-488. [CrossRef] [PubMed]

13. Van Nocker, S.; Sadis, S.; Rubin, D.M.; Glickman, M.; Fu, H.; Coux, O.; Wefes, I.; Finley, D.; Vierstra, R.D. The multiubiquitin-chain-binding protein Mcb1 is a component of the $26 \mathrm{~S}$ proteasome in Saccharomyces cerevisiae and plays a nonessential, substrate-specific role in protein turnover. Mol. Cell. Biol. 1996, 16, 6020-6028. [CrossRef]

14. Unverdorben, P.; Beck, F.; Śledź, P.; Schweitzer, A.; Pfeifer, G.; Plitzko, J.M.; Baumeister, W.; Förster, F. Deep classification of a large cryo-EM dataset defines the conformational landscape of the $26 \mathrm{~S}$ proteasome. Proc. Natl. Acad. Sci. USA 2014, 111, 5544-5549. [CrossRef] [PubMed]

15. Wehmer, M.; Rudack, T.; Beck, F.; Aufderheide, A.; Pfeifer, G.; Plitzko, J.M.; Förster, F.; Schulten, K.; Baumeister, W.; Sakata, E. Structural insights into the functional cycle of the ATPase module of the $26 \mathrm{~S}$ proteasome. Proc. Natl. Acad. Sci. USA 2017, 114, 1305-1310. [CrossRef] [PubMed]

16. Chen, S.; Wu, J.; Lu, Y.; Ma, Y.-B.; Lee, B.-H.; Yu, Z.; Ouyang, Q.; Finley, D.J.; Kirschner, M.W.; Mao, Y. Structural basis for dynamic regulation of the human $26 \mathrm{~S}$ proteasome. Proc. Natl. Acad. Sci. USA 2016, 113, 12991-12996. [CrossRef]

17. Zhu, Y.; Wang, W.L.; Yu, D.; Ouyang, Q.; Lu, Y.; Mao, Y. Structural mechanism for nucleotide-driven remodeling of the AAA-ATPase unfoldase in the activated human $26 \mathrm{~S}$ proteasome. Nat. Commun. 2018, 9, 1-12. [CrossRef] 
18. Ferrington, D.A.; Gregerson, D.S. Immunoproteasomes: Structure, function, and antigen presentation. Prog. Mol. Biol. Transl. Sci. 2012, 109, 75-112. [CrossRef]

19. Reis, J.; Guan, X.Q.; Kisselev, A.F.; Papasian, C.J.; Qureshi, A.A.; Morrison, D.C.; Van Way, C.W.; Vogel, S.N.; Qureshi, N. LPS-Induced Formation of Immunoproteasomes: TNF- $\alpha$ and Nitric Oxide Production are Regulated by Altered Composition of Proteasome-Active Sites. Cell Biophys. 2011, 60, 77-88. [CrossRef]

20. Freudenburg, W.; Gautam, M.; Chakraborty, P.; James, J.; Richards, J.; Salvatori, A.S.; Baldwin, A.; Schriewer, J.; Buller, R.M.L.; Corbett, J.A.; et al. Reduction in ATP Levels Triggers Immunoproteasome Activation by the 11S (PA28) Regulator during Early Antiviral Response Mediated by IFN $\beta$ in Mouse Pancreatic $\beta$-Cells. PLOS ONE 2013, 8, e52408. [CrossRef]

21. Kotamraju, S.; Matalon, S.; Matsunaga, T.; Shang, T.; Hickman-Davis, J.; Kalyanaraman, B. Upregulation of immunoproteasomes by nitric oxide: Potential antioxidative mechanism in endothelial cells. Free. Radic. Biol. Med. 2006, 40, 1034-1044. [CrossRef] [PubMed]

22. Grimm, S.; Ott, C.; Hörlacher, M.; Weber, D.; Höhn, A.; Grune, T. Advanced-glycation-end-product-induced formation of immunoproteasomes: Involvement of RAGE and Jak2/STAT1. Biochem. J. 2012, 448, 127-139. [CrossRef] [PubMed]

23. Moebius, J.; Broek, M.V.D.; Groettrup, M.; Basler, M. Immunoproteasomes are essential for survival and expansion of T cells in virus-infected mice. Eur. J. Immunol. 2010, 40, 3439-3449. [CrossRef] [PubMed]

24. Hussong, S.A.; Roehrich, H.; Kapphahn, R.J.; Maldonado, M.; Pardue, M.T.; Ferrington, D.A. A novel role for the immunoproteasome in retinal function. Investig. Opthalmology Vis. Sci. 2011, 52, 714-723. [CrossRef]

25. Muchamuel, T.; Basler, M.; Aujay, M.; Suzuki, E.; Kalim, K.W.; Lauer, C.; Sylvain, C.; Ring, E.R.; Shields, J.; Jiang, J.; et al. A selective inhibitor of the immunoproteasome subunit LMP7 blocks cytokine production and attenuates progression of experimental arthritis. Nat. Med. 2009, 15, 781-787. [CrossRef]

26. Vachharajani, N.; Joeris, T.; Luu, M.; Hartmann, S.; Pautz, S.; Jenike, E.; Pantazis, G.; Prinz, I.; Hofer, M.J.; Steinhoff, U.; et al. Prevention of colitis-associated cancer by selective targeting of immunoproteasome subunit LMP7. Oncotarget 2017, 8, 50447-50459. [CrossRef]

27. Zhang, Z.; Zhang, R. Proteasome activator PA28 $\gamma$ regulates p53 by enhancing its MDM2-mediated degradation. EMBO J. 2008, 27, 852-864. [CrossRef]

28. Drews, O.; Wildgruber, R.; Zong, C.; Sukop, U.; Nissum, M.; Weber, G.; Gomes, A.V.; Ping, P. Mammalian Proteasome Subpopulations with Distinct Molecular Compositions and Proteolytic Activities. Mol. Cell. Proteom. 2007, 6, 2021-2031. [CrossRef]

29. Dahlmann, B.; Ruppert, T.; Kuehn, L.; Merforth, S.; Kloetzel, P.-M. Different proteasome subtypes in a single tissue exhibit different enzymatic properties. J. Mol. Biol. 2000, 303, 643-653. [CrossRef]

30. De, M.; Jayarapu, K.; Elenich, L.; Monaco, J.J.; Colbert, R.A.; Griffin, T.A. $\beta 2$ Subunit Propeptides Influence Cooperative Proteasome Assembly. J. Biol. Chem. 2002, 278, 6153-6159. [CrossRef]

31. Guillaume, B.; Chapiro, J.; Stroobant, V.; Colau, D.; Van Holle, B.; Parvizi, G.; Bousquet-Dubouch, M.-P.; Théate, I.; Parmentier, N.; Eynde, B.J.V.D. Two abundant proteasome subtypes that uniquely process some antigens presented by HLA class I molecules. Proc. Natl. Acad. Sci. USA 2010, 107, 18599-18604. [CrossRef] [PubMed]

32. Sasaki, K.; Takada, K.; Ohte, Y.; Kondo, H.; Sorimachi, H.; Tanaka, K.; Takahama, Y.; Murata, S. Thymoproteasomes produce unique peptide motifs for positive selection of CD8+ T cells. Nat. Commun. 2015, 6, 7484. [CrossRef] [PubMed]

33. Huang, L.; Haratake, K.; Miyahara, H.; Chiba, T. Proteasome activators, PA28 $\gamma$ and PA200, play indispensable roles in male fertility. Sci. Rep. 2016, 6, 23171. [CrossRef] [PubMed]

34. Blickwedehl, J.; Agarwal, M.; Seong, C.; Pandita, R.K.; Melendy, T.; Sung, P.; Bangia, N.; Pandita, T.K. Role for proteasome activator PA200 and postglutamyl proteasome activity in genomic stability. Proc. Natl. Acad. Sci. USA 2008, 105, 16165-16170. [CrossRef] [PubMed]

35. Jung, T.; Grune, T. The proteasome and the degradation of oxidized proteins: Part I—structure of proteasomes. Redox Biol. 2013, 1, 178-182. [CrossRef]

36. Jung, T.; Höhn, A.; Grune, T. The proteasome and the degradation of oxidized proteins: Part II - protein oxidation and proteasomal degradation. Redox Biol. 2014, 2, 99-104. [CrossRef]

37. Raynes, R.; Pomatto, L.C.D.; Davies, K.J.A. Degradation of oxidized proteins by the proteasome: Distinguishing between the 20S, 26S, and immunoproteasome proteolytic pathways. Mol. Asp. Med. 2016, 50, 41-55. [CrossRef] 
38. Pickering, A.M.; Davies, K.J.A. Differential roles of proteasome and immunoproteasome regulators Pa28 $\alpha \beta$, Pa28 $\gamma$ and Pa200 in the degradation of oxidized proteins. Arch. Biochem. Biophys. 2012, 523, 181-190. [CrossRef]

39. Luciani, F.; Kesmir, C.; Mishto, M.; Or-Guil, M.; De Boer, R.J. A Mathematical Model of Protein Degradation by the Proteasome. Biophys. J. 2005, 88, 2422-2432. [CrossRef]

40. Stein, R.L.; Melandri, A.F.; Dick, L. Kinetic Characterization of the Chymotryptic Activity of the $20 \mathrm{~S}$ Proteasome. Biochemistry 1996, 35, 3899-3908. [CrossRef] [PubMed]

41. Kisselev, A.F.; Akopian, T.N.; Castillo, V.; Goldberg, A.L. Proteasome Active Sites Allosterically Regulate Each Other, Suggesting a Cyclical Bite-Chew Mechanism for Protein Breakdown. Mol. Cell 1999, 4, 395-402. [CrossRef]

42. Stohwasser, R.; Salzmann, U.; Giesebrecht, J.; Kloetzel, P.-M.; Holzhütter, H.-G. Kinetic evidences for facilitation of peptide channelling by the proteasome activator PA28. JBIC J. Biol. Inorg. Chem. 2000, 267, 6221-6230. [CrossRef] [PubMed]

43. Schmidtke, G.; Emch, S.; Groettrup, M.; Holzhütter, H.-G. Evidence for the Existence of a Non-catalytic Modifier Site of Peptide Hydrolysis by the 20 S Proteasome. J. Biol. Chem. 2000, 275, 22056-22063. [CrossRef] [PubMed]

44. Holzhütter, H.-G.; Kloetzel, P.-M. A Kinetic Model of Vertebrate 20S Proteasome Accounting for the Generation of Major Proteolytic Fragments from Oligomeric Peptide Substrates. Biophys. J. 2000, 79, 1196-1205. [CrossRef]

45. Köhler, A.; Cascio, P.; Leggett, D.S.; Woo, K.M.; Goldberg, A.L.; Finley, D. The Axial Channel of the Proteasome Core Particle Is Gated by the Rpt2 ATPase and Controls Both Substrate Entry and Product Release. Mol. Cell 2001, 7, 1143-1152. [CrossRef]

46. Mishto, M.; Luciani, F.; Holzhütter, H.-G.; Bellavista, E.; Santoro, A.; Textoris-Taube, K.; Franceschi, C.; Kloetzel, P.M.; Zaikin, A. Modeling the in Vitro 20S Proteasome Activity: The Effect of PA28- $\alpha \beta$ and of the Sequence and Length of Polypeptides on the Degradation Kinetics. J. Mol. Biol. 2008, 377, 1607-1617. [CrossRef]

47. $\mathrm{Xu}, \mathrm{L} . ; \mathrm{Qu}, \mathrm{Z}$. Roles of Protein Ubiquitination and Degradation Kinetics in Biological Oscillations. PLoS ONE 2012, 7, e34616. [CrossRef]

48. Lu, Y.; Lee, B.-H.; King, R.W.; Finley, D.; Kirschner, M.W. Substrate degradation by the proteasome: A single-molecule kinetic analysis. Science 2015, 348, 1250834. [CrossRef]

49. Ding, Z.; Xu, C.; Sahu, I.; Wang, Y.; Fu, Z.; Huang, M.; Wong, C.C.; Glickman, M.H.; Cong, Y. Structural Snapshots of $26 S$ Proteasome Reveal Tetraubiquitin-Induced Conformations. Mol. Cell 2019, 73, 1150-1161.e6. [CrossRef]

50. Reichard, E.L.; Chirico, G.G.; Dewey, W.J.; Nassif, N.D.; Bard, K.E.; Millas, N.E.; Kraut, D.A. Substrate Ubiquitination Controls the Unfolding Ability of the Proteasome. J. Biol. Chem. 2016, 291, 18547-18561. [CrossRef]

51. Bard, J.A.; Bashore, C.; Dong, K.C.; Martin, A. The 26S Proteasome Utilizes a Kinetic Gateway to Prioritize Substrate Degradation. Cell 2019, 177, 286-298.e15. [CrossRef] [PubMed]

52. Cascio, P. PA28 $\alpha \beta$ : The Enigmatic Magic Ring of the Proteasome? Biomolecules 2014, 4, 566-584. [CrossRef] [PubMed]

53. Petersen, A.; Honarvar, A.; Zetterberg, M. Changes in Activity and Kinetic Properties of the Proteasome in Different Rat Organs during Development and Maturation. Curr. Gerontol. Geriatr. Res. 2010, 2010, 1-9. [CrossRef] [PubMed]

54. Jung, T.; Höhn, T.J.A.; Grune, T. The proteasome and the degradation of oxidized proteins: Part III-Redox regulation of the proteasomal system. Redox Biol. 2014, 2, 388-394. [CrossRef] [PubMed]

55. Kwak, M.-K.; Wakabayashi, N.; Greenlaw, J.L.; Yamamoto, M.; Kensler, T.W. Antioxidants Enhance Mammalian Proteasome Expression through the Keap1-Nrf2 Signaling Pathway. Mol. Cell. Biol. 2003, 23, 8786-8794. [CrossRef]

56. Kapeta, S.; Chondrogianni, N.; Gonos, E.S. Nuclear Erythroid Factor 2-mediated Proteasome Activation Delays Senescence in Human Fibroblasts. J. Biol. Chem. 2010, 285, 8171-8184. [CrossRef]

57. Radhakrishnan, S.K.; Lee, C.S.; Young, P.; Beskow, A.; Chan, J.Y.; Deshaies, R.J. Transcription Factor Nrf1 Mediates the Proteasome Recovery Pathway after Proteasome Inhibition in Mammalian Cells. Mol. Cell 2010, 38, 17-28. [CrossRef]

58. Motosugi, R.; Murata, S. Dynamic Regulation of Proteasome Expression. Front. Mol. Biosci. 2019, 6, 30. [CrossRef]

59. Baird, L.; Tsujita, T.; Kobayashi, E.H.; Funayama, R.; Nagashima, T.; Nakayama, K.; Yamamoto, M. A Homeostatic Shift Facilitates Endoplasmic Reticulum Proteostasis through Transcriptional Integration of Proteostatic Stress Response Pathways. Mol. Cell. Biol. 2017, 37, 00439-16. [CrossRef] 
60. Moritz, K.E.; McCormack, N.M.; Abera, M.B.; Viollet, C.; Yauger, Y.J.; Sukumar, G.; Dalgard, C.L.; Burnett, B.G. The role of the immunoproteasome in interferon- $\gamma$-mediated microglial activation. Sci. Rep. 2017, 7, 1-16. [CrossRef]

61. Johnston-Carey, H.K.; Pomatto, L.C.D.; Davies, K.J.A. The Immunoproteasome in oxidative stress, aging, and disease. Crit. Rev. Biochem. Mol. Biol. 2016, 51, 268-281. [CrossRef] [PubMed]

62. Sun, J.; Luan, Y.; Xiang, D.; Tan, X.; Chen, H.; Deng, Q.; Zhang, J.; Chen, M.; Huang, H.; Wang, W.; et al. The 11S Proteasome Subunit PSME3 Is a Positive Feedforward Regulator of NF-kB and Important for Host Defense against Bacterial Pathogens. Cell Rep. 2016, 14, 737-749. [CrossRef] [PubMed]

63. Schulz, E.; Münzel, T. Intracellular pH: A fundamental modulator of vascular function. Circulation 2011, 124, 1806-1807. [CrossRef] [PubMed]

64. Rêgo, A.T.; Da Fonseca, P.C.A. Characterization of Fully Recombinant Human 20S and 20S-PA200 Proteasome Complexes. Mol. Cell 2019, 76, 138-147.e5. [CrossRef]

65. Images 6RGQ, 5A5B, 5MX5, 6E5B, 6KWY, 2RAM, 2LZ1, 6XMJ, 1G0U Were Created Using Mol* (Sehnal, D.; Rose, A.S.; Kovca, J.; Burley, S.K.; Velankar, S. Mol*: Towards a Common Library and Tools for Web molecular graphics MolVA/EuroVis Proceedings. 2018, doi:10.2312/molva.20181103.) and RCSB PDB (rcsb.org) H.M. Berman, J. Westbrook, Z. Feng, G. Gilliland, T.N. Bhat, H. Weissig, I.N. Shindyalov, P.E. Bourne. Nucleic Acids Research. 2020, Volume 28, pp. 235-242. Available online: https:/academic.oup.com/nar/article/28/1/235/ 2384399 (accessed on 15 November 2020).

66. Aufderheide, A.; Beck, F.; Stengel, F.; Hartwig, M.; Schweitzer, A.; Pfeifer, G.; Goldberg, A.L.; Sakata, E.; Baumeister, W.; Förster, F. Structural characterization of the interaction of Ubp6 with the 26S proteasome. Proc. Natl. Acad. Sci. USA 2015, 112, 8626-8631. [CrossRef]

67. Huber, E.M.; Groll, M. The Mammalian Proteasome Activator PA28 Forms an Asymmetric $\alpha 4 \beta 3$ Complex. Structure 2017, 25, 1473-1480.e3. [CrossRef]

68. Ladi, E.; Everett, C.; Stivala, C.E.; Daniels, B.E.; Durk, M.R.; Harris, S.F.; Huestis, M.P.; Purkey, H.E.; Staben, S.T.; Augustin, M.; et al. Design and Evaluation of Highly Selective Human Immunoproteasome Inhibitors Reveal a Compensatory Process That Preserves Immune Cell Viability. J. Med. Chem. 2019, 62, 7032-7041. [CrossRef]

69. Guan, H.; Wang, Y.; Yu, T.; Huang, Y.; Li, M.; Saeed, A.F.U.H.; Perčulija, V.; Li, D.; Xiao, J.; Wang, D.; et al. Cryo-EM structures of the human PA200 and PA200-20S complex reveal regulation of proteasome gate opening and two PA200 apertures. PLoS Biol. 2020, 18, e3000654. [CrossRef]

70. Chen, Y.-Q.; Ghosh, S.; Ghosh, G. A novel DNA recognition mode by the NF-кB p65 homodimer. Nat. Struct. Mol. Biol. 1998, 5, 67-73. [CrossRef]

71. Eletsky, A.; Pulavarti, S.V.S.R.K.; Lee, D.; Kohan, E.; Janjua, H.; Xiao, R.; Acton, T.B.; Everett, J.K.; Montelione, G.T. Solution NMR Structure of the DNA-Binding Domain of Human NF-E2-Related Factor 2 (2012) Northeast Structural Genomics Consortium (NESG) Target HR3520O. 2020, to Be Published, doi:10.2210/pdb2lz1/pdb. Image from the RCSB PDB (Rcsb.Org) of PDB ID: 2LZ1. Available online: https://www.rcsb.org/structure/2lz1 (accessed on 15 November 2020).

72. Bailey, J.L.; Wang, X.; England, B.K.; Price, S.R.; Ding, X.; Mitch, W. The acidosis of chronic renal failure activates muscle proteolysis in rats by augmenting transcription of genes encoding proteins of the ATP-dependent ubiquitin-proteasome pathway. J. Clin. Investig. 1996, 97, 1447-1453. [CrossRef]

73. Peters, L.Z.; Hazan, R.; Breker, M.; Schuldiner, M.; Ben-Aroya, S. Formation and dissociation of proteasome storage granules are regulated by cytosolic pH. J. Cell Biol. 2013, 201, 663-671. [CrossRef] [PubMed]

74. Marshall, R.S.; Vierstra, R.D. To save or degrade: Balancing proteasome homeostasis to maximize cell survival. Autophagy 2018, 14, 2029-2031. [CrossRef] [PubMed]

75. Jia, M.; Zheng, D.; Wang, X.; Zhang, Y.; Chen, S.; Cai, X.; Mo, L.; Hu, Z.; Li, H.; Zhou, Z.; et al. Cancer Cell enters reversible quiescence through Intracellular Acidification to resist Paclitaxel Cytotoxicity. Int. J. Med. Sci. 2020, 17, 1652-1664. [CrossRef]

76. Wojcik, C.; Di Napoli, M. Ubiquitin-Proteasome System and Proteasome Inhibition: New Strategies in Stroke Therapy. Stroke 2004, 35, 1506-1518. [CrossRef] [PubMed]

77. Munder, M.C.; Midtvedt, D.; Franzmann, T.; Nuske, E.; Otto, O.; Herbig, M.; Ulbricht, E.; Müller, P.; Taubenberger, A.; Maharana, S.; et al. A pH-driven transition of the cytoplasm from a fluid- to a solid-like state promotes entry into dormancy. eLife 2016, 5, 09347. [CrossRef] [PubMed] 
78. Ugai, S.-I.; Tamura, T.-A.; Tanahashi, N.; Takai, S.; Komi, N.; Chung, C.H.; Tanaka, K.; Ichihara, A. Purification and Characterization of the 26S Proteasome Complex Catalyzing ATP-Dependent Breakdown of Ubiquitin-Ligated Prot from Rat Liver. J. Biochem. 1993, 113, 754-768. [CrossRef]

79. Klinkradt, S.; Naudé, R.J.; Muramoto, K.; Oelofsen, W. Purification and characterization of proteasome from ostrich liver. Int. J. Biochem. Cell Biol. 1997, 29, 611-622. [CrossRef]

80. Ostrowska, H.; Ostrowska, J.K.; Worowski, K.; Radziwon, P. Human platelet 20S proteasome: Inhibition of its chymotrypsin-like activity and identification of the proteasome activator PA28. A preliminary report. Platelets 2003, 14, 151-157. [CrossRef]

81. Lam, T.I.; Brennan-Minnella, A.M.; Won, S.J.; Shen, Y.; Hefner, C.; Shi, Y.; Sun, D.; Swanson, R.A. Intracellular $\mathrm{pH}$ reduction prevents excitotoxic and ischemic neuronal death by inhibiting NADPH oxidase. Proc. Natl. Acad. Sci. USA 2013, 110, E4362-E4368. [CrossRef]

82. Tsai, K.-L.; Wang, S.-M.; Chen, C.-C.; Fong, T.-H.; Wu, M.-L. Mechanism of oxidative stress-induced intracellular acidosis in rat cerebellar astrocytes and C6 glioma cells. J. Physiol. 1997, 502, 161-174. [CrossRef]

83. Reinheckel, T.; Sitte, N.; Ullrich, O.; Kuckelkorn, U.; Davies, K.J.A.; Grune, T. Comparative resistance of the $20 \mathrm{~S}$ and $26 \mathrm{~S}$ proteasome to oxidative stress. Biochem. J. 1998, 335, 637-642. [CrossRef] [PubMed]

84. Eleuteri, A.M.; Cuccioloni, M.; Bellesi, J.; Lupidi, G.; Fioretti, E.; Angeletti, M. Interaction of Hsp90 with $20 S$ proteasome: Thermodynamic and kinetic characterization. Proteins Struct. Funct. Bioinform. 2002, 48, 169-177. [CrossRef] [PubMed]

85. Passmore, L.; Barford, D.; Harper, J.W. Purification and Assay of the Budding Yeast Anaphase-Promoting Complex. Methods Enzymol. 2005, 398, 195-219. [CrossRef] [PubMed]

86. Zünd, G.; Uezono, S.; Stahl, G.L.; Dzus, A.L.; McGowan, F.X.; Hickey, P.R.; Colgan, S.P. Hypoxia enhances induction of endothelial ICAM-1: Role for metabolic acidosis and proteasomes. Am. J. Physiol. Physiol. 1997, 273, C1571-C1580. [CrossRef] [PubMed]

87. Mathew, A.; Mathur, S.K.; Morimoto, R.I. Heat Shock Response and Protein Degradation: Regulation of HSF2 by the Ubiquitin-Proteasome Pathway. Mol. Cell. Biol. 1998, 18, 5091-5098. [CrossRef]

88. Luo, G.-J.; Sun, X.; Hasselgren, P.-O. Hyperthermia stimulates energy-proteasome-dependent protein degradation in cultured myotubes. Am. J. Physiol. Integr. Comp. Physiol. 2000, 278, R749-R756. [CrossRef]

89. Beedholm, R.; Clark, B.F.; Rattan, S.I. Mild heat stress stimulates $20 \mathrm{~S}$ proteasome and its $11 \mathrm{~S}$ activator in human fibroblasts undergoing aging in vitro. Cell Stress Chaperon 2004, 9, 49-57. [CrossRef]

90. Pispa, J.; Matilainen, O.; Holmberg, C.I. Tissue-specific effects of temperature on proteasome function. Cell Stress Chaperon 2020, 25, 563-572. [CrossRef]

91. Bozaykut, P.; Özer, N.K.; Karademir, B. Nrf2 silencing to inhibit proteolytic defense induced by hyperthermia in HT22 cells. Redox Biol. 2016, 8, 323-332. [CrossRef]

92. Pajonk, F.; Van Ophoven, A.; McBride, W.H. Hyperthermia-Induced Proteasome Inhibition and Loss of Androgen Receptor Expression in Human Prostate Cancer Cells. Cancer Res. 2005, 65, 4836-4843. [CrossRef]

93. Kuckelkorn, U.; Knuehl, C.; Boes-Fabian, B.; Drung, I.; Kloetzel, P.-M. The Effect of Heat Shock on 20S/26S Proteasomes. Biol. Chem. 2000, 381, 1017-1023. [CrossRef] [PubMed]

94. Geng, Q.; Romero, J.; Saini, V.; Baker, T.A.; Picken, M.M.; Gamelli, R.L.; Majetschak, M. A subset of 26S proteasomes is activated at critically low ATP concentrations and contributes to myocardial injury during cold ischemia. Biochem. Biophys. Res. Commun. 2009, 390, 1136-1141. [CrossRef] [PubMed]

95. Smith, D.M.; Fraga, H.; Reis, C.; Kafri, G.; Goldberg, A.L. ATP Binds to Proteasomal ATPases in Pairs with Distinct Functional Effects, Implying an Ordered Reaction Cycle. Cell 2011, 144, 526-538. [CrossRef] [PubMed]

96. Peth, A.; Nathan, J.A.; Goldberg, A.L. The ATP Costs and Time Required to Degrade Ubiquitinated Proteins by the 26 S Proteasome. J. Biol. Chem. 2013, 288, 29215-29222. [CrossRef] [PubMed]

97. Höglinger, G.U.; Carrard, G.; Michel, P.P.; Medja, F.; Lombès, A.; Ruberg, M.; Friguet, B.; Hirsch, E.C. Dysfunction of mitochondrial complex I and the proteasome: Interactions between two biochemical deficits in a cellular model of Parkinson's disease. J. Neurochem. 2003, 86, 1297-1307. [CrossRef]

98. Vernace, V.A.; Arnaud, L.; Schmidt-Glenewinkel, T.; Figueiredo-Pereira, M.E. Aging perturbs 26S proteasome assembly in Drosophila melanogaster. FASEB J. 2007, 21, 2672-2682. [CrossRef]

99. Meul, T.; Berschneider, K.; Schmitt, S.; Mayr, C.H.; Mattner, L.F.; Schiller, H.B.; Yazgili, A.S.; Wang, X.; Lukas, C.; Schlesser, C.; et al. Mitochondrial Regulation of the 26S Proteasome. Cell Rep. 2020, 32, 108059. [CrossRef] [PubMed] 
100. Huang, H.; Zhang, X.; Li, S.; Liu, N.; Lian, W.; McDowell, E.; Zhou, P.; Zhao, C.; Guo, H.; Zhang, C.; et al. Physiological levels of ATP negatively regulate proteasome function. Cell Res. 2010, 20, 1372-1385. [CrossRef] [PubMed]

101. Powell, S.R.; Davies, K.J.; Divald, A. Optimal determination of heart tissue 26S-proteasome activity requires maximal stimulating ATP concentrations. J. Mol. Cell. Cardiol. 2007, 42, 265-269. [CrossRef] [PubMed]

102. Ottenheijm, C.A.C.; Heunks, L.M.A.; Li, Y.-P.; Jin, B.; Minnaard, R.; Van Hees, H.W.H.; Dekhuijzen, P.N.R. Activation of the Ubiquitin-Proteasome Pathway in the Diaphragm in Chronic Obstructive Pulmonary Disease. Am. J. Respir. Crit. Care Med. 2006, 174, 997-1002. [CrossRef]

103. Kors, S.; Geijtenbeek, K.; Reits, E.; Schipper-Krom, S. Regulation of Proteasome Activity by (Post-) transcriptional Mechanisms. Front. Mol. Biosci. 2019, 6, 48. [CrossRef] [PubMed]

104. Cui, Z.; Scruggs, S.B.; Gilda, J.E.; Ping, P.; Gomes, A.V. Regulation of cardiac proteasomes by ubiquitination, SUMOylation, and beyond. J. Mol. Cell. Cardiol. 2014, 71, 32-42. [CrossRef] [PubMed]

105. Hirano, H.; Kimura, Y.; Kimura, A. Biological significance of co- and post-translational modifications of the yeast 26 S proteasome. J. Proteom. 2016, 134, 37-46. [CrossRef] [PubMed]

106. Paulsen, C.E.; Carroll, K.S. Cysteine-Mediated Redox Signaling: Chemistry, Biology, and Tools for Discovery. Chem. Rev. 2013, 113, 4633-4679. [CrossRef]

107. Gallogly, M.M.; Mieyal, J.J. Mechanisms of reversible protein glutathionylation in redox signaling and oxidative stress. Curr. Opin. Pharmacol. 2007, 7, 381-391. [CrossRef]

108. Sanchez, R.; Riddle, M.; Woo, J.; Momand, J. Prediction of reversibly oxidized protein cysteine thiols using protein structure properties. Protein Sci. 2008, 17, 473-481. [CrossRef]

109. Demasi, M.; Netto, L.E.S.; Silva, G.M.; Hand, A.; De Oliveira, C.L.P.; Bicev, R.N.; Gozzo, F.; De Barros, M.H.; Leme, J.D.M.M.; Ohara, E. Redox regulation of the proteasome via S-glutathionylation. Redox Biol. 2014, 2, 44-51. [CrossRef]

110. Silva, G.M.; Netto, L.; Simões, V.; Santos, L.F.A.; Gozzo, F.C.; Demasi, M.A.A.; De Oliveira, C.L.P.; Bicev, R.N.; Klitzke, C.F.; Sogayar, M.C.; et al. Redox Control of 20 S Proteasome Gating. Antioxid. Redox Signal. 2012, 16, 1183-1194. [CrossRef]

111. Leme, J.M.; Ohara, E.; Santiago, V.F.; Barros, M.H.; Netto, L.E.; Pimenta, D.C.; Mariano, D.O.; Oliveira, C.L.; Bicev, R.N.; Barreto-Chaves, M.L.; et al. Mutations of Cys and Ser residues in the $\alpha 5$-subunit of the $20 \mathrm{~S}$ proteasome from Saccharomyces cerevisiae affects gating and chronological lifespan. Arch. Biochem. Biophys. 2019, 666, 63-72. [CrossRef]

112. Demasi, M.; Shringarpure, R.; Davies, K.J. Glutathiolation of the Proteasome Is Enhanced by Proteolytic Inhibitors. Arch. Biochem. Biophys. 2001, 389, 254-263. [CrossRef]

113. Silva, G.M.; Netto, L.E.S.; Discola, K.F.; Piassa-Filho, G.M.; Pimenta, D.C.; Bárcena, J.A.; Demasi, M. Role of glutaredoxin 2 and cytosolic thioredoxins in cysteinyl-based redox modification of the 20S proteasome. FEBS J. 2008, 275, 2942-2955. [CrossRef] [PubMed]

114. Livnat-Levanon, N.; Kevei, É.; Kleifeld, O.; Krutauz, D.; Segref, A.; Rinaldi, T.; Erpapazoglou, Z.; Cohen, M.; Reis, N.; Hoppe, T.; et al. Reversible 26S Proteasome Disassembly upon Mitochondrial Stress. Cell Rep. 2014, 7, 1371-1380. [CrossRef] [PubMed]

115. Zmijewski, J.W.; Banerjee, S.; Abraham, E. S-Glutathionylation of the Rpn2 Regulatory Subunit Inhibits $26 \mathrm{~S}$ Proteasomal Function. J. Biol. Chem. 2009, 284, 22213-22221. [CrossRef]

116. Grune, T.; Catalgol, B.; Licht, A.; Ermak, G.; Pickering, A.M.; Ngo, J.K.; Davies, K.J.A. HSP70 mediates dissociation and reassociation of the $26 \mathrm{~S}$ proteasome during adaptation to oxidative stress. Free. Radic. Biol. Med. 2011, 51, 1355-1364. [CrossRef]

117. Reinheckel, T.; Ullrich, O.; Sitte, N.; Grune, T. Differential Impairment of 20S and 26S Proteasome Activities in Human Hematopoietic K562 Cells during Oxidative Stress. Arch. Biochem. Biophys. 2000, 377, 65-68. [CrossRef]

118. Obin, M.; Shang, F.; Gong, X.; Handelman, G.; Blumberg, J.; Taylor, A. Redox regulation of ubiquitin-conjugating enzymes: Mechanistic insights using the thiol-specific oxidant diamide. FASEB J. 1998, 12, 561-569. [CrossRef]

119. Gould, N.; Doulias, P.-T.; Tenopoulou, M.; Raju, K.; Ischiropoulos, H. Regulation of Protein Function and Signaling by Reversible Cysteine S-Nitrosylation. J. Biol. Chem. 2013, 288, 26473-26479. [CrossRef]

120. Murray, C.I.; Uhrigshardt, H.; O'Meally, R.N.; Cole, R.N.; Van Eyk, J.E. Identification and Quantification of S-Nitrosylation by Cysteine Reactive Tandem Mass Tag Switch Assay. Mol. Cell. Proteom. 2012, 11, 013441. [CrossRef] 
121. Kapadia, M.R.; Eng, J.W.; Jiang, Q.; Stoyanovsky, D.A.; Kibbe, M.R. Nitric oxide regulates the $26 \mathrm{~S}$ proteasome in vascular smooth muscle cells. Nitric Oxide 2009, 20, 279-288. [CrossRef]

122. Wang, Y.; Zhang, P.; Xu, Z.; Yue, W.; Zhuang, Y.; Chen, Y.; Chen, Y. S-nitrosylation of PDE5 increases its ubiquitin-proteasomal degradation. Free. Radic. Biol. Med. 2015, 86, 343-351. [CrossRef] [PubMed]

123. Azad, N.; Vallyathan, V.; Wang, L.; Tantishaiyakul, V.; Stehlik, C.; Leonard, S.S.; Rojanasakul, Y. S-Nitrosylation of Bcl-2 Inhibits Its Ubiquitin-Proteasomal Degradation: A Novel Antiapoptotic Mechanism That Suppresses Apoptosis. J. Biol. Chem. 2006, 281, 34124-34134. [CrossRef] [PubMed]

124. Marcone, S.; Evans, P.; Fitzgerald, D.J. 15-Deoxy- $\Delta 12,14-$ Prostaglandin J2 Modifies Components of the Proteasome and Inhibits Inflammatory Responses in Human Endothelial Cells. Front. Immunol. 2016, 7, 459. [CrossRef] [PubMed]

125. Sohal, R.S.; Orr, W.C. The redox stress hypothesis of aging. Free. Radic. Biol. Med. 2012, 52, $539-555$. [CrossRef] [PubMed]

126. Ferrington, D.A.; Husom, A.D.; Thompson, L.V. Altered proteasome structure, function, and oxidation in aged muscle. FASEB J. 2005, 19, 1-24. [CrossRef]

127. Zong, C.; Young, G.W.; Wang, Y.; Lu, H.; Deng, N.; Drews, O.; Ping, P. Two-dimensional electrophoresis-based characterization of post-translational modifications of mammalian $20 \mathrm{~S}$ proteasome complexes. Proteomics 2008, 8, 5025-5037. [CrossRef]

128. Schreiber, V.; Dantzer, F.; Ame, J.-C.; De Murcia, G. Poly(ADP-ribose): Novel functions for an old molecule. Nat. Rev. Mol. Cell Biol. 2006, 7, 517-528. [CrossRef]

129. Hu, K.; Wu, W.; Li, Y.; Lin, L.; Chen, D.; Yan, H.; Xiao, X.; Chen, H.; Chen, Z.; Zhang, Y.; et al. Poly(ADP -ribosyl)ation of BRD 7 by PARP 1 confers resistance to DNA -damaging chemotherapeutic agents. EMBO Rep. 2019, 20, 46166. [CrossRef]

130. Ullrich, O.; Reinheckel, T.; Sitte, N.; Hass, R.; Grune, T.; Davies, K.J. Poly-ADP ribose polymerase activates nuclear proteasome to degrade oxidatively damaged histones. Proc. Natl. Acad. Sci. USA 1999, 96, 6223-6228. [CrossRef]

131. Catalgol, B.; Wendt, B.; Grimm, S.; Breusing, N.; Özer, N.K.; Grune, T. Chromatin repair after oxidative stress: Role of PARP-mediated proteasome activation. Free. Radic. Biol. Med. 2010, 48, 673-680. [CrossRef]

132. Ullrich, O.; Diestel, A.; Bechmann, I.; Homberg, M.; Grune, T.; Hass, R.; Nitsch, R. Turnover of oxidatively damaged nuclear proteins in BV-2 microglial cells is linked to their activation state by poly(ADP-ribose)polymerase. FASEB J. 2001, 15, 1460-1462. [CrossRef]

133. Sha, Z.; Peth, A.; Goldberg, A.L. Keeping proteasomes under control-a role for phosphorylation in the nucleus. Proc. Natl. Acad. Sci. USA 2011, 108, 18573-18574. [CrossRef] [PubMed]

134. VerPlank, J.J.; Goldberg, A.L. Regulating protein breakdown through proteasome phosphorylation. Biochem. J. 2017, 474, 3355-3371. [CrossRef] [PubMed]

135. Guo, X.; Huang, X.; Chen, M.J. Reversible phosphorylation of the 26S proteasome. Protein Cell 2017, 8, $255-272$. [CrossRef] [PubMed]

136. Guo, X.; Engel, J.L.; Xiao, J.; Tagliabracci, V.S.; Wang, X.; Huang, L.; E Dixon, J. UBLCP1 is a $26 \mathrm{~S}$ proteasome phosphatase that regulates nuclear proteasome activity. Proc. Natl. Acad. Sci. USA 2011, 108, 18649-18654. [CrossRef] [PubMed]

137. Mason, G.G.F.; Hendil, K.B.; Rivett, A.J. Phosphorylation of Proteasomes in Mammalian Cells. Identification of Two Phosphorylated Subunits and the Effect of Phosphorylation on Activity. JBIC J. Biol. Inorg. Chem. 1996, 238, 453-462. [CrossRef]

138. Mason, G.G.; Murray, R.Z.; Pappin, D.; Rivett, A.J. Phosphorylation of ATPase subunits of the 26S proteasome. FEBS Lett. 1998, 430, 269-274. [CrossRef]

139. Bose, S.; Stratford, F.L.L.; Broadfoot, K.I.; Mason, G.G.F.; Rivett, A.J. Phosphorylation of 20 S proteasome alpha subunit C8 (alpha7) stabilizes the $26 \mathrm{~S}$ proteasome and plays a role in the regulation of proteasome complexes by gamma-interferon. Biochem. J. 2004, 378, 177-184. [CrossRef]

140. Iwafune, Y.; Kawasaki, H.; Hirano, H. Electrophoretic analysis of phosphorylation of the yeast $20 \mathrm{~S}$ proteasome. Electrophoresis 2002, 23, 329-338. [CrossRef]

141. Castaño, J.G.; Mahillo, E.; Arizti, P.; Arribas, J. Phosphorylation of C8 and C9 Subunits of the Multicatalytic Proteinase by Casein Kinase II and Identification of the C8 Phosphorylation Sites by Direct Mutagenesis. Biochemistry 1996, 35, 3782-3789. [CrossRef] 
142. Li, N.; Lerea, K.M.; Etlinger, J.D. Phosphorylation of the Proteasome Activator PA28 Is Required for Proteasome Activation. Biochem. Biophys. Res. Commun. 1996, 225, 855-860. [CrossRef]

143. Feng, Y.; Longo, D.L.; Ferris, D.K. Polo-like kinase interacts with proteasomes and regulates their activity. Cell Growth Differ. 2001, 12, 29-37. [PubMed]

144. Lu, H.; Zong, C.; Wang, Y.; Young, G.W.; Deng, N.; Souda, P.; Li, X.; Whitelegge, J.P.; Drews, O.; Yang, P.-Y.; et al. Revealing the Dynamics of the 20 S Proteasome Phosphoproteome: A combined CID and electron transfer dissociation approach. Mol. Cell. Proteom. 2008, 7, 2073-2089. [CrossRef]

145. Zong, C.; Gomes, A.V.; Drews, O.; Li, X.; Young, G.W.; Berhane, B.; Qiao, X.; French, S.; Bardag-Gorce, F.; Ping, P. Regulation of Murine Cardiac 20S Proteasomes. Circ. Res. 2006, 99, 372-380. [CrossRef] [PubMed]

146. Marambaud, P.; Wilk, S.; Checler, F. Protein Kinase A Phosphorylation of the Proteasome: A Contribution to the $\alpha$-Secretase Pathway in Human Cells. J. Neurochem. 2002, 67, 2616-2619. [CrossRef]

147. Rabl, J.; Smith, D.M.; Yu, Y.; Chang, S.-C.; Goldberg, A.L.; Cheng, Y. Mechanism of Gate Opening in the $20 \mathrm{~S}$ Proteasome by the Proteasomal ATPases. Mol. Cell 2008, 30, 360-368. [CrossRef]

148. Zhang, F.; Hu, Y.; Huang, P.; Toleman, C.A.; Paterson, A.J.; Kudlow, J.E. Proteasome Function Is Regulated by Cyclic AMP-dependent Protein Kinase through Phosphorylation of Rpt. J. Biol. Chem. 2007, 282, 22460-22471. [CrossRef]

149. Djakovic, S.N.; Schwarz, L.A.; Barylko, B.; DeMartino, G.N.; Patrick, G.N. Regulation of the Proteasome by Neuronal Activity and Calcium/Calmodulin-dependent Protein Kinase II. J. Biol. Chem. 2009, 284, 26655-26665. [CrossRef]

150. Satoh, K.; Sasajima, H.; Nyoumura, K.-I.; Yokosawa, H.; Sawada, H. Assembly of the 26S proteasome is regulated by phosphorylation of the p45/Rpt6 ATPase subunit. Biochemistry 2001, 40, 314-319. [CrossRef]

151. Guo, X.; Wang, X.; Wang, Z.; Banerjee, S.; Yang, J.; Huang, L.; Dixon, J.E. Site-specific proteasome phosphorylation controls cell proliferation and tumorigenesis. Nat. Cell Biol. 2016, 18, 202-212. [CrossRef]

152. Fan, K.; Wang, F.; Li, Y.; Chen, L.; Gao, Z.; Zhang, Y.; Duan, J.-Y.; Huang, T.; Zhong, J.; Liu, R.-B.; et al. CRL4DCAF2 is required for mature T-cell expansion via Aurora B-regulated proteasome activity. J. Autoimmun. 2019, 96, 74-85. [CrossRef]

153. Pathare, G.R.; Nagy, I.; Bohn, S.; Unverdorben, P.; Hubert, A.; Körner, R.; Nickell, S.; Lasker, K.; Sali, A.; Tamura, T.; et al. The proteasomal subunit Rpn6 is a molecular clamp holding the core and regulatory subcomplexes together. Proc. Natl. Acad. Sci. USA 2012, 109, 149-154. [CrossRef] [PubMed]

154. VerPlank, J.J.S.; Lokireddy, S.; Zhao, J.; Goldberg, A.L. 26S Proteasomes are rapidly activated by diverse hormones and physiological states that raise cAMP and cause Rpn6 phosphorylation. Proc. Natl. Acad. Sci. USA 2019, 116, 4228-4237. [CrossRef] [PubMed]

155. Lokireddy, S.; Kukushkin, N.V.; Goldberg, A.L. cAMP-induced phosphorylation of $26 \mathrm{~S}$ proteasomes on Rpn6/PSMD11 enhances their activity and the degradation of misfolded proteins. Proc. Natl. Acad. Sci. USA 2015, 112, E7176-E7185. [CrossRef] [PubMed]

156. Myeku, N.; Clelland, C.L.; Emrani, S.; Kukushkin, N.V.; Yu, W.H.; Goldberg, A.L.; E Duff, K. Tau-driven $26 \mathrm{~S}$ proteasome impairment and cognitive dysfunction can be prevented early in disease by activating cAMP-PKA signaling. Nat. Med. 2016, 22, 46-53. [CrossRef]

157. Tomita, T.; Hirayama, S.; Sakurai, Y.; Ohte, Y.; Yoshihara, H.; Saeki, Y.; Hamazaki, J.; Murata, S. Specific Modification of Aged Proteasomes Revealed by Tag-Exchangeable Knock-In Mice. Mol. Cell. Biol. 2018, 39, 00426-18. [CrossRef]

158. Liu, X.; Huang, W.; Li, C.; Li, P.; Yuan, J.; Li, X.; Qiu, X.-B.; Ma, Q.; Cao, C. Interaction between c-Abl and Arg Tyrosine Kinases and Proteasome Subunit PSMA7 Regulates Proteasome Degradation. Mol. Cell 2006, 22, 317-327. [CrossRef]

159. Aiken, C.T.; Kaake, R.M.; Wang, X.; Huang, L. Oxidative Stress-Mediated Regulation of Proteasome Complexes. Mol. Cell. Proteom. 2011, 10, R110.006924. [CrossRef]

160. Um, J.W.; Im, E.; Park, J.; Oh, Y.; Min, B.; Lee, H.J.; Yoon, J.-B.; Chung, K.C. ASK1 Negatively Regulates the 26 S Proteasome. J. Biol. Chem. 2010, 285, 36434-36446. [CrossRef]

161. Wang, X.; Yen, J.; Kaiser, P.; Huang, L. Regulation of the 26S Proteasome Complex during Oxidative Stress. Sci. Signal. 2010, 3, ra88. [CrossRef]

162. Wani, P.S.; Suppahia, A.; Capalla, X.; Ondracek, A.; Roelofs, J. Phosphorylation of the C-terminal tail of proteasome subunit $\alpha 7$ is required for binding of the proteasome quality control factor Ecm29. Sci. Rep. 2016, 6, 27873. [CrossRef] 
163. Iwafune, Y.; Kawasaki, H.; Hirano, H. Identification of three phosphorylation sites in the $\alpha 7$ subunit of the yeast 20S proteasome in vivo using mass spectrometry. Arch. Biochem. Biophys. 2004, 431, 9-15. [CrossRef]

164. Lee, S.-H.; Park, Y.; Yoon, S.K.; Yoon, J.-B. Osmotic Stress Inhibits Proteasome by p38 MAPK-dependent Phosphorylation. J. Biol. Chem. 2010, 285, 41280-41289. [CrossRef]

165. Zhang, F.; Su, K.; Yang, X.; Bowe, D.B.; Paterson, A.J.; Kudlow, J.E. O-GlcNAc Modification Is an Endogenous Inhibitor of the Proteasome. Cell 2003, 115, 715-725. [CrossRef]

166. Overath, T.; Kuckelkorn, U.; Henklein, P.; Strehl, B.; Bonar, D.; Kloss, A.; Siele, D.; Kloetzel, P.-M.; Janek, K. Mapping of O-GlcNAc Sites of $20 \mathrm{~S}$ Proteasome Subunits and Hsp90 by a Novel Biotin-Cystamine Tag. Mol. Cell. Proteom. 2012, 11, 467-477. [CrossRef]

167. Ngoh, G.A.; Watson, L.J.; Facundo, H.T.; Jones, S.P. Augmented O-GlcNAc signaling attenuates oxidative stress and calcium overload in cardiomyocytes. Amino Acids 2011, 40, 895-911. [CrossRef]

168. Ma, J.; Hart, G.W. Protein O-GlcNAcylation in diabetes and diabetic complications. Expert Rev. Proteom. 2013, 10, 365-380. [CrossRef]

169. Wang, Z.; Park, K.; Comer, F.; Hsieh-Wilson, L.C.; Saudek, C.D.; Hart, G.W. Site-Specific GlcNAcylation of Human Erythrocyte Proteins: Potential Biomarker(s) for Diabetes. Diabetes 2008, 58, 309-317. [CrossRef]

170. Butkinaree, C.; Park, K.; Hart, G.W. O-linked $\beta$-N-acetylglucosamine (O-GlcNAc): Extensive crosstalk with phosphorylation to regulate signaling and transcription in response to nutrients and stress. Biochim. Et Biophys. Acta (BBA) Gen. Subj. 2010, 1800, 96-106. [CrossRef]

171. Sümegi, M.; Hunyadi-Gulyas, E.; Medzihradszky, K.F.; Udvardy, A. 26S proteasome subunits are O-linked $\mathrm{N}$-acetylglucosamine-modified in Drosophila melanogaster. Biochem. Biophys. Res. Commun. 2003, 312, 1284-1289. [CrossRef]

172. Ruan, H.-B.; Nie, Y.; Yang, X. Regulation of Protein Degradation by O-GlcNAcylation: Crosstalk with Ubiquitination. Mol. Cell. Proteom. 2013, 12, 3489-3497. [CrossRef]

173. Zhao, S.; Xu, W.; Jiang, W.; Yu, W.; Lin, Y.; Zhang, T.; Yao, J.; Zhou, L.; Zeng, Y.; Li, H.; et al. Regulation of Cellular Metabolism by Protein Lysine Acetylation. Science 2010, 327, 1000-1004. [CrossRef] [PubMed]

174. Choudhary, C.; Kumar, C.; Gnad, F.; Nielsen, M.L.; Rehman, M.; Walther, T.C.; Olsen, J.V.; Mann, M. Lysine Acetylation Targets Protein Complexes and Co-Regulates Major Cellular Functions. Science 2009, 325, 834-840. [CrossRef] [PubMed]

175. Wang, D.; Fang, C.; Zong, N.C.; Liem, D.A.; Cadeiras, M.; Scruggs, S.B.; Yu, H.; Kim, A.K.; Yang, P.; Deng, M.; et al. Regulation of acetylation restores proteolytic function of diseased myocardium in mouse and human. Mol. Cell. Proteom. 2013, 12, 3793-3802. [CrossRef] [PubMed]

176. Liu, J.; Wang, Y.; Li, L.; Zhou, L.; Wei, H.; Zhou, Q.; Wang, W.; Ji, L.; Shan, P.; Wang, Y.; et al. Site-specific Acetylation of the Proteasome Activator REG $\gamma$ Directs Its Heptameric Structure and Functions. J. Biol. Chem. 2013, 288, 16567-16578. [CrossRef] [PubMed]

177. Min, L.; Xu, H.; Wang, J.; Qu, L.; Jiang, B.; Zeng, Y.; Meng, L.; Jin, H.; Shou, C. N- $\alpha$-acetyltransferase 10 protein is a negative regulator of $28 \mathrm{~S}$ proteasome through interaction with PA28ß. FEBS Lett. 2013, 587, 1630-1637. [CrossRef] [PubMed]

178. Arendt, C.S.; Hochstrasser, M. Eukaryotic $20 S$ proteasome catalytic subunit propeptides prevent active site inactivation by N-terminal acetylation and promote particle assembly. EMBO J. 1999, 18, 3575-3585. [CrossRef]

179. Chen, P.; Hochstrasser, M. Autocatalytic Subunit Processing Couples Active Site Formation in the $20 \mathrm{~S}$ Proteasome to Completion of Assembly. Cell 1996, 86, 961-972. [CrossRef]

180. Boyault, C.; Khochbin, S. Regulatory cross-talk between lysine acetylation and ubiquitination: Role in the control of protein stability. BioEssays 2005, 27, 408-415. [CrossRef]

181. Wang, X.; Taplick, J.; Geva, N.; Oren, M. Inhibition of p53 degradation by Mdm2 acetylation. FEBS Lett. 2004, 561, 195-201. [CrossRef]

182. Gregory, R.C.; Taniguchi, T.; D'Andrea, A.D. Regulation of the Fanconi anemia pathway by monoubiquitination. Semin. Cancer Biol. 2003, 13, 77-82. [CrossRef]

183. Schmitt, S.M.; Neslund-Dudas, C.; Shen, M.; Cui, C.; Mitra, B.; Dou, Q.P. Involvement of ALAD-20S Proteasome Complexes in Ubiquitination and Acetylation of Proteasomal $\alpha 2$ Subunits. J. Cell. Biochem. 2015, 117, 144-151. [CrossRef] [PubMed]

184. Isasa, M.; Katz, E.J.; Kim, W.; Yugo, V.; González, S.; Kirkpatrick, D.S.; Thomson, T.M.; Finley, D.; Gygi, S.P.; Crosas, B. Monoubiquitination of RPN10 Regulates Substrate Recruitment to the Proteasome. Mol. Cell 2010, 38, 733-745. [CrossRef] [PubMed] 
185. Zuin, A.; Bichmann, A.; Isasa, M.; Puig-Sàrries, P.; Díaz, L.M.; Crosas, B. Rpn10 monoubiquitination orchestrates the association of the ubiquilin-type DSK2 receptor with the proteasome. Biochem. J. 2015, 472, 353-365. [CrossRef] [PubMed]

186. Keren-Kaplan, T.; Peters, L.Z.; Levin-Kravets, O.; Attali, I.; Kleifeld, O.; Shohat, N.; Artzi, S.; Zucker, O.; Pilzer, I.; Reis, N.; et al. Structure of ubiquitylated-Rpn10 provides insight into its autoregulation mechanism. Nat. Commun. 2016, 7, 12960. [CrossRef]

187. Uchiki, T.; Kim, H.T.; Zhai, B.; Gygi, S.P.; A Johnston, J.; O’Bryan, J.P.; Goldberg, A.L. The Ubiquitin-interacting Motif Protein, S5a, Is Ubiquitinated by All Types of Ubiquitin Ligases by a Mechanism Different from Typical Substrate Recognition. J. Biol. Chem. 2009, 284, 12622-12632. [CrossRef]

188. Besche, H.C.; Sha, Z.; Kukushkin, N.V.; Peth, A.; Hock, E.; Kim, W.; Gygi, S.; A Gutierrez, J.; Liao, H.; Dick, L.; et al. Autoubiquitination of the 26S Proteasome on Rpn13 Regulates Breakdown of Ubiquitin Conjugates. EMBO J. 2014, 33, 1159-1176. [CrossRef]

189. Golebiowski, F.; Matic, I.; Tatham, M.H.; Cole, C.; Yin, Y.; Nakamura, A.; Cox, J.; Barton, G.J.; Mann, M.; Hay, R.T. System-Wide Changes to SUMO Modifications in Response to Heat Shock. Sci. Signal. 2009, 2, ra24. [CrossRef]

190. Ryu, H.; Gygi, S.P.; Azuma, Y.; Arnaoutov, A.; Dasso, M. SUMOylation of Psmd1 Controls Adrm1 Interaction with the Proteasome. Cell Rep. 2014, 7, 1842-1848. [CrossRef]

191. Lamoliatte, F.; McManus, F.P.; Maarifi, G.; Chelbi-Alix, M.K.; Thibault, P. Uncovering the SUMOylation and ubiquitylation crosstalk in human cells using sequential peptide immunopurification. Nat. Commun. 2017, 8, 14109. [CrossRef]

192. Kimura, A.; Kato, Y.; Hirano, H. N-myristoylation of the Rpt2 subunit regulates intracellular localization of the yeast $26 \mathrm{~S}$ proteasome. Biochemistry 2012, 51, 8856-8866. [CrossRef]

193. Kimura, A.; Kurata, Y.; Nakabayashi, J.; Kagawa, H.; Hirano, H. N-Myristoylation of the Rpt2 subunit of the yeast 26S proteasome is implicated in the subcellular compartment-specific protein quality control system. J. Proteom. 2016, 130, 33-41. [CrossRef]

194. Erce, M.A.; Pang, C.N.I.; Hart-Smith, G.; Wilkins, M.R. The methylproteome and the intracellular methylation network. Proteomics 2012, 12, 564-586. [CrossRef] [PubMed]

195. Kimura, Y.; Kurata, Y.; Ishikawa, A.; Okayama, A.; Kamita, M.; Hirano, H. N-Terminal methylation of proteasome subunit Rpt1 in yeast. Proteomics 2013, 13, 3167-3174. [CrossRef] [PubMed]

196. Gomes, A.V.; Young, G.W.; Wang, Y.; Zong, C.; Eghbali, M.; Drews, O.; Lu, H.; Stefani, E.; Ping, P. Contrasting Proteome Biology and Functional Heterogeneity of the 20S Proteasome Complexes in Mammalian Tissues. Mol. Cell. Proteom. 2008, 8, 302-315. [CrossRef] [PubMed]

197. Osna, N.A.; White, R.L.; Donohue, T.M.; Beard, M.R.; Tuma, D.J.; Kharbanda, K.K. Impaired methylation as a novel mechanism for proteasome suppression in liver cells. Biochem. Biophys. Res. Commun. 2010, 391, 1291-1296. [CrossRef] [PubMed]

198. Osna, N.A.; Bardag-Gorce, F.; White, R.L.; Weinman, S.A.; Donohue, T.M., Jr.; Kharbanda, K.K. Ethanol and Hepatitis C Virus Suppress Peptide-MHC Class I Presentation in Hepatocytes by Altering Proteasome Function. Alcohol. Clin. Exp. Res. 2012, 36, 2028-2035. [CrossRef]

199. Knowles, J.R. Chemical modification and the reactivity of amino acids in proteins. MTP Intl. Rev. Sci. Biochem. 1974, 1, 149.

200. Baslé, E.; Joubert, N.; Pucheault, M. Protein Chemical Modification on Endogenous Amino Acids. Chem. Biol. 2010, 17, 213-227. [CrossRef]

201. Davies, J.M.; Horwitz, D.A.; Davies, K.J. Potential roles of hypochlorous acid and N-chloroamines in collagen breakdown by phagocytic cells in synovitis. Free. Radic. Biol. Med. 1993, 15, 637-643. [CrossRef]

202. Ishii, T.; Sakurai, T.; Usami, H.; Uchida, K. Oxidative Modification of Proteasome: Identification of an Oxidation-Sensitive Subunit in 26S Proteasome. Biochemistry 2005, 44, 13893-13901. [CrossRef]

203. Stadtman, E.R.; Levine, R.L. Free radical-mediated oxidation of free amino acids and amino acid residues in proteins. Amino Acids 2003, 25, 207-218. [CrossRef] [PubMed]

204. Møller, I.M.; Rogowska-Wrzesinska, A.; Rao, S.P. Protein carbonylation and metal-catalyzed protein oxidation in a cellular perspective. J. Proteom. 2011, 74, 2228-2242. [CrossRef] [PubMed]

205. Divald, A.; Kivity, S.; Wang, P.; Hochhauser, E.; Roberts, B.; Teichberg, S.; Gomes, A.V.; Powell, S.R. Myocardial Ischemic Preconditioning Preserves Postischemic Function of the 26S Proteasome Through Diminished Oxidative Damage to $19 S$ Regulatory Particle Subunits. Circ. Res. 2010, 106, 1829-1838. [CrossRef] [PubMed] 
206. Predmore, J.M.; Wang, P.; Davis, F.; Bartolone, S.N.; Westfall, M.V.; Dyke, D.B.; Pagani, F.D.; Powell, S.R.; Day, S.M. Ubiquitin proteasome dysfunction in human hypertrophic and dilated cardiomyopathies. Circulation 2010, 121, 997-1004. [CrossRef] [PubMed]

207. Gillette, T.G.; Kumar, B.; Thompson, D.; Slaughter, C.A.; DeMartino, G.N. Differential Roles of the COOH Termini of AAA Subunits of PA700 (19 S Regulator) in Asymmetric Assembly and Activation of the $26 \mathrm{~S}$ Proteasome. J. Biol. Chem. 2008, 283, 31813-31822. [CrossRef]

208. Aslebagh, R.; Pfeffer, B.A.; Fliesler, S.J.; Darie, C.C. Mass spectrometry-based proteomics of oxidative stress: Identification of 4-hydroxy-2-nonenal (HNE) adducts of amino acids using lysozyme and bovine serum albumin as model proteins. Electrophoresis 2016, 37, 2615-2623. [CrossRef]

209. Doorn, J.A.; Petersen, D.R. Covalent Modification of Amino Acid Nucleophiles by the Lipid Peroxidation Products 4-Hydroxy-2-nonenal and 4-Oxo-2-nonenal. Chem. Res. Toxicol. 2002, 15, 1445-1450. [CrossRef]

210. Spickett, C.M. The lipid peroxidation product 4-hydroxy-2-nonenal: Advances in chemistry and analysis. Redox Biol. 2013, 1, 145-152. [CrossRef]

211. Just, J.; Jung, T.; Friis, N.A.; Lykkemark, S.; Drasbek, K.R.; Siboska, G.; Grune, T.; Kristensen, P.L. Identification of an unstable 4-hydroxynoneal modification on the $20 \mathrm{~S}$ proteasome subunit $\alpha 7$ by recombinant antibody technology. Free. Radic. Biol. Med. 2015, 89, 786-792. [CrossRef]

212. Musatov, A.; Carroll, C.A.; Liu, Y.-C.; Henderson, G.I.; Weintraub, S.T.; Robinson, N.C. Identification of Bovine Heart Cytochrome c Oxidase Subunits Modified by the Lipid Peroxidation Product 4-Hydroxy-2-nonenal. Biochemistry 2002, 41, 8212-8220. [CrossRef]

213. Humphries, K.M.; Szweda, L.I. Selective Inactivation of $\alpha$-Ketoglutarate Dehydrogenase and Pyruvate Dehydrogenase: Reaction of Lipoic Acid with 4-Hydroxy-2-nonenal. Biochemistry 1998, 37, 15835-15841. [CrossRef] [PubMed]

214. Castro, J.P.; Jung, T.; Grune, T.; Siems, W. 4-Hydroxynonenal (HNE) modified proteins in metabolic diseases. Free. Radic. Biol. Med. 2017, 111, 309-315. [CrossRef] [PubMed]

215. Bulteau, A.-L.; Lundberg, K.C.; Humphries, K.M.; Sadek, H.A.; Szweda, P.A.; Friguet, B.; Szweda, L.I. Oxidative Modification and Inactivation of the Proteasome during Coronary Occlusion/Reperfusion. J. Biol. Chem. 2001, 276, 30057-30063. [CrossRef]

216. Keller, J.N.; Huang, F.F.; Zhu, H.; Yu, J.; Ho, Y.-S.; Kindy, M.S. Oxidative Stress-Associated Impairment of Proteasome Activity during Ischemia-Reperfusion Injury. Br. J. Pharmacol. 2000, 20, 1467-1473. [CrossRef] [PubMed]

217. Okada, K.; Wangpoengtrakul, C.; Osawa, T.; Toyokuni, S.; Tanaka, K.; Uchida, K. 4-Hydroxy-2-nonenal- mediated Impairment of Intracellular Proteolysis during Oxidative Stress. J. Biol. Chem. 1999, 274, 23787-23793. [CrossRef]

218. Carrard, G.; Dieu, M.; Raes, M.; Toussaint, O.; Friguet, B. Impact of ageing on proteasome structure and function in human lymphocytes. Int. J. Biochem. Cell Biol. 2003, 35, 728-739. [CrossRef]

219. Keller, J.; Huang, F.; Markesbery, W. Decreased levels of proteasome activity and proteasome expression in aging spinal cord. Neuroscience 2000, 98, 149-156. [CrossRef]

220. Ferrington, D.A.; Kapphahn, R.J. Catalytic site-specific inhibition of the 20 S proteasome by 4 -hydroxynonenal. FEBS Lett. 2004, 578, 217-223. [CrossRef]

221. Amici, M.; Lupidi, G.; Angeletti, M.; Fioretti, E.; Eleuteri, A.M. Peroxynitrite-induced oxidation and its effects on isolated proteasomal systems. Free. Radic. Biol. Med. 2003, 34, 987-996. [CrossRef]

222. Gavilán, M.P.; Castaño, A.; Torres, M.; Portavella, M.; Caballero, C.; Jiménez, S.; García-Martínez, A.; Parrado, J.; Vitorica, J.; Ruano, D. Age-related increase in the immunoproteasome content in rat hippocampus: Molecular and functional aspects. J. Neurochem. 2009, 108, 260-272. [CrossRef]

223. Thorpe, S.R.; Baynes, J.W. Role of the Maillard Reaction in Diabetes Mellitus and Diseases of Aging. Drugs Aging 1996, 9, 69-77. [CrossRef] [PubMed]

224. Zhang, Q.; Ames, J.M.; Smith, R.D.; Baynes, J.W.; Metz, T.O. A Perspective on the Maillard Reaction and the Analysis of Protein Glycation by Mass Spectrometry: Probing the Pathogenesis of Chronic Disease. J. Proteome Res. 2009, 8, 754-769. [CrossRef] [PubMed]

225. Queisser, M.A.; Yao, D.; Geisler, S.; Hammes, H.-P.; Lochnit, G.; Schleicher, E.D.; Brownlee, M.; Preissner, K.T. Hyperglycemia Impairs Proteasome Function by Methylglyoxal. Diabetes 2010, 59, 670-678. [CrossRef] [PubMed]

226. Račková, L.; Šnirc, V.; Jung, T.; Stefek, M.; Karasu, Ç.; Grune, T. Metabolism-induced oxidative stress is a mediator of glucose toxicity in HT22 neuronal cells. Free. Radic. Res. 2009, 43, 876-886. [CrossRef] 
227. Moheimani, F.; Morgan, P.E.; Van Reyk, D.; Davies, M.J. Deleterious effects of reactive aldehydes and glycated proteins on macrophage proteasomal function: Possible links between diabetes and atherosclerosis. Biochim. Biophys. Acta Mol. Basis Dis. 2010, 1802, 561-571. [CrossRef]

228. Kisselev, A.F.; Van Der Linden, W.A.; Overkleeft, H.S. Proteasome Inhibitors: An Expanding Army Attacking a Unique Target. Chem. Biol. 2012, 19, 99-115. [CrossRef]

229. Gräwert, M.A.; Gallastegui, N.; Stein, M.; Schmidt, B.; Kloetzel, P.-M.; Huber, R.; Groll, M. Elucidation of the $\alpha$-Keto-Aldehyde Binding Mechanism: A Lead Structure Motif for Proteasome Inhibition. Angew. Chem. Int. Ed. 2010, 50, 542-544. [CrossRef]

230. Bartesaghi, S.; Radi, R. Fundamentals on the biochemistry of peroxynitrite and protein tyrosine nitration. Redox Biol. 2018, 14, 618-625. [CrossRef]

231. Radi, R. Protein Tyrosine Nitration: Biochemical Mechanisms and Structural Basis of Functional Effects. Acc. Chem. Res. 2013, 46, 550-559. [CrossRef]

232. Xu, J.; Wang, S.; Zhang, M.; Wang, Q.; Asfa, S.; Zou, M.-H. Tyrosine Nitration of PA700 Links Proteasome Activation to Endothelial Dysfunction in Mouse Models with Cardiovascular Risk Factors. PLoS ONE 2012, 7, e29649. [CrossRef]

233. Xu, J.; Wang, S.; Wu, Y.; Song, P.; Zou, M.-H. Tyrosine Nitration of PA700 Activates the 26S Proteasome to Induce Endothelial Dysfunction in Mice with Angiotensin II-Induced Hypertension. Hypertension 2009, 54, 625-632. [CrossRef] [PubMed]

234. Grune, T.; Blasig, I.E.; Sitte, N.; Roloff, B.; Haseloff, R.; Davies, K.J. Peroxynitrite Increases the Degradation of Aconitase and Other Cellular Proteins by Proteasome. J. Biol. Chem. 1998, 273, 10857-10862. [CrossRef] [PubMed]

235. Osna, N.A.; Haorah, J.; Krutik, V.M.; Donohue, T.M. Peroxynitrite alters the catalytic activity of rodent liver proteasome in vitro and in vivo. Hepatology 2004, 40, 574-582. [CrossRef]

236. Dobson, C.M. Protein folding and misfolding. Nat. Cell Biol. 2003, 426, 884-890. [CrossRef] [PubMed]

237. Hartl, F.U. Molecular Chaperones in the Cytosol: From Nascent Chain to Folded Protein. Science 2002, 295, 1852-1858. [CrossRef]

238. Routledge, K.E.; Tartaglia, G.G.; Platt, G.W.; Vendruscolo, M.; Radford, S.E. Competition between Intramolecular and Intermolecular Interactions in an Amyloid-Forming Protein. J. Mol. Biol. 2009, 389, 776-786. [CrossRef]

239. Markossian, K.A.; Kurganov, B.I. Protein Folding, Misfolding, and Aggregation. Formation of Inclusion Bodies and Aggresomes. Biochemistry 2004, 69, 971-984. [CrossRef]

240. Ross, C.A.; A Poirier, M. Protein aggregation and neurodegenerative disease. Nat. Med. 2004, 10, S10-S17. [CrossRef]

241. Esteras-Chopo, A.; Pastor, M.T.; Serrano, L. Protein Misfolding and $\beta$-Amyloid Formation. In Protein Folding, Misfolding and Aggregation; Muñoz, V., Ed.; Royal Society of Chemistry (RSC): Milton Road, Cambridge, UK, 2008; pp. 214-240. [CrossRef]

242. Morales, R.; Moreno-Gonzalez, I.; Soto, C. Cross-Seeding of Misfolded Proteins: Implications for Etiology and Pathogenesis of Protein Misfolding Diseases. PloS Pathog. 2013, 9, e1003537. [CrossRef]

243. Jarrett, J.T.; Lansbury, P.T. Seeding "one-dimensional crystallization" of amyloid: A pathogenic mechanism in Alzheimer's disease and scrapie? Cell 1993, 73, 1055-1058. [CrossRef]

244. Mirzaei, H.; Regnier, F.E. Protein:protein aggregation induced by protein oxidation. J. Chromatogr. B 2008, 873, 8-14. [CrossRef] [PubMed]

245. Weids, A.J.; Ibstedt, S.; Tamás, M.J.; Grant, C.M. Distinct stress conditions result in aggregation of proteins with similar properties. Sci. Rep. 2016, 6, 24554. [CrossRef] [PubMed]

246. David, D.C. Aging and the aggregating proteome. Front. Genet. 2012, 3, 247. [CrossRef] [PubMed]

247. Mitraki, A. Protein Aggregation: From inclusion bodies to amyloid and biomaterials. Adv. Protein. Chem. Struct. Biol. 2010, 79, 89-125. [CrossRef]

248. Bolognesi, B.; Kumita, J.R.; Barros, T.P.; Esbjorner, E.K.; Luheshi, L.M.; Crowther, D.C.; Wilson, M.R.; Dobson, C.M.; Favrin, G.; Yerbury, J.J. ANS Binding Reveals Common Features of Cytotoxic Amyloid Species. ACS Chem. Biol. 2010, 5, 735-740. [CrossRef]

249. Chiti, F.; Dobson, C.M. Protein Misfolding, Functional Amyloid, and Human Disease. Annu. Rev. Biochem. 2006, 75, 333-366. [CrossRef] 
250. Brunk, U.T.; Terman, A. Lipofuscin: Mechanisms of age-related accumulation and influence on cell. Free. Radic. Biol. Med. 2002, 33, 611-619. [CrossRef]

251. Boellaard, J.W.; Schlote, W.; Höfer, W. Species-Specific Ultrastructure of Neuronal Lipofuscin in Hippocampus and Neocortex of Subhuman Mammals and Humans. Ultrastruct. Pathol. 2004, 28, 341-351. [CrossRef]

252. Terman, A.; Brunk, U.T. Lipofuscin. Int. J. Biochem. Cell Biol. 2004, 36, 1400-1404. [CrossRef]

253. Höhn, A.; Jung, T.; Grimm, S.; Grune, T. Lipofuscin-bound iron is a major intracellular source of oxidants: Role in senescent cells. Free. Radic. Biol. Med. 2010, 48, 1100-1108. [CrossRef]

254. Jung, T.; Bader, N.; Grune, T. Lipofuscin: Formation, Distribution, and Metabolic Consequences. Ann. N. Y. Acad. Sci. 2007, 1119, 97-111. [CrossRef] [PubMed]

255. Kikugawa, K.; Kato, T.; Beppu, M.; Hayasaka, A. Fluorescent and Cross-Linked Proteins Formed by Free Radical and Aldehyde Species Generated during Lipid Oxidation. Biol. Mammary Gland 1990, 266, 345-357. [CrossRef]

256. Leeuwenburgh, C.; Rasmussen, J.E.; Hsu, F.F.; Mueller, D.M.; Pennathur, S.; Heinecke, J.W. Mass Spectrometric Quantification of Markers for Protein Oxidation by Tyrosyl Radical, Copper, and Hydroxyl Radical in Low Density Lipoprotein Isolated from Human Atherosclerotic Plaques. J. Biol. Chem. 1997, 272, 3520-3526. [CrossRef] [PubMed]

257. Höhn, A.; Sittig, A.; Jung, T.; Grimm, S.; Grune, T. Lipofuscin is formed independently of macroautophagy and lysosomal activity in stress-induced prematurely senescent human fibroblasts. Free. Radic. Biol. Med. 2012, 53, 1760-1769. [CrossRef] [PubMed]

258. Kopito, R.R. Aggresomes, inclusion bodies and protein aggregation. Trends Cell Biol. 2000, 10, 524-530. [CrossRef]

259. Johnston, J.A.; Ward, C.L.; Kopito, R.R. Aggresomes: A Cellular Response to Misfolded Proteins. J. Cell Biol. 1998, 143, 1883-1898. [CrossRef]

260. García-Mata, R.; Bebök, Z.; Sorscher, E.J.; Sztul, E. Characterization and Dynamics of Aggresome Formation by a Cytosolic Gfp-Chimera. J. Cell Biol. 1999, 146, 1239-1254. [CrossRef]

261. Mayer, R.J.; Lowe, J.; Lennox, G.; Landon, M.; MacLennan, K.; Doherty, F.J. Intermediate filament-ubiquitin diseases: Implications for cell sanitization. Biochem. Soc. Symp. 1989, 55, 193-201.

262. Wigley, W.C.; Fabunmi, R.P.; Lee, M.G.; Marino, C.R.; Muallem, S.; DeMartino, G.N.; Thomas, P.J. Dynamic Association of Proteasomal Machinery with the Centrosome. J. Cell Biol. 1999, 145, 481-490. [CrossRef]

263. Hao, R.; Nanduri, P.; Rao, Y.; Panichelli, R.S.; Ito, A.; Yoshida, M.; Yao, T.-P. Proteasomes activate aggresome disassembly and clearance by producing unanchored ubiquitin chains. Mol. Cell 2013, 51, 819-828. [CrossRef]

264. Chin, L.-S.; Olzmann, J.A.; Li, L. Aggresome Formation and Neurodegenerative Diseases: Therapeutic Implications. Curr. Med. Chem. 2008, 15, 47-60. [CrossRef] [PubMed]

265. McNaught, K.S.; Shashidharan, P.; Perl, D.P.; Jenner, P.; Olanow, C.W. Aggresome-related biogenesis of Lewy bodies. Eur. J. Neurosci. 2002, 16, 2136-2148. [CrossRef] [PubMed]

266. Fratta, P.; Engel, W.K.; McFerrin, J.; Davies, K.J.; Lin, S.W.; Askanas, V. Proteasome Inhibition and Aggresome Formation in Sporadic Inclusion-Body Myositis and in Amyloid- $\beta$ Precursor Protein-Overexpressing Cultured Human Muscle Fibers. Am. J. Pathol. 2005, 167, 517-526. [CrossRef]

267. Mah, A.L.; Perry, G.; Smith, M.A.; Monteiro, M.J. Identification of Ubiquilin, a Novel Presenilin Interactor That Increases Presenilin Protein Accumulation. J. Cell Biol. 2000, 151, 847-862. [CrossRef] [PubMed]

268. Ardley, H.C.; Scott, G.B.; Rose, S.A.; Tan, N.G.S.; Markham, A.F.; Robinson, P.A. Inhibition of Proteasomal Activity Causes Inclusion Formation in Neuronal and Non-Neuronal Cells Overexpressing Parkin. Mol. Biol. Cell 2003, 14, 4541-4556. [CrossRef]

269. Lee, H.-J.; Shin, S.Y.; Choi, C.; Lee, Y.H.; Lee, S.J. Formation and Removal of $\alpha$-Synuclein Aggregates in Cells Exposed to Mitochondrial Inhibitors. J. Biol. Chem. 2001, 277, 5411-5417. [CrossRef]

270. Waelter, S.; Boeddrich, A.; Lurz, R.; Scherzinger, E.; Lueder, G.; Lehrach, H.; Wanker, E.E. Accumulation of Mutant Huntingtin Fragments in Aggresome-like Inclusion Bodies as a Result of Insufficient Protein Degradation. Mol. Biol. Cell 2001, 12, 1393-1407. [CrossRef]

271. Olanow, C.W.; Perl, D.P.; DeMartino, G.N.; McNaught, K.S.P. Lewy-body formation is an aggresome-related process: A hypothesis. Lancet Neurol. 2004, 3, 496-503. [CrossRef]

272. Bence, N.F.; Sampat, R.M.; Kopito, R.R. Impairment of the Ubiquitin-Proteasome System by Protein Aggregation. Science 2001, 292, 1552-1555. [CrossRef]

273. Keck, S.; Nitsch, R.; Grune, T.; Ullrich, O. Proteasome inhibition by paired helical filament-tau in brains of patients with Alzheimer's disease. J. Neurochem. 2003, 85, 115-122. [CrossRef] 
274. Lowe, J.; Blanchard, A.; Morrell, K.; Lennox, G.; Reynolds, L.; Billett, M.; Landon, M.; Mayer, R.J. Ubiquitin is a common factor in intermediate filament inclusion bodies of diverse type in man, including those of Parkinson's disease, Pick's disease, and Alzheimer's disease, as well as Rosenthal fibres in cerebellar astrocytomas, cytoplasmic bodies in muscle, and mallory bodies in alcoholic liver disease. J. Pathol. 1988, 155, 9-15. [CrossRef] [PubMed]

275. Matilla, A.; Gorbea, C.; Einum, D.D.; Townsend, J.; Michalik, A.; Van Broeckhoven, C.; Jensen, C.C.; Murphy, K.J.; Ptácek, L.J.; Fu, Y.-H. Association of ataxin-7 with the proteasome subunit S4 of the 19S regulatory complex. Hum. Mol. Genet. 2001, 10, 2821-2831. [CrossRef] [PubMed]

276. Deriziotis, P.; André, R.; Smith, D.M.; Goold, R.; Kinghorn, K.J.; Kristiansen, M.; A Nathan, J.; Rosenzweig, R.; Krutauz, D.; Glickman, M.H.; et al. Misfolded PrP impairs the UPS by interaction with the 20S proteasome and inhibition of substrate entry. EMBO J. 2011, 30, 3065-3077. [CrossRef] [PubMed]

277. Elnashar, M.M.M. The Art of Immobilization Using Biopolymers, Biomaterials and Nanobiotechnology. In Biotechnology of Biopolymers; IntechOpen: Rijeka, Croatia, 2011; p. 3.

278. Castillo, J.; Sasso, L.; Svendsen, W.E. Self-Assembled Peptide Nanostructures: Advances and Applications in Nanobiotechnology; CRC Press: Boca Raton, FL, USA, 2012; p. 56.

279. Raynes, J.K.; Pearce, F.; Meade, S.J.; Gerrard, J.A. Immobilization of organophosphate hydrolase on an amyloid fibril nanoscaffold: Towards bioremediation and chemical detoxification. Biotechnol. Prog. 2011, 27, 360-367. [CrossRef]

280. Bhak, G.; Lee, S.; Park, J.W.; Cho, S.; Paik, S.R. Amyloid hydrogel derived from curly protein fibrils of $\alpha$-synuclein. Biomaterials 2010, 31, 5986-5995. [CrossRef]

281. Rinas, U.; Garcia-Fruitós, E.; Corchero, J.L.; Vázquez, E.; Seras-Franzoso, J.; Villaverde, A. Bacterial Inclusion Bodies: Discovering Their Better Half. Trends Biochem. Sci. 2017, 42, 726-737. [CrossRef]

282. Corchero, J.L. Eukaryotic aggresomes: From a model of conformational diseases to an emerging type of immobilized biocatalyzers. Appl. Microbiol. Biotechnol. 2015, 100, 559-569. [CrossRef]

283. Engasser, J.-M.; Horvath, C. Diffusion and Kinetics with Immobilized Enzymes. In Applied Biochemistry and Bioengineering: Immobilized Enzyme Principles; Wingard, L.B., Katchalski-Katzir, E., Goldstein, L., Eds.; Academic Press: New York, NY, USA, 1976; Volume 1, pp. 127-220.

284. Datta, S.; Christena, L.R.; Rajaram, Y.R.S. Enzyme immobilization: An overview on techniques and support materials. 3 Biotech 2013, 3, 1-9. [CrossRef]

285. Holmberg, C.; E Staniszewski, K.; Mensah, K.N.; Matouschek, A.; Morimoto, R.I. Inefficient degradation of truncated polyglutamine proteins by the proteasome. EMBO J. 2004, 23, 4307-4318. [CrossRef]

286. Stenoien, D.L.; Mielke, M.; Mancini, M.A. Intranuclear ataxin1 inclusions contain both fast- and slow-exchanging components. Nat. Cell Biol. 2002, 4, 806-810. [CrossRef]

287. Höhn, A.; Jung, T.; Grimm, S.; Catalgol, B.; Weber, D.; Grune, T. Lipofuscin inhibits the proteasome by binding to surface motifs. Free. Radic. Biol. Med. 2011, 50, 585-591. [CrossRef] [PubMed]

288. Feng, Q.; Xia, X.; Wei, A.; Wang, X.; Cai, W.; Huo, D.; Wei, A. Preparation of Cu(II)-chelated poly(vinyl alcohol) nanofibrous membranes for catalase immobilization. J. Appl. Polym. Sci. 2011, 120, 3291-3296. [CrossRef]

289. Barnham, K.J.; Masters, C.L.; Bush, A.I. Neurodegenerative diseases and oxidative stress. Nat. Rev. Drug Discov. 2004, 3, 205-214. [CrossRef] [PubMed]

290. Beck, M.W.; Pithadia, A.S.; DeToma, A.S.; Korshavn, K.J.; Lim, M.H. Ligand Design to Target and Modulate Metal-Protein Interactions in Neurodegenerative Diseases. In Ligand Design in Medicinal Inorganic Chemistry; Storr, T., Ed.; John Wiley \& Sons: Chichester, Germany, 2014; pp. 257-286.

291. Brunk, U.T.; Terman, A. The mitochondrial-lysosomal axis theory of aging: Accumulation of damaged mitochondria as a result of imperfect autophagocytosis. Eur. J. Biochem. 2002, 269, 1996-2002. [CrossRef] [PubMed]

292. Secundo, F. Conformational changes of enzymes upon immobilisation. Chem. Soc. Rev. 2013, 42, 6250-6261. [CrossRef]

293. Rodrigues, R.C.; Ortiz, C.; Berenguer-Murcia, Á.; Torres, R.; Fernández-Lafuente, R. Modifying enzyme activity and selectivity by immobilization. Chem. Soc. Rev. 2013, 42, 6290-6307. [CrossRef]

294. Venkatraman, P.; Wetzel, R.; Tanaka, M.; Nukina, N.; Goldberg, A.L. Eukaryotic proteasomes cannot digest polyglutamine sequences and release them during degradation of polyglutamine-containing proteins. Mol. Cell. 2004, 14, 95-104. [CrossRef] 
295. Gregori, L.; Hainfeld, J.F.; Simon, M.N.; Goldgaber, D. Binding of Amyloid $\beta$ Protein to the $20 \mathrm{~S}$ Proteasome. J. Biol. Chem. 1997, 272, 58-62. [CrossRef]

296. Andre, R.; Tabrizi, S.J. Misfolded PrP and a novel mechanism of proteasome inhibition. Prion 2012, 6, 32-36. [CrossRef]

297. Snyder, H.; Mensah, K.; Theisler, C.; Lee, J.; Matouschek, A.; Wolozin, B. Aggregated and Monomeric $\alpha$-Synuclein Bind to the S6' Proteasomal Protein and Inhibit Proteasomal Function. J. Biol. Chem. 2003, 278, 11753-11759. [CrossRef]

298. De la Pena, A.H.; Opoku-Nsiah, K.A.; Williams, S.K.; Chopra, N.; Sali, A.; Gestwicki, J.E.; Lander, G.C. The Yphi Motif Defines the Structure-Activity Relationships of Human 20S Proteasome Activators. 2020, to Be Published, doi:10.2210/pdb6xmj/pdb. Image from the RCSB PDB (Rcsb.Org) of PDB ID: 6XMJ. Available online: https://www.rcsb.org/structure/6xmj (accessed on 15 November 2020).

299. Groll, M.; Bajorek, M.; Kohler, A.; Moroder, L.; Rubin, D.M.; Huber, R.; Glickman, M.H.; Finley, D. A gated channel into the proteasome core particle. Nat. Struct. Biol. 2000, 7, 1062-1067. [CrossRef] [PubMed]

300. Diaz-Hernandez, M.; Valera, A.G.; Moran, M.A.; Gomez-Ramos, P.; Alvarez-Castelao, B.; Castano, J.G.; Hernandez, F.; Lucas, J.J. Inhibition of 26S proteasome activity by huntingtin filaments but not inclusion bodies isolated from mouse and human brain. J. Neurochem. 2006, 98, 1585-1596. [CrossRef] [PubMed]

301. Bennett, E.J.; Bence, N.F.; Jayakumar, R.; Kopito, R.R. Global Impairment of the Ubiquitin-Proteasome System by Nuclear or Cytoplasmic Protein Aggregates Precedes Inclusion Body Formation. Mol. Cell 2005, 17, 351-365. [CrossRef] [PubMed]

302. Rodrigues, R.C.; Hernández, K.; Barbosa, O.; Rueda, N.; Garcia-Galan, C.; Dos Santos, J.C.S.; Berenguer-Murcia, Á.; Fernandez-Lafuente, R. Immobilization of Proteins in Poly-Styrene-Divinylbenzene Matrices: Functional Properties and Applications. Curr. Org. Chem. 2015, 19, 1707-1718. [CrossRef]

303. Nielsen, S.B.; Yde, P.; Giehm, L.; Sundbye, S.; Christiansen, G.; Mathiesen, J.; Jensen, M.H.; Jensen, P.H.; Otzen, D. Multiple Roles of Heparin in the Aggregation of p25 $\alpha$. J. Mol. Biol. 2012, 421, 601-615. [CrossRef]

304. Zhao, D.; Zhang, S.; Meng, Y.; Xiongwei, D.; Zhang, D.; Yang, Y.; Wang, L.; Liu, C. Polyanion binding accelerates the formation of stable and low-toxic aggregates of ALS-linked SOD1 mutant A4V. Proteins: Struct. Funct. Bioinform. 2014, 82, 3356-3372. [CrossRef]

305. Carr, P.W.; Bowers, L.D. Immobilized Enzymes in Analytical and Clinical Chemistry: Fundamentals and Applications (Chemical Analysis: A Series of Monographs on Analytical Chemistry and Its Applications); John Wiley \& Sons: New York, NY, USA, 1980; Volume 56, pp. 148-196.

306. Kennedy, J.F.; Cabral, J.M.S. Enzyme immobilization. In Biotechnology Enzyme Technology; Rehm, H.-I., Reed, G., Eds.; VCH: Weinheim, Germany, 1987; Volume 7a, pp. 347-404.

307. Bar-Eli, A.; Katchalski, E. Preparation and properties of water-insoluble derivatives of trypsin. J. Biol. Chem. 1963, 238, 1690-1698.

308. Seemüller, E.; Lupas, A.; Baumeister, W. Autocatalytic processing of the 20 S proteasome. Nat. Cell Biol. 1996, 382, 468-470. [CrossRef]

309. Tanaka, K.; Ichihara, A. Autodegradation of rat liver proteasomes (large multicatalytic proteinase complexes). Biochem. Biophys. Res. Commun. 1989, 158, 548-554. [CrossRef]

310. Palomo, J.M.; Fernández-Lorente, G.; Mateo, C.; Segura, R.L.; Ortiz, C.; Fernandez-Lafuente, R.; Guisan, J.M. Purification, Immobilization, Hyperactivation, and Stabilization of Lipases by Selective Adsorption on Hydrophobic Supports. In Immobilization of Enzymes and Cells; Guisan, J.M., Ed.; Humana Press: Totowa, NJ, USA, 2006; pp. 143-152.

311. Jana, N.R.; Zemskov, E.A.; Wang, G.-H.; Nukina, N. Altered proteasomal function due to the expression of polyglutamine-expanded truncated $\mathrm{N}$-terminal huntingtin induces apoptosis by caspase activation through mitochondrial cytochrome c release. Hum. Mol. Genet. 2001, 10, 1049-1059. [CrossRef]

312. Hernandez, K.; Fernandez-Lafuente, R. Lipase B from Candida antarctica immobilized on octadecyl Sepabeads: A very stable biocatalyst in the presence of hydrogen peroxide. Process. Biochem. 2011, 46, 873-878. [CrossRef]

313. Mateo, C.; Fernandes, B.; Van Rantwijk, F.; Stolz, A.; A Sheldon, R. Stabilisation of oxygen-labile nitrilases via co-aggregation with poly(ethyleneimine). J. Mol. Catal. B Enzym. 2006, 38, 154-157. [CrossRef]

314. Taylor, J.P.; Tanaka, F.; Robitschek, J.; Sandoval, C.M.; A Taye, A.; Markovic-Plese, S.; Fischbeck, K.H. Aggresomes protect cells by enhancing the degradation of toxic polyglutamine-containing protein. Hum. Mol. Genet. 2003, 12, 749-757. [CrossRef] [PubMed] 
315. Kawaguchi, Y.; Kovacs, J.J.; McLaurin, A.; Vance, J.M.; Ito, A.; Yao, T.-P. The Deacetylase HDAC6 Regulates Aggresome Formation and Cell Viability in Response to Misfolded Protein Stress. Cell 2003, 115, 727-738. [CrossRef]

316. Yamamoto, A.; Cremona, M.L.; Rothman, J.E. Autophagy-mediated clearance of huntingtin aggregates triggered by the insulin-signaling pathway. J. Cell Biol. 2006, 172, 719-731. [CrossRef]

317. Arrasate, M.; Mitra, S.; Schweitzer, E.S.; Segal, M.R.; Finkbeiner, S. Inclusion body formation reduces levels of mutant huntingtin and the risk of neuronal death. Nat. Cell Biol. 2004, 431, 805-810. [CrossRef]

318. Cummings, C.J.; Reinstein, E.; Sun, Y.; Antalffy, B.; Jiang, Y.-H.; Ciechanover, A.; Orr, H.T.; Beaudet, A.L.; Zoghbi, H.Y. Mutation of the E6-AP Ubiquitin Ligase Reduces Nuclear Inclusion Frequency While Accelerating Polyglutamine-Induced Pathology in SCA1 Mice. Neuron 1999, 24, 879-892. [CrossRef]

319. Schipper-Krom, S.; Juenemann, K.; Jansen, A.H.; Wiemhoefer, A.; Nieuwendijk, R.V.D.; Smith, D.L.; Hink, M.A.; Bates, G.P.; Overkleeft, H.; Ovaa, H.; et al. Dynamic recruitment of active proteasomes into polyglutamine initiated inclusion bodies. FEBS Lett. 2013, 588, 151-159. [CrossRef]

320. Kim, S.; Nollen, E.A.A.; Kitagawa, K.; Bindokas, V.P.; Morimoto, R.I. Polyglutamine protein aggregates are dynamic. Nat. Cell Biol. 2002, 4, 826-831. [CrossRef]

321. Hrabárová, E.; Achbergerová, L.; Nahalka, J. Insoluble Protein Applications: The Use of Bacterial Inclusion Bodies as Biocatalysts. Methods Mol. Biol. 2014, 1258, 411-422. [CrossRef]

322. Jäger, V.D.; Kloss, R.; Grünberger, A.; Seide, S.; Hahn, D.; Karmainski, T.; Piqueray, M.; Embruch, J.; Longerich, S.; Mackfeld, U.; et al. Tailoring the properties of (catalytically)-active inclusion bodies. Microb. Cell Factories 2019, 18, 1-20. [CrossRef] [PubMed]

323. Steinmann, B.; Christmann, A.; Heiseler, T.; Fritz, J.; Kolmar, H. In Vivo Enzyme Immobilization by Inclusion Body Display. Appl. Environ. Microbiol. 2010, 76, 5563-5569. [CrossRef] [PubMed]

324. Dantuma, N.P.; Bott, L.C. The ubiquitin-proteasome system in neurodegenerative diseases: Precipitating factor, yet part of the solution. Front. Mol. Neurosci. 2014, 7, 70. [CrossRef] [PubMed]

325. Lindsten, K.; De Vrij, F.M.; Verhoef, L.G.; Fischer, D.F.; Van Leeuwen, F.W.; Hol, E.M.; Masucci, M.G.; Dantuma, N.P. Mutant ubiquitin found in neurodegenerative disorders is a ubiquitin fusion degradation substrate that blocks proteasomal degradation. J. Cell Biol. 2002, 157, 417-427. [CrossRef]

326. Han, D.H.; Na, H.-K.; Choi, W.H.; Lee, J.H.; Kim, Y.-K.; Won, C.; Lee, S.-H.; Kim, K.P.; Kuret, J.; Min, D.-H.; et al. Direct cellular delivery of human proteasomes to delay tau aggregation. Nat. Commun. 2014, 5, 5633. [CrossRef]

Publisher's Note: MDPI stays neutral with regard to jurisdictional claims in published maps and institutional affiliations.

(C) 2020 by the authors. Licensee MDPI, Basel, Switzerland. This article is an open access article distributed under the terms and conditions of the Creative Commons Attribution (CC BY) license (http://creativecommons.org/licenses/by/4.0/). 